\title{
Properties of individual contrails: a compilation of observations and some comparisons
}

\author{
Ulrich Schumann $^{1}$, Robert Baumann ${ }^{1}$, Darrel Baumgardner ${ }^{2}$, Sarah T. Bedka $^{3}$, David P. Duda ${ }^{3}$, \\ Volker Freudenthaler $^{4}$, Jean-Francois Gayet ${ }^{5}$, Andrew J. Heymsfield ${ }^{6}$, Patrick Minnis ${ }^{7}$, Markus Quante ${ }^{8}$, \\ Ehrhard Raschke $^{9}$, Hans Schlager ${ }^{1}$, Margarita Vázquez-Navarro ${ }^{1}$, Christiane Voigt ${ }^{1,10}$, and Zhien Wang ${ }^{11}$ \\ ${ }^{1}$ Deutsches Zentrum für Luft- und Raumfahrt, Institut für Physik der Atmosphäre, 82234 Oberpfaffenhofen, Germany \\ ${ }^{2}$ Droplet Measurement Technologies Inc., Boulder, CO, USA \\ ${ }^{3}$ Science Systems and Applications, Inc., Hampton, VA, USA \\ ${ }^{4}$ Ludwig-Maximilians-Universität, Meteorologisches Institut, Munich, Germany \\ ${ }^{5}$ Laboratoire de Météorologie Physique, CNRS, Clermont-Ferrand, France \\ ${ }^{6}$ National Center for Atmospheric Research, Boulder, CO, USA \\ ${ }^{7}$ NASA Langley Research Center, Hampton, VA, USA \\ ${ }^{8}$ Helmholtz-Zentrum Geesthacht, Institute of Coastal Research, Geesthacht, Germany \\ ${ }^{9}$ Max Planck Institute for Meteorology and University of Hamburg, Hamburg, Germany \\ ${ }^{10}$ Johannes Gutenberg-Universität, Institut für Physik der Atmosphäre, Mainz, Germany \\ ${ }^{11}$ University of Wyoming, Department of Atmospheric Sciences, Laramie, WY, USA
}

Correspondence to: Ulrich Schumann (ulrich.schumann@dlr.de)

Received: 28 August 2016 - Published in Atmos. Chem. Phys. Discuss.: 15 September 2016

Revised: 26 November 2016 - Accepted: 18 December 2016 - Published: 10 January 2017

\begin{abstract}
Mean properties of individual contrails are characterized for a wide range of jet aircraft as a function of age during their life cycle from seconds to $11.5 \mathrm{~h}(7.4-18.7 \mathrm{~km}$ altitude, -88 to $-31{ }^{\circ} \mathrm{C}$ ambient temperature), based on a compilation of about 230 previous in situ and remote sensing measurements. The airborne, satellite, and ground-based observations encompass exhaust contrails from jet aircraft from 1972 onwards, as well as a few older data for propeller aircraft. The contrails are characterized by mean ice particle sizes and concentrations, extinction, ice water content, optical depth, geometrical depth, and contrail width. Integral contrail properties include the cross-section area and total number of ice particles, total ice water content, and total extinction (area integral of extinction) per contrail length. When known, the contrail-causing aircraft and ambient conditions are characterized. The individual datasets are briefly described, including a few new analyses performed for this study, and compiled together to form a "contrail library" (COLI). The data are compared with results of the Contrail Cirrus Prediction (CoCiP) model. The observations confirm that the number of ice particles in contrails is controlled by
\end{abstract}

the engine exhaust and the formation process in the jet phase, with some particle losses in the wake vortex phase, followed later by weak decreases with time. Contrail cross sections grow more quickly than expected from exhaust dilution. The cross-section-integrated extinction follows an algebraic approximation. The ratio of volume to effective mean radius decreases with time. The ice water content increases with increasing temperature, similar to non-contrail cirrus, while the equivalent relative humidity over ice saturation of the contrail ice mass increases at lower temperatures in the data. Several contrails were observed in warm air above the SchmidtAppleman threshold temperature. The "emission index" of ice particles, i.e., the number of ice particles formed in the young contrail per burnt fuel mass, is estimated from the measured concentrations for estimated dilution; maximum values exceed $10^{15} \mathrm{~kg}^{-1}$. The dependence of the data on the observation methods is discussed. We find no obvious indication for significant contributions from spurious particles resulting from shattering of ice crystals on the microphysical probes. 


\section{Introduction}

Contrails are well known as line-shaped ice clouds behind aircraft containing many small ice particles (Schumann, 2005). Contrails form mainly from water vapor and particles emitted by the aircraft engines in cold air (Schumann and Heymsfield, 2016). After formation, contrails grow in width and ice water content (IWC) in ice-supersaturated air (Brewer, 1946). With aging, the initially linearly shaped contrails deform and merge with other contrails and cirrus to form "contrail cirrus" (Liou et al., 1990; Sassen, 1997; Schumann, 2002). Individual contrails may be observable for hours (Minnis et al., 1998; Vázquez-Navarro et al., 2015). Contrails and contrail cirrus have climate effects, which are relevant compared to other climate effects of aviation (Penner et al., 1999; Lee et al., 2009; Boucher et al., 2013; Brasseur et al., 2016).

Much has been learned from measurements about contrail properties and their climate effects (Heymsfield et al., 2010). Various models have been developed to compute contrail properties for individual contrails (Paoli and Shariff, 2016) and for contrail cirrus (Burkhardt and Kärcher, 2011). To predict and diagnose contrail formation and life cycle, Schumann (2012) developed the Contrail Cirrus Prediction model (CoCiP), which uses various approximations to simulate a large ensemble of contrails efficiently.

Still, many questions are open: how realistic are the contrail model results? Do the models simulate the life cycle with local and "integral" (cross-section-integrated) properties (Jeßberger et al., 2013; Lewellen, 2014) similarly as observed? Can one verify large-eddy simulation predictions which show that only a small fraction of contrail ice particles survive the wake vortex regime (Unterstrasser, 2016) with measurements? Can one exclude that additional ice particles form later in contrails, e.g., for high humidity and strong upward motion (Jensen et al., 1998a; Spinhirne et al., 1998)? Which ice particle habits are formed in contrails and how do they affect radiative climate forcing (Liou, 1998; Markowicz and Witek, 2011)? How important are fallstreaks from contrails and what limits the resultant contrail depth (Knollenberg, 1972; Unterstrasser and Gierens, 2010b)? How do contrails influence subsequent cirrus formation, i.e., will the combustion particles emitted reactivate as cirrus crystals after they have been conditioned as contrail crystals (Zhou and Penner, 2014; Schumann and Heymsfield, 2016)?

For an improved understanding of contrail formation and evolution and for model testing and improvement, contrail observational data are needed. Contrail observations have been reported since 1915 (Ettenreich, 1919). Early measurements behind a propeller-driven aircraft (see Appendix A) provided evidence that contrail ice formation requires liquid saturation to start (aufm Kampe, 1943), consistent with the now established Schmidt-Appleman criterion (Schumann, 1996). Those observations, with ice particles collected on impactors and halo observations, also provided the first in- formation on the size and shape of contrail and cirrus ice particles (Weickmann, 1945). Measurements of contrail ice with optical particle counters were introduced by Knollenberg (1972). Besides "exhaust contrails" forming from engine emissions, "aerodynamic contrails" forming because of adiabatic cooling near curved surfaces of the aircraft (Gierens et al., 2009; Kärcher et al., 2009b; Gierens et al., 2011; Jansen and Heymsfield, 2015) have also been identified. In addition to the question of when contrails form, one needs to understand the entire life cycle of contrails, from initiation until final sublimation or precipitation (Schumann and Heymsfield, 2016).

The critical testing of models requires reliable quantitative data, not only on the contrail and plume properties but also on the contrail age and the generating aircraft, on the atmosphere conditions in which the contrail formed, and on the observational methods. This paper considers individual contrails with known ages, because these should enable more specific model tests.

For this study, we have collected data on individual contrails from various measurements reported in previous publications, partly with additional information collected from the experimenters and some from reanalysis of the data, and compare them to CoCiP results. The results extend a previously constructed figure with data in Schumann and Heymsfield (2016) and include data from recent measurements during ML-CIRRUS (Voigt et al., 2016). In addition to in situ data from contrail measurements, remote sensing data from ground-based or airborne lidar and spectroradiometer, satellites, cameras, and visual observations are also included.

The results are compiled in a "contrail library" (COLI), i.e., a dataset containing mean values with some error bounds representing observed properties as well as information on the measurement methods, which may be useful for contrail research beyond the present study. Most in situ data include ice particle size spectra measured with optical particle spectrometers (Baumgardner et al., 2011; Wendisch and Brenguier, 2013), from which we take mean values such as ice particle number concentration and IWC. Remote sensing data provide mean properties like width and optical depth $\tau$ (Spinhirne et al., 1998; Duda et al., 2004). Future studies should include exhaust and aerosol properties, data of aerodynamic contrails, comparisons of the data with other model results, and contrail cirrus.

\section{Contrail-library parameters}

The contrail library, COLI, contains a list of contrail observations in an Excel table (see Supplement). For each observation, we collected available information on the aircraft and engines used, fuel (here kerosene in all jet cases), atmosphere, instrumentation, projects and references, and mean contrail properties. Tables 1-6 list and define the corresponding parameters. The list of parameters should be extended 
Table 1. Aircraft and engine.

\begin{tabular}{llc}
\hline Designation & Property & Unit \\
\hline ATYP & Aircraft type & text \\
Engine & Engine type & text \\
$N_{\text {engine }}$ & Number of engines & 1 \\
Span & Wing span & $\mathrm{m}$ \\
$z$ & Altitude above mean sea level $(\mathrm{m} . \mathrm{s} .1)$. & $\mathrm{m}$ \\
$\mathrm{FL}$ & Pressure altitude, flight level in hft, $1 \mathrm{hft}=30.48 \mathrm{~m}$ & $\mathrm{hft}$ \\
$p$ & Pressure at flight level according to ICAO standard atmosphere & $\mathrm{hPa}$ \\
$M$ & Aircraft mass & $\mathrm{Mg}$ \\
TAS & True air speed & $\mathrm{m} \mathrm{s}^{-1}$ \\
Heading & True heading (flight direction): $0^{\circ}:$ northbound; $90^{\circ}:$ eastbound & $\mathrm{degree}$ \\
$m_{\mathrm{F}}$ & All-engine fuel consumption per flight distance & $\mathrm{kg} \mathrm{m}^{-1}$ \\
$\eta$ & Overall propulsion efficiency: $\eta, F /\left(m_{\mathrm{F}} Q_{\mathrm{C}}\right) ; F:$ thrust; $Q_{\mathrm{C}}:$ combustion heat; typically $\eta \approx 0.3$ & 1 \\
PEI ${ }_{\text {soot }}$ & Soot number emission index: number of soot particles suitable as contrail condensation nuclei & $\mathrm{kg}^{-1}$ \\
Traffic data & Information on source for traffic data & text \\
\hline
\end{tabular}

Table 2. Fuel.

\begin{tabular}{lll}
\hline Designation & Property & Unit \\
\hline Fuel & Fuel type, mostly kerosene & \\
$Q_{\mathrm{C}}$ & Fuel combustion heat, typically $43.2 \mathrm{MJ} \mathrm{kg}^{-1}$ for kerosene & $\mathrm{MJ} \mathrm{kg}^{-1}$ \\
$\mathrm{EI}_{\mathrm{H}_{2} \mathrm{O}}$ & Water emission index: mass of water per mass of fuel, typically 1.24 & 1 \\
FSC & Fuel sulfur content (mass fraction), typically $400 \mu \mathrm{g} \mathrm{g}^{-1}$ & $\mu \mathrm{g} \mathrm{g}^{-1}$
\end{tabular}

Table 3. Atmosphere.

\begin{tabular}{|c|c|c|}
\hline Designation & Property & Unit \\
\hline yearmmdd & Date (year, month, day) of observation & text \\
\hline UTC_s & Begin and end UTC times of observations in $\mathrm{s}$ and in $\mathrm{h}$, min, $\mathrm{s}$, since midnight & s \\
\hline \multicolumn{3}{|l|}{ UTC_hhmmss } \\
\hline Position & Longitude/latitude or region & text \\
\hline$p$ & Pressure (computable from flight level) & $\mathrm{hPa}$ \\
\hline$T$ & Temperature in $\mathrm{K}$ & $\mathrm{K}$ \\
\hline ISSR & Ice-supersaturated region: $1=$ yes or $0=$ no & 1 \\
\hline $\mathrm{RH}_{\mathrm{i}}$ & Relative humidity over ice & $\%$ \\
\hline $\mathrm{Sh}_{\mathrm{T}}$ & Total wind shear & $s^{-1}$ \\
\hline Sh & Wind shear normal to flight direction & $s^{-1}$ \\
\hline$N_{\mathrm{BV}}$ & Brunt-Väisälä frequency & $\mathrm{s}^{-1}$ \\
\hline Ambient cloudiness & Presence of ambient cloud (e.g., visible cirrus): yes or no or further explanation & text \\
\hline
\end{tabular}

when more data (e.g., for alternative fuels) become available. Because of the variety of sources, the information available for individual observations covers subsets of the set of all parameters. Here we collect data from the investigations listed in Table 7, sorted by year of observation. We also include older data, discussing instrument aspects, because the number of observations with sufficient information is small and we try to cover a wide range of ages and atmospheric conditions.
Mean values are plotted versus age in Figs. 1 and 2. For reference to the theoretically expected order of magnitude and for consistency checks, the plots also depict mean values of results from a CoCiP-CAM study as described in Schumann et al. (2015). CoCiP is a Lagrangian model simulating the life cycle of individual contrail segments for a given contrail-generating aircraft and ambient meteorology, in this case as provided by the climate model CAM; see Appendix B. CoCiP results have previously been compared to observations (Voigt et al., 2010; Schumann, 2012; Jeßberger 

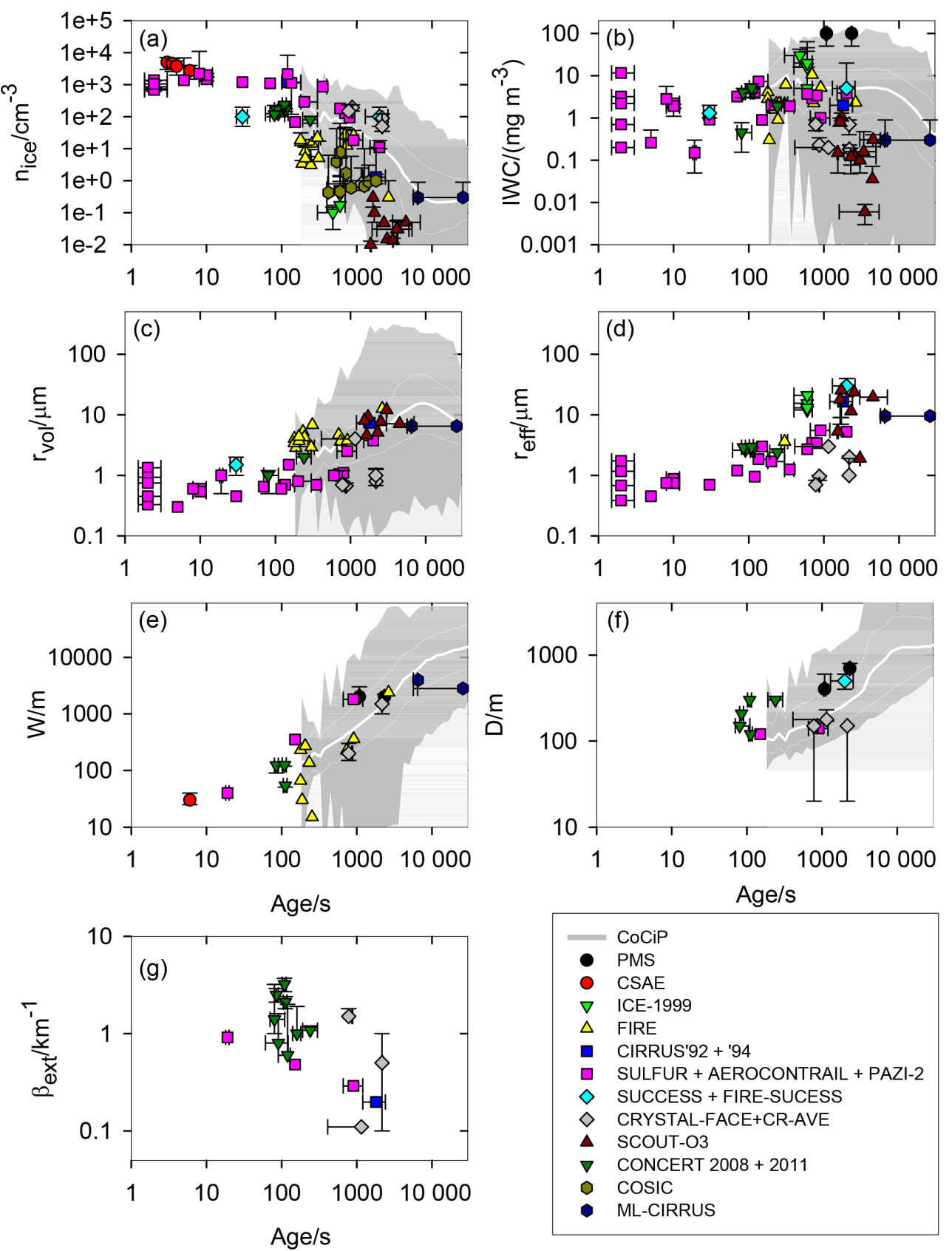

\begin{tabular}{|ll|}
\hline & COCiP \\
$\bullet$ & PMS \\
0 & CSAE \\
$\nabla$ & ICE-1999 \\
$\Delta$ & FIRE \\
$\square$ & CIRRUS'92 + '94 \\
$\square$ & SULFUR + AEROCONTRAIL + PAZI-2 \\
$\diamond$ & SUCCESS + FIRE-SUCESS \\
$\diamond$ & CRYSTAL-FACE+CR-AVE \\
$\Delta$ & SCOUT-O3 \\
$\nabla$ & CONCERT 2008 + 2011 \\
0 & COSIC \\
- & ML-CIRRUS \\
\hline
\end{tabular}

Figure 1. Contrail parameters from in situ observations versus contrail age, together with results from a model simulation (CoCiP). (a) Number concentration of ice particles $n_{\text {ice }}$ in $\mathrm{cm}^{-3}$, (b) ice water content IWC in $\mathrm{mg} \mathrm{m}^{-3}$, (c) volume mean radius $r_{\mathrm{vol}}$ in $\mu \mathrm{m}$, (d) effective radius $r_{\text {eff }}$ in $\mu \mathrm{m}$, (e) contrail width $W$ in $\mathrm{m}$, (f) total contrail depth $D$ in $\mathrm{m}$, and (g) optical extinction $\beta_{\mathrm{ext}}$ in $\mathrm{km}^{-1}$. The grey-shaded white lines depict mean CoCiP results (0th, 10th, 50th, 90th, and 100th percentiles); the thick white line is the median value (50\%). Various symbols denote various observation projects (or group of projects); see Table 7. Error bars, as far as available, indicate estimated ranges of variability during the measurements and reflect uncertainties (e.g., in age).

et al., 2013; Schumann et al., 2013a, b; Voigt et al., 2016), including remote sensing observations for a large set of individual contrails (with unknown contrail ages) from Iwabuchi et al. (2012) and contrail-cirrus observations (Minnis et al., 2013; Schumann and Graf, 2013).
Original measurement data or links to the data banks containing the data were collected when available. The COLI table includes information, when known, on how to access at least part of the original measurement data. Data archives are available for the NASA aircraft field experiments (https://espoarchive.nasa.gov/), the UK BAe146 air- 

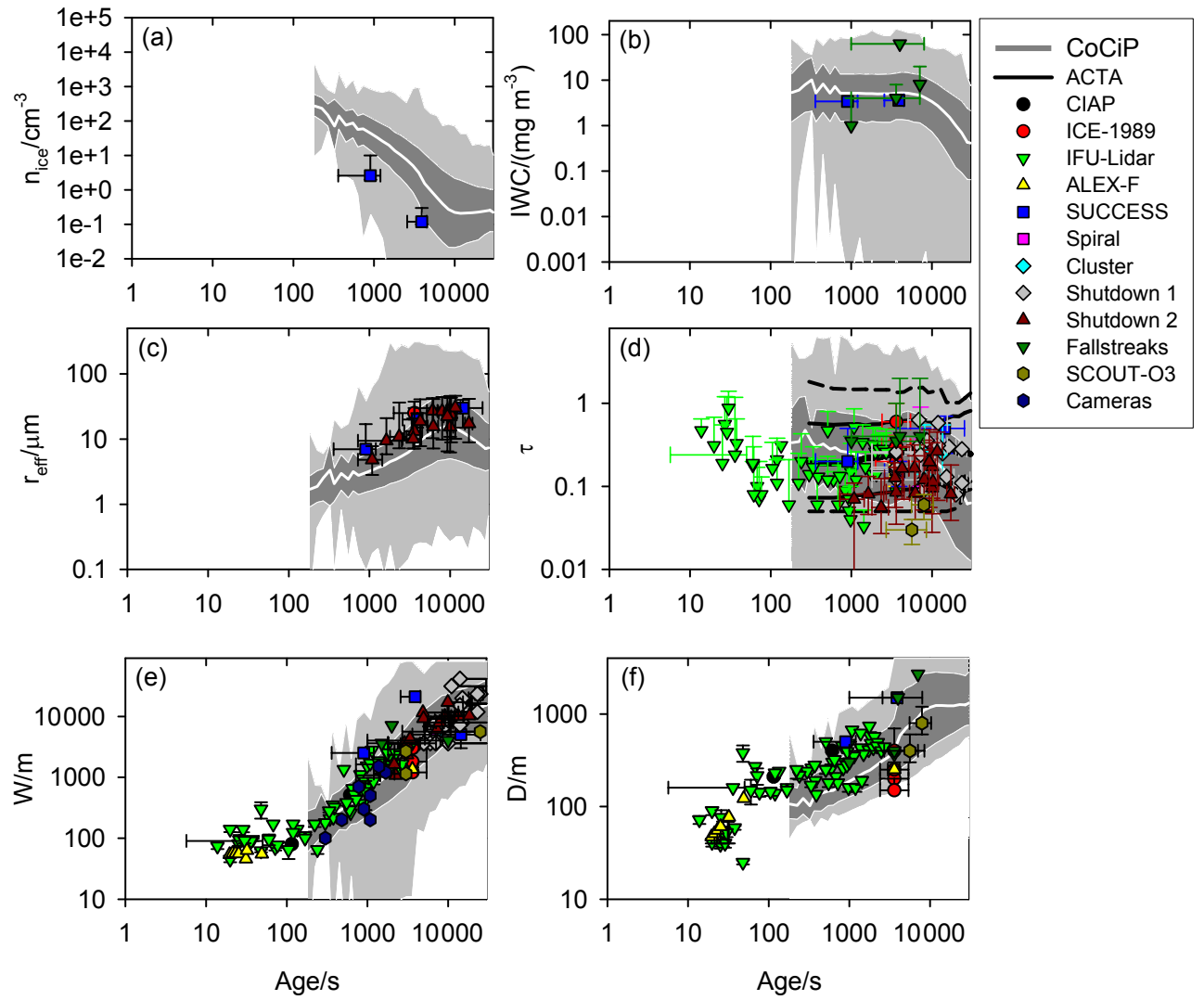

Figure 2. Same as Fig. 1 for remote sensing data. (a) $n_{\text {ice }}$, (b) IWC, (c) $r_{\text {eff }}$, (d) optical depth $\tau$ at solar wavelengths, (e) $W$, and (f) $D$. The black lines in panel (d) depict mean values of optical depth $\tau$ derived from 25600 ACTA results (0th, 10th, 50th, 90th, 100th percentiles).

Table 4. Instrumentation.

\begin{tabular}{lll}
\hline Designation & Property & Unit \\
\hline ITYP & instrument type & text \\
min_value & minimum detectable values & unit of data \\
max_value & maximum detectable values & unit of data \\
\hline
\end{tabular}

Table 5. Contrail observation cases.

\begin{tabular}{lll}
\hline Designation & Property & Unit \\
\hline Project & Acronym & Text \\
Author & One or several references & Text \\
Platform & $\begin{array}{l}\text { Observation aircraft, station, } \\
\text { satellite (possibly several) }\end{array}$ & Text \\
& Observation case identifier & Text \\
Obscase & Information on data source & Text \\
Source & for observation data & \\
&
\end{tabular}

craft (http://badc.nerc.ac.uk/), and for the Deutsches Zentrum für Luft- und Raumfahrt (DLR) research aircraft, Falcon and HALO (https://halo-db.pa.op.dlr.de/). Meteorological data are partly derived from nearby radiosondes (e.g., from http://weather.uwyo.edu/upperair/sounding.html) and from numerical weather prediction (NWP) analyses, e.g., from the ERA-Interim reanalysis data of the European Centre for Medium-Range Weather Forecasts (ECMWF; Dee et al., 2011).

Air traffic data are usually not available publicly. Some projects have collected flight data from air traffic control or ground-based observations (Schumann et al., 2013b, 2016a). Projects with air traffic subsets (since 2005) are identified in the table when available. Some traffic data for the USA and southern Canada were collected for 2000-2005 by Garber et al. (2005) (http://www-pm.larc.nasa.gov/prod/flttrkdbase/). For Germany, traffic data are collected and archived by the Deutsche Flugsicherung (DFS) starting from the year 2006, for the more recent projects. The Aviation and Climate Change Research Initiative (ACCRI; Brasseur et al., 2016) provided a global waypoint dataset for the year 2006 to scientists involved in the ACCRI project.

Aircraft properties (size, mass, speed, fuel consumption, propulsion efficiency) were obtained from various sources, including the Base of Aircraft Data (BADA) (EUROCONTROL, 2009). Some engine properties, such as fuel consumption and emissions at surface pressure, can be obtained from the International Civil Avia- 
Table 6. Contrail properties.

\begin{tabular}{|c|c|c|}
\hline Designation & Property & Unit \\
\hline Age & Contrail age at time of observation & $\mathrm{s}$ \\
\hline$n_{\text {ice }}$ & Ice particle number concentration per ambient volume & $\mathrm{cm}^{-3}$ \\
\hline$A_{\text {ice }}$ & Projected surface area of ice particles per air volume & $\mu \mathrm{m}^{2} \mathrm{~cm}^{-3}$ \\
\hline$V_{\text {ice }}$ & Volume of ice particles per air volume & $\mu \mathrm{m}^{3} \mathrm{~cm}^{-3}$ \\
\hline IWC & Ice water content, $\rho_{\text {ice }} V_{\text {ice }}$ : mass of ice per volume & $\mathrm{mg} \mathrm{m}^{-3}$ \\
\hline$\rho_{\text {ice }}$ & Ice bulk density, typically $917 \mathrm{~kg} \mathrm{~m}^{-3}$ & $\mathrm{~kg} \mathrm{~m}^{-3}$ \\
\hline$r_{\mathrm{vol}}$ & Volume mean ice particle radius $=\left[3 \mathrm{IWC} /\left(4 \pi \rho_{\text {ice }} n_{\text {ice }}\right)\right]^{1 / 3}$ & $\mu \mathrm{m}$ \\
\hline$r_{\text {eff }}$ & Effective radius $=3 V_{\text {ice }} /\left(4 A_{\text {ice }}\right)$ & $\mu \mathrm{m}$ \\
\hline ext, $\beta_{\text {ext }}$ & Optical extinction at visible wavelengths, cross-section mean & $\mathrm{km}^{-1}$ \\
\hline tau, $\tau$ & Optical depth at visible wavelengths, width mean & 1 \\
\hline$D$ & Contrail depth (maximum altitude difference between contrail parts) & $\mathrm{m}$ \\
\hline$D_{\text {eff }}$ & Effective vertical contrail depth & $\mathrm{m}$ \\
\hline$W$ & (Visible) geometrical contrail width & $\mathrm{m}$ \\
\hline$A_{\mathrm{c}}$ & Contrail cross-section area, $W D_{\text {eff }}$ & $\mathrm{m}^{2}$ \\
\hline$N_{\text {ice }}$ & Total contrail ice particle number per contrail length & $\mathrm{m}^{-1}$ \\
\hline TWC & Total contrail ice mass per contrail length & $\mathrm{kg} \mathrm{m}^{-1}$ \\
\hline EA & Total extinction (cross-section integral of extinction $\beta_{\text {ext }}$ ) & $\mathrm{m}$ \\
\hline
\end{tabular}

tion Organization (ICAO) Aircraft Engine Emissions Databank (http://www.easa.europa.eu/document-library/ icao-aircraft-engine-emissions-databank). Because of incomplete information (e.g., on aircraft weight), some data had to be estimated. Comments in the table explain these estimates. Mistakes when reading data from various sources cannot be fully excluded and users should check and verify original sources when details matter. Additional information may lead to revised library variants in the future. Revised versions will be made available at https://halo-db.pa.op.dlr.de/.

For analysis of contrail data, an estimate of dilution of exhaust gases in the wake is often needed. A dilution factor $N_{\text {dil }}$ can be defined, which is the ratio of plume air mass to fuel mass burnt per flight distance. Here, we use

$N_{\text {dil }}=7000\left(t / t_{\text {dil }}\right)^{0.8}$,

with $t_{\text {dil }}=1 \mathrm{~s}$, for plume ages $t$ of about 1 to $10000 \mathrm{~s} \mathrm{(Schu-}$ mann et al., 1998). This relationship has been derived empirically from a set of airborne exhaust measurements behind various jet aircraft in cruise conditions. The relationship approximates exhaust dilution observations within a factor of about 3. It may underestimate dilution in contrails. Mixing and dilution depend on turbulence in the aircraft wake and in the ambient air, and are dependent, among other things, on aircraft parameters, shear, and stratification (Paoli and Shariff, 2016). For this reason, related parameters are included in COLI.

Also, we often refer to the ratio

$C=r_{\mathrm{vol}} / r_{\mathrm{eff}}=\left(r_{\text {area }} / r_{\mathrm{vol}}\right)^{2}$

between effective, volume, and area mean radii, which is a consequence of the radius definitions; see Table 6 (Schumann et al., 2011; Schumann and Heymsfield, 2016). The value of $C$ is one for spherical and monodispersed particles; it can be larger than one for non-spherical ice particles and can be far smaller than one for clouds with a wide particle-size distribution (PSD) of number density which decreases with particle size $d$ as $d^{-n}$, where $n$ is between 0 and 4. The corresponding volume size distribution varies as $d^{3-n}$ for spherical particles and must decrease at least with power -4 at high $d$ to have a finite integral. For such PSDs, the volume size distribution reaches its maximum value for larger sizes than the number size distribution. $C$ becomes small when this size ratio becomes large. The parameter $C$ is important because the projected area density of ice particles in a cloud is

$A_{\text {ice }}=C(9 \pi / 16)^{1 / 3} n_{\text {ice }}^{1 / 3} V_{\text {ice }}^{2 / 3}$

for given number and volume densities $n_{\text {ice }}$ and $V_{\text {ice }}$ (see Eq. 11 in Schumann et al., 2011), and $A_{\text {ice }}$ becomes small for small $C$. Models deriving optical cirrus properties for given $n_{\text {ice }}$ and $r_{\text {vol }}$ (from IWC and $n_{\text {ice }}$ ) have to parameterize $C$ to estimate $r_{\mathrm{eff}}=r_{\mathrm{vol}} / C$ (Lohmann, 2002; Liu et al., 2007; Penner et al., 2009; Schumann, 2012).

Below, the various observations are identified by the project name, if available. New project names were invented in case of missing project names or for results from several projects. Moreover, we distinguish between in situ and remote sensing observations.

The following section explains the data selection from the observations, first for in situ data and then for remote sensing data (with some overlap). Some related projects are discussed together; the last column in Table 7 provides the link between the projects and the subsections. Each subsection identifies the sources of individual data, the conditions under which the contrails formed, and how they were observed. This includes, 
Table 7. Observations included in the contrail library (ad hoc project names in italic).

\begin{tabular}{|c|c|c|c|c|c|c|}
\hline Year & Project name & Source aircraft & A prime reference & Measurement & Carrier/location & Section \\
\hline 1971 & $P M S$ & Sabreliner & Knollenberg (1972) & in situ & NCAR Learjet & 3.1 .1 \\
\hline 1972 & CIAP & B-52 & Hoshizaki et al. (1975) & camera & California & 3.2 .1 \\
\hline 1989 & CSAE & Learjet 35 & Baumgardner and Cooper (1994) & in situ & NCAR Sabreliner & 3.1 .2 \\
\hline 1989 & ICE 1989 & airliners & Raschke et al. (1990) & $\begin{array}{l}\text { in situ }+ \\
\text { lidar }+ \\
\text { satellite }\end{array}$ & $\begin{array}{l}\text { CAM Merlin IV + } \\
\text { DLR Falcon + } \\
\text { DLR DO228 }\end{array}$ & $\begin{array}{l}3.1 .3+ \\
3.2 .2\end{array}$ \\
\hline 1991 & FIRE/ARM & C500 & Poellot et al. (1999) & in situ & UND Cessna Citation & 3.1 .4 \\
\hline 1991 & $A L E X-F(\mathrm{SiL})$ & B747-200 & Baumann et al. (1993) & lidar & DLR Falcon & 3.2 .3 \\
\hline 1992 & CIRRUS'92 & airliners & Strauss et al. (1997) & in situ & DLR Falcon & 3.1 .6 \\
\hline 1994 & CIRRUS'94 & airliners & Wendling et al. (1997) & in situ & DLR Falcon & 3.1 .6 \\
\hline 1994 & IFU-Lidar & airliners & Freudenthaler et al. (1995) & lidar & Garmisch & 3.2 .4 \\
\hline 1994 & SULFUR-1 & ATTAS & Busen and Schumann (1995) & in situ & a business jet & 3.1 .5 \\
\hline 1995 & SULFUR-2 & ATTAS & Schumann et al. (1996) & in situ & DLR Falcon & 3.1 .5 \\
\hline 1996 & SULFUR-4 & ATTAS, A310 & Petzold et al. (1997) & in situ & DLR Falcon & 3.1 .5 \\
\hline 1996 & AEROCONTRAIL & airliners & Schröder et al. (2000) & in situ & DLR Falcon & 3.1 .6 \\
\hline 1996 & SUCCESS & DC-8 & Heymsfield et al. (1998) & in situ & NASA DC-8 & 3.1 .7 \\
\hline 1996 & SUCCESS & DC-8 & Minnis et al. (1998) & satellite & GOES-8 & 3.2 .5 \\
\hline 1996 & FIRE, SUCCESS & B777 & Baumgardner and Gandrud (1998) & in situ & southern Kansas & 3.1 .8 \\
\hline 1996 & AEROCONTRAIL & B747-200 & Sussmann and Gierens (1999) & lidar & Augsburg & 3.2 .4 \\
\hline 1996 & SUCCESS & airliners & Spinhirne et al. (1998) & $\begin{array}{l}\text { lidar }+ \\
\text { radiometer }\end{array}$ & Oklahoma & 3.2 .6 \\
\hline 1998 & Spiral & B707 & Schumann (2002) & satellite & North Sea & 3.2 .7 \\
\hline 2000 & Cluster & airliners & Duda et al. (2004) & satellite & Great Lakes & 3.2 .8 \\
\hline 2001 & Shutdown & B747 + fighters & Minnis et al. (2002) & satellites & northwestern USA & 3.2 .9 \\
\hline 2002 & CRYSTAL-FACE & WB-57 & Gao et al. (2006) & in situ & NASA WB-57 & 3.1 .9 \\
\hline 2003 & Fallstreaks 2003 & airliners & Atlas and Wang (2010) & lidar & Goddard & 3.2 .10 \\
\hline 2005 & PAZI-2 & airliners & Febvre et al. (2009) & in situ & DLR Falcon & 3.1 .10 \\
\hline 2005 & SCOUT-O3 & Geophysica & de Reus et al. (2009) & in situ & MDB Geophysica & 3.1 .11 \\
\hline 2006 & CR-AVE & WB-57 & Flores et al. (2006) & in situ & NASA WB-57 & 3.1 .9 \\
\hline 2008 & CONCERT & airliners & Voigt et al. (2010) & in situ & DLR Falcon & 3.1 .12 \\
\hline 2008 & Fallstreaks 2008 & airliners & Atlas and Wang (2010) & lidar & Goddard & 3.2 .10 \\
\hline 2008 & ACTA & airliners & Vázquez-Navarro et al. (2015) & satellite & Europe \& North Atlantic & 3.2 .12 \\
\hline 2011 & CONCERT2011 & airliners & Kaufmann et al. (2014) & in situ & DLR Falcon & 3.1 .12 \\
\hline 2011 & COSIC & BAe 146 & Jones et al. (2012) & in situ & FAAM BAe-146 & 3.1 .14 \\
\hline 2012 & Cameras & airliners & Schumann et al. (2013b) & cameras & Munich & 3.2 .12 \\
\hline 2014 & ML-CIRRUS & B772 or F900 & Voigt et al. (2016) & in situ & HALO & 3.1 .15 \\
\hline
\end{tabular}

for example, information on whether the contrails formed in clear air or in cirrus, in ice-supersaturated or subsaturated conditions. The intent of this description is to give the reader sufficient context and references for assessing and selecting suitable data for analyses.

\section{Contrail-library description}

\subsection{In situ observations of contrail properties}

\subsubsection{PMS: first particle-size optical spectrometry in contrails}

The first set of contrail ice particle data from in situ observations became available from Knollenberg (1972). Knollenberg is known as a pioneer of optical particle-size spectrometers and founder of the company Particle Measurement Systems (PMS). The reader is referred to Wendisch and Brenguier (2013) for a tribute to Robert Knollenberg.
The measurements were performed using a Learjet observing the contrail of the National Center for Atmospheric Research (NCAR) Sabreliner. The contrail formed in relatively warm and highly ice-supersaturated air. A photo shows that the contrail formed cirrus uncinus (Heymsfield, 1975) with large ice particles sedimenting in fallstreaks more than $500 \mathrm{~m}$ below the contrail core. The particle spectrometer, a onedimensional optical array probe (OAP) (Knollenberg, 1970), counted and sized ice particles of 75 to $1200 \mu \mathrm{m}$ diameter at two flight levels embracing the contrail core. Hence, the many small ice particles below $75 \mu \mathrm{m}$ diameter were not measured. The study quantifies the ice particle concentration $n_{\text {ice }}$ of the larger crystals and their IWC and provides estimates of the contrail width $W$ and depth $D$, as well as the total ice mass TWC and total number of ice particles $N_{\text {ice }}$ per unit contrail length, at ages of 1080 and $2340 \mathrm{~s}$, for a contrail associated with uplift from mountain-induced waves. At $1080 \mathrm{~s}$ age, the contrail has removed about $41 \mathrm{~kg} \mathrm{~m}^{-1}$ of ice mass from the ambient, ice-supersaturated air, more than 
26000 times the mass of water emitted from the engines $\left(1.6 \mathrm{~g} \mathrm{~m}^{-1}\right)$. The $N_{\text {ice }}$ reached $1.5 \times 10^{10} \mathrm{~m}^{-1}$. This value is far below other values, as we will see. Both values (and also $W$ ) decreased between 1080 and $2340 \mathrm{~s}$, without indications of fresh ice particle nucleation in the contrail. IWC, $W$, and $D$ data are shown in Fig. 1 . The $n_{\text {ice }}$ and particle-size values are not included in the plots because of missing small ice particles.

We note that the reported ambient temperature of $-38.2^{\circ} \mathrm{C}$ exceeds the Schmidt-Appleman criterion (SAC) threshold temperature of $-40.1^{\circ} \mathrm{C}$ for contrail formation by at least $1.9 \mathrm{~K}$, even if one uses ambient pressure $p$ for the given flight level $(29500 \mathrm{ft}$; i.e., $p=307.8 \mathrm{hPa}$ instead of the reported $326 \mathrm{hPa}$ ), assumes ambient humidity at liquid saturation, a high water emission index $\mathrm{EI}_{\mathrm{H}_{2} \mathrm{O}}=1.25$, a low combustion heat $Q_{\mathrm{C}}=43 \mathrm{MJ} \mathrm{kg}^{-1}$, and a high propulsion efficiency $\eta=0.35$. The discrepancy may be explained by temperature measurement errors (Knollenberg, 1972) (e.g., measurements at altitudes slightly below the contrail formation level) or by added plume humidity from ambient cirrus ice particles entrained into the exhaust plume. Also, the engine may have been still cooler during non-steady operation than at steady state, absorbing some of the combustion heat. Further possibilities are discussed in Sect. 4.4.

\subsubsection{CSAE: high particle concentrations in young contrails}

In a short note, Baumgardner and Cooper (1994) presented airborne measurements of ice particle size spectra in a young contrail of a Learjet 35 obtained from the NCAR Sabreliner at short distances, 50 to $1600 \mathrm{~m}$ behind the source aircraft. The data were obtained during the Contrail Studies Airborne Exhaust (CSAE) project near the Front Range of the Rocky Mountains in Colorado and Wyoming, including 18 individual flights (within 40$44^{\circ} \mathrm{N}, 102-107^{\circ} \mathrm{W}$ ) in March/April 1989 (Baumgardner et al., 1998). The raw data and some videos are available online (http://data.eol.ucar.edu/codiac/dss/id=252.004). Six flights, between 23 March and 13 April 1989 (see Supplement), were used to derive the data. From these, the mean values of flight conditions when the Sabreliner was in the Learjet exhaust plume, based on condensation nuclei (CN) concentrations, can be determined: $p=256 \pm 14 \mathrm{hPa}$, pressure altitude $=10.22 \pm 0.36 \mathrm{~km}, \quad T=-55.3 \pm 2.6^{\circ} \mathrm{C}$, $\mathrm{RH}_{\mathrm{i}}=104 \pm 21 \%$, and TAS $=189 \pm 1.5 \mathrm{~m} \mathrm{~s}^{-1}$. Unfortunately, the Learjet positions versus time are not in the archive files, so that the distances between the two aircraft cannot be reconstructed. Instead, we complete the data using published information. Some details from these measurements are given in Andronache and Chameides (1998), who compared the observations to model results. The measured exhaust plume was compared with a wake-flow model and found to stay within about $W=30(25-40) \mathrm{m}$ during the first $25 \mathrm{~s}$ plume age (Baumgardner et al., 1998). The parti- cles were sized and counted with the then new PMS FSSP300 optical particle counter, detecting particles in the size range from 0.35 to $20 \mu \mathrm{m}$ (Baumgardner et al., 1992). Most of the ice particles had sizes between 0.35 and $1.5 \mu \mathrm{m}$, with $10 \mu \mathrm{m}$ maximum size. The $n_{\text {ice }}$ reached a maximum of about $7000 \mathrm{~cm}^{-3}$ at plume ages of about $3.5 \mathrm{~s}$. For ages $>3.5 \mathrm{~s}$, the observed $n_{\text {ice }}$ values are consistent with model studies (Andronache and Chameides, 1998; Kärcher and Yu, 2009). For shorter ages, the measured $n_{\text {ice }}$ are far smaller than the model results. The $n_{\text {ice }}$ at short distances might be low because the sampling was mainly outside the core of the younger contrails or because contrail particles had not yet grown to detectable sizes. Moreover, particle concentrations of $7000 \mathrm{~cm}^{-3}$ are near the upper detection limit of the FSSP300 . The IWC values estimated from the reported particle sizes are about 10 to $50 \mathrm{mg} \mathrm{m}^{-3}$ at maximum, roughly as simulated (Andronache and Chameides, 1997).

\subsubsection{ICE-1989: contrails in cirrus}

The properties of aged contrails from airliners were derived from observations during the International Cirrus Experiment (ICE) 1989 over the German Bay of the North Sea (Raschke et al., 1990). Here, we report results from three ICE days (experiment numbers ICE-206, -210, -216; Hennings et al., 1990). The source aircraft and traffic details are unknown and contrail ages are estimates.

A contrail of 300-480 s age, produced by an airliner en route from Schiphol, Netherlands, was observed about $40 \mathrm{~km}$ east of Helgoland with the DLR Falcon aircraft during flight ICE 206, 24 September 1989. The observations were first presented by F. Albers et al. (1990) at a conference (unpublished). A photo, microphysics data, and turbulence measurements for this case are reported in Quante (2006). The Falcon was equipped with PMS instruments (FSSP100 and OAP-2D-C) operated by the Research Center at Geesthacht, Germany (formerly GKSS) (Gayet et al., 1993). Some microphysical properties are given in comparison to remote sensing and simulation results by Betancor Gothe and Graßl (1993) and Boin and Levkov (1994).

The measurements were performed along a $20 \mathrm{~km}$ long distance essentially in the center of the contrail. Kinetic energy spectra and rms values of the three velocity components show considerable turbulence inside the contrail (order $0.18 \mathrm{~m} \mathrm{~s}^{-1}$, quasi-isotropic), significantly larger than in the ambient cirrus $\left(0.03 \mathrm{~m} \mathrm{~s}^{-1}\right.$, stronger horizontal than vertical). The PMS FSSP-100 and OAP-2D-C probes detected ice particles larger than $3 \mu \mathrm{m}$ with concentrations of $0.1 \mathrm{~cm}^{-3}$ and IWC of $\sim 40 \mathrm{mg} \mathrm{m}^{-3}$. The Helgoland radiosonde indicated near-ice saturation at $8.5-10 \mathrm{~km}$ altitude (Hennings et al., 1990).

Higher ice particle concentrations (up to $1.5 \mathrm{~cm}^{-3}$ ) were derived for another contrail, observed over the North Sea during ICE 210 on 13 October 1989. In situ measurements were obtained with a PMS FSSP-100 and a PMS 2D-C 
probe onboard the MERLIN aircraft of the Centre d'Aviation Météorologique, Météo France (Gayet et al., 1993), and with an upward-looking lidar ALEX-F (Mörl et al., 1981) on a DO-228 aircraft operated by the DLR (Gayet et al., 1996b). Gayet et al. (1996a) analyzed both the FSSP-100 and 2D$\mathrm{C}$ probes and listed data for $n_{\text {ice }}, r_{\text {eff }}$, and IWC in addition to $T$ and altitude for four contrail samples. The MERLIN flew a $120 \mathrm{~km}$ long racetrack pattern about 5 to $10 \mathrm{~km}$ east (downwind) of the upper air traffic route UA7, between about $54^{\circ} \mathrm{N}, 7.3^{\circ} \mathrm{E}$ and $55^{\circ} \mathrm{N}, 7.8^{\circ} \mathrm{E}$, mostly at $7000-7900 \mathrm{~m}$ altitude, between 11:15 and 13:05 UTC. The air was icesupersaturated between 6200 and $8200 \mathrm{~m}$ and was warmer than expected from the SAC. Cirrus was observed in the southern part of this flight. The contrail age $600(400-700) \mathrm{s}$ was roughly estimated from the distance to the air traffic route, given wind speed and wind direction. Remote sensing observations for an additional ICE case are reported below.

\subsubsection{FIRE/ARM: multiple contrail data from self-encounter}

Poellot et al. (1999) reported microphysical characteristics of 21 jet contrails from in situ measurements and discussed radiative properties of the contrails. For 12 cases, the observed contrail was generated by the sampling aircraft, the University of North Dakota (UND) Cessna Citation 500, at ages of 187-2640 s after generation. The sources and ages of the contrails in the other cases are unknown and not used here. Ice particles of about 1 to $50 \mu \mathrm{m}$ were measured with the FSSP100 particle spectrometer, and larger ice particles with 2DC and 1D-C PMS OAPs. For each case, the paper lists $T$, $p$, mean and maximum $n_{\text {ice, }}$, average sizes, and $\mathrm{CN}$ concentrations indicating exhaust contributions. The $\mathrm{CN}$ concentrations do not correlate well with plume ages, likely because of sampling at variable distances from the plume center. Data used from this study include $n_{\text {ice }}, r_{\text {vol }}$, IWC, and $W$ for the Cessna Citation contrails; see Fig. 1. Size spectra have peaks between 5 and $8 \mu \mathrm{m}$ diameters. Smaller ice particles may be underrepresented due to the lower size limit of the FSSP-100.

\subsubsection{SULFUR: fuel-sulfur influence on contrails}

SULFUR 1 was an ad hoc project of the DLR, with a single flight by a propeller aircraft for visual contrail observations behind the DLR ATTAS, a twin-engine jet aircraft used as a test facility. The ATTAS burned different fuels on the two engines, with known fuel-sulfur content (FSC, 2 and $250 \mu \mathrm{g} \mathrm{g}^{-1}$ ), in northern Germany, 13 December 1994 (Busen and Schumann, 1995). The changes in FSC were found to have minimal impact on contrail onset, visible about 25-35 $\mathrm{m}$ behind the engines at threshold conditions. The jet contrails had diameters of about $2 \mathrm{~m}$ each and this value is used to estimate the initial width/depth and cross-section area. The data showed that the SAC threshold temperature increases slightly when accounting for higher overall propul- sion efficiency. These observations were of importance in understanding the impact of fuel sulfur on aerosol and contrail formation, and were used for comparisons to model studies in several follow-on papers (Kärcher et al., 1996, 2015; Schumann, 1996; Brown et al., 1997; Andronache and Chameides, 1998).

SULFUR 2 continued the investigation of sulfur impact on aerosol and contrails using airborne in situ measurements from the DLR Falcon behind the ATTAS aircraft for fuels with different FSC (170 and $\left.5500 \mu \mathrm{g} \mathrm{g}^{-1}\right)$. The singleflight experiment was performed over southern Germany, 22 March 1995, for temperatures at and below the contrail threshold. Here, we include the $W$ and $D$ data at about $3 \mathrm{~km}$ distance (18 s age) behind the aircraft. The measured $n_{\text {ice }}=70 \mathrm{~cm}^{-3}$, obtained with an FSSP-100, with a lower size threshold of $3 \mu \mathrm{m}$, underestimates the true concentration of very small ice particles by possibly an order of magnitude and is, therefore, not plotted in Fig. 1. Again, the observations influenced aerosol and contrail formation studies (Gierens and Schumann, 1996; Kärcher et al., 1998; Yu and Turco, 1998; Alcala-Jornod et al., 2002).

SULFUR-3 performed exhaust measurements at the surface (not discussed here). SULFUR-4 sampled the contrail of the ATTAS and an Airbus A310 with improved aerosol and cirrus particle measurement instrumentation, including the FSSP-300, and a prototype multi-angle aerosol spectrometer probe (MASP; size range 0.4 to $10 \mu \mathrm{m}$ ) (Baumgardner et al., 1996) with simultaneous measurements of particle forward/backward scattering (Petzold et al., 1997; Kuhn et al., 1998). The results include a total of six data points, from sampling for low and high FSC (6 and $2700 \mathrm{ppm}$ ), in the plume center and at the plume edge for young plumes $(2 \mathrm{~s}$ old) and one case for a $10 \mathrm{~s}$ age behind the ATTAS. One further $5 \mathrm{~s}$ age A310 data point is included in Schröder et al. (2000).

Among other findings, the results show strong variations in the particle-size distributions from the plume center to the diluted plume edge for young contrails. The respective spectra were identified by the excess temperature above ambient air ( $>1.5 \mathrm{~K}$ in the plume center and $<0.5 \mathrm{~K}$ at the plume edge).

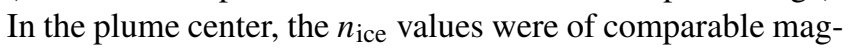
nitude for both high and low FSC. The $r_{\text {eff }}$ and IWC values are lower by factors of 1.5 and 3.5, respectively, in the highsulfur fuel case compared to the low-sulfur fuel case. Schumann et al. (2002) provide a summary of the SULFUR 1-7 projects, with experimental details and results of the aerosol properties for variable fuel-sulfur contents.

\subsubsection{AEROCONTRAIL: contrail-cirrus transition}

Schröder et al. (2000) discuss a series of airborne in situ measurements of microphysical properties of contrails and cirrus clouds from more than 15 airborne missions over central Europe, and describe the transition of the ice particle size spectrum from fresh contrails to contrail cirrus. The measure- 
ments were performed as part of various national and European projects ("Schadstoffe in der Luftfahrt" (SiL), i.e., "Pollution from Aviation"; DLR-CIRRUS and SULFUR, and the European project AEROCONTRAIL), between March 1996 and April 1997. Concentrations and sizes of the smallest ice particles were measured with a PMS FSSP-300. Other optical spectrometers, a Hallett-type replicator, and a novel polar nephelometer (Gayet et al., 1998) were used to characterize the size, concentration, shape, and scattering phase function of larger ice particles. Gayet et al. (1998) list the mean properties of the contrails and cirrus clouds measured in terms of temperature, $n_{\text {ice }}, r_{\mathrm{vol}}$, and $r_{\mathrm{eff}}$. The given humidity values mostly suggest subsaturation, but the large IWC detected in the contrails suggests humidity exceeding ice saturation. The pressure values were added from Schumann (2012). COLI includes information and a few additional data from the campaigns CIRRUS'92 and CIRRUS'94 (Strauss et al., 1997) and from an unpublished project report (Wendling et al., 1997). For most of the contrails, the aircraft causing the contrail and the corresponding contrail ages were identified from direct evidence or from air-traffic-controller information.

For cases A1 and U of Schröder et al. (2000) (60 and $1200 \mathrm{~s}$ aged contrails behind an Airbus A319 and an aircraft of undefined type), scattering phase functions as measured by the polar nephelometer, or as derived from FSSP-100 data with assumptions on the particle habit, were presented in Gayet et al. (1998). The scattering phase function analyses showed that the young contrail particles had quasi-spherical shapes. It was noted that the older contrail and ambient cirrus particles were far more irregular, possibly with rough surfaces.

\subsubsection{SUCCESS: transition of a young persistent contrail into a precipitation trail}

The Subsonic Aircraft Contrail and Cloud Effects Special Study (SUCCESS) was a multi-aircraft field campaign in April and May 1996 over the central and western USA (Toon and Miake-Lye, 1998). The NASA DC-8 aircraft sampled its own contrail at ages of up to $0.75 \mathrm{~h}$ during a flight over the Pacific Ocean, off the northern Californian coast, 12 May 1996. The observations are discussed in several papers (Heymsfield et al., 1998; Jensen et al., 1998a; Lawson et al., 1998; Minnis et al., 1998; Tan et al., 1998; Twohy and Gandrud, 1998). The investigations showed the transition of a young persistent contrail into a precipitation trail. The contrail was generated at about $10.6 \mathrm{~km}$ altitude $(p=239 \mathrm{hPa})$, in clear but highly ice-supersaturated (RHI $<160 \%)$ air; however, patchy cirrus was also observed. Ambient shear was highly variable, $\mathrm{Sh}_{\mathrm{T}} \sim 0.01 \mathrm{~s}^{-1}$ on average, with low Brunt-Väisälä frequency, $N_{\mathrm{BV}}=0.0066 \mathrm{~s}^{-1}$, suggesting strong mixing. The many small ice particles in the contrail core (diameters $\sim 1$ to $10 \mu \mathrm{m} ; n_{\text {ice }} \sim 10$ to $100 \mathrm{~cm}^{-3}$ ) reduced the vapor density to ice saturation. Along the contrail periphery, crystals grew to sizes $>300 \mu \mathrm{m}$. The particles were falling from the contrail into the supersaturated environment below, feeding precipitation trails (Heymsfield et al., 1998). The larger ice crystals in the periphery were mostly columns and bullet rosettes, with featureless shapes as deduced from the scattering phase functions (Lawson et al., 1998).

Data derived from these studies included in Fig. 1 are $n_{\text {ice }}=100(50-150) \mathrm{cm}^{-3}$, IWC $=5(<20) \mathrm{mg} \mathrm{m}^{-3}$ for the contrail core, and $D$ of $500(400-600) \mathrm{m}$. An age of $2000(1300-2600)$ s was reanalyzed from the original DC-8 data. The TAS was $232 \mathrm{~m} \mathrm{~s}^{-1}$ (Twohy and Gandrud, 1998). The wind speed components at contrail level were about 30 and $20 \mathrm{~m} \mathrm{~s}^{-1}$ in easterly and northerly directions, respectively. Some of the high particle $n_{\text {ice }}$ values may have resulted from two DC-8 flight paths long the same flight track.

Simulations of this contrail showed that the contrail spread by shear and possibly radiative heating driving local updrafts, and the $n_{\text {ice }}$ observed could be explained with ice crystals nucleated during the initial contrail formation (Jensen et al., 1998a). Further results from remote sensing are given below.

\subsubsection{FIRE-SUCCESS: contrails from airliners}

On another occasion, during SUCCESS in connection with the First International Satellite Cloud Climatology Project Regional Experiment (FIRE), a flight took place over northern Oklahoma and south-central Kansas. The air was mostly cloud-free; contrails were present but not persistent. The DC8 followed a B757 at distances ranging from 3 to $20 \mathrm{~km}$ (Tan et al., 1998). At 18:54 UTC on 4 May 1996, Baumgardner and Gandrud (1998) performed in situ measurements with the DC-8 in the contrail about $5 \mathrm{~km}$ behind a B757 over south-central Kansas, for ages of about 30 (25-35) s, at $-63{ }^{\circ} \mathrm{C}, 197 \mathrm{hPa}$, with $\sim 40 \mathrm{ppm}$ of water vapor molar mixing ratio (about $112 \% \mathrm{RH}_{\mathrm{i}}$ ). The measurements, performed with the MASP instrument, yielded $n_{\text {ice }}=100(50$ $200) \mathrm{cm}^{-3}$ and $r_{\mathrm{vol}} \approx 2(1-3) \mu \mathrm{m}$, as determined from the published plots. For $n_{\text {ice }}=100 \mathrm{~cm}^{-3}$ and $r_{\mathrm{vol}}=2 \mu \mathrm{m}$, the computed IWC is $1.3 \mathrm{mg} \mathrm{m}^{-3}$. Figure 2 in Baumgardner and Gandrud (1998) shows IWC of $20-80 \mathrm{mg} \mathrm{m}^{-3}$, likely including contributions from ambient cirrus; these values are not included in the Fig. 1.

Data from an earlier part of the same flight behind the B757 at 18:12-18:14 UTC, at a slightly lower altitude ( $p=$ $\left.203.5 \mathrm{hPa}, T=-61^{\circ} \mathrm{C}\right)$ and lower ambient humidity $(80 \%$ over ice), are discussed in other papers (Jensen et al., 1998b; Twohy and Gandrud, 1998), including data on crystal habits, which are important because these have a large effect on the radiative properties of contrails (Goodman et al., 1998; Markowicz and Witek, 2011). Here, the MASP data are cited with $n_{\text {ice }}=1-50 \mathrm{~cm}^{-3}$ for crystals $>1.5 \mu \mathrm{m}$ in radius, and the simulation considers a $70 \mathrm{~s}$ aged contrail (Jensen et al., $1998 \mathrm{~b})$. The measured $n_{\text {ice }}$ appears low for this rather uncertain age. 


\subsubsection{CRYSTAL-FACE and CR-AVE: low-temperature contrails at the tropical tropopause}

During Cirrus Regional Study of Tropical Anvils and Cirrus Layers-Florida Area (CRYSTAL-FACE), a field experiment addressing cirrus from deep convection, measurements were made in the upper tropical troposphere onboard the NASA WB-57F while sampling its own contrail at 300 to $2400 \mathrm{~s}$ age near southern Florida $\left(25.8^{\circ} \mathrm{N}, 81^{\circ} \mathrm{W}\right)$ on 13 July 2002 . The data are available from https://espoarchive.nasa.gov/archive/ browse/crystalf/WB57/20020713. At the time of contrail formation (about $64700 \mathrm{~s}$ UTC) the aircraft was descending with a mass of about $(24300 \pm 450) \mathrm{kg}$ and fuel consumption of $680 \mathrm{~kg} \mathrm{~h}^{-1}$, based on information from the aircraft operators. The contrail was observed within some thin cirrus with large ice particles (Jensen et al., 2005). Gao et al. (2006) report measurements of water vapor and nitric oxide (NO) molar mixing ratio, $p, T, \mathrm{RH}_{\mathrm{i}}$, ice and particle number, size, surface area, and volume as derived from measured $1 \mathrm{~s}$ size distributions. The contrail was formed at low temperatures $\left(-77^{\circ} \mathrm{C}\right.$ at $120 \mathrm{hPa}, \sim 15 \mathrm{~km}$ altitude). The temperature data agree well with the nearby Miami radiosonde data. From the plotted results we read mean values for 780 and 1560 s contrail ages with $n_{\text {ice }} \sim 50$ to $160 \mathrm{~cm}^{-3}$ and low IWC of 0.18 to $0.23 \mathrm{mg} \mathrm{m}^{-3}$, implying low $r_{\mathrm{vol}}$ values of 0.7 to $1 \mu \mathrm{m}$ and $r_{\mathrm{eff}}$ of 1 to $2 \mu \mathrm{m}$. Large, steady-state $\mathrm{RH}_{\mathrm{i}}$ values were measured inside the contrails. The analysis suggests that nitric acid increases relative humidity in low-temperature cirrus clouds (Gao et al., 2004, 2016).

The same measurements were analyzed independently with respect to microphysical properties in a master's thesis (Mullins, 2006) (Timothy Garrett, advisor). The thesis presents reevaluated CAPS (Baumgardner et al., 2001) data implying smaller extinction $\left(\beta_{\mathrm{ext}}\right)$ values. Together with a larger IWC estimate, including a few larger ice particles possibly from ambient subvisible cirrus, nearly a factor of 2 smaller $r_{\text {eff }}$ is derived from the IWC and $\beta_{\text {ext }}$ values. The contrail $W$ is estimated (about 200 to $1500 \mathrm{~m}$ from the first penetration to $1800 \mathrm{~s}$ age) from a sequence of photos at various times of contrail development. Using a wake vortex descent model, the total depth $D$ of the contrail was estimated. The reported $W$ is consistent with age, ambient wind shear, and the estimated $D$. The effective depth $D_{\text {eff }}$ is, however, likely far smaller than $D$ because of shear-induced cross-section deformation, giving smaller cross section $A_{\mathrm{c}}=$ $D_{\text {eff }} W<D W$ and, hence, about constant $N_{\text {ice }}$. The data suggest quite high ice particle numbers per fuel consumption.

At $\sim 10 \mathrm{~K}$ lower temperatures, a contrail was observed during the NASA Costa Rica Aura Validation Experiment (CR-AVE) over the Pacific south of Costa Rica on 1 February 2006. During validation flights for satellite retrievals, airborne measurements were performed again with the NASA WB-57F, sampling its own contrail in the uppermost tropical troposphere. The contrail observations are described briefly in two informal conference papers (Flores et al., 2006; Law- son et al., 2006). The cirrus data are discussed in Lawson et al. (2008). Here we compile the essential data.

Raw data are available from https://espoarchive.nasa.gov/ archive/browse/cr_ave/WB57/20060201. Only 30 s averaged CAPS data and no $\mathrm{CO}$ and $\mathrm{HNO}_{3}$ trace gas data are available for the contrail period. At the time of contrail formation (about $64700 \mathrm{~s}$ UTC), the aircraft was cruising at a constant altitude of $18 \mathrm{~km}(79 \mathrm{hPa})$ near the Equator at $83^{\circ} \mathrm{W}$. It measured its own contrail between 65350 and 65700 s UTC. Fuel consumption and aircraft mass were estimated by the flight operators as $1270 \mathrm{~kg} \mathrm{~h}^{-1}$ and $(24800 \pm 450) \mathrm{kg}$. The contrail formed at a low ambient temperature, near $-88^{\circ} \mathrm{C}$, consistent with radiosonde data of San Andrés $\left(12.58^{\circ} \mathrm{N}\right.$, $81.71^{\circ} \mathrm{W}$ ) from 12:00 UTC the same day. The contrail was penetrated at least four times, at plume ages of 410 to $1150 \mathrm{~s}$. The contrail penetration times and positions were computed for each flight path with the measured wind data. The atmosphere was stably stratified $\left(N_{\mathrm{BV}}=0.02\right.$ to $\left.0.03 \mathrm{~s}^{-1}\right)$ with variable shear around $\mathrm{Sh}_{\mathrm{T}} \approx 0.02 \mathrm{~s}^{-1}$.

Our analysis shows that the penetrations occurred mainly above the core contrail, in the secondary wake. For given wake scales $b_{0}=29.3 \mathrm{~m}, t_{0}=19.0 \mathrm{~s}$, and $w_{0}=1.54 \mathrm{~m} \mathrm{~s}^{-1}$, the product $N_{\mathrm{BV}} t_{0}$ controlling wake descent in stratified air is about 0.47 , implying a wake vortex descent of about $6 b_{0}=$ $178 \mathrm{~m}$ (Schumann and Heymsfield, 2016). During contrail measurements, the flight path was higher than at the times of contrail formation. Hence, the contrail would not have been penetrated at altitudes as measured, had there been no upward motion in the ambient air, of about $0.13 \pm 0.05 \mathrm{~m} \mathrm{~s}^{-1}$.

The maximum $n_{\text {ice }}$ was found in the last penetration, either because it occurred closest to the contrail core or because the contrail ice particles had grown in ice-supersaturated air to sizes detectable by the CAPS instrument $(0.5 \mu \mathrm{m})$. The contrail penetration is also reflected in weak and noisy changes in some of the wind speed, temperature, $\mathrm{CO}_{2}$, water vapor, and condensation nuclei measurement data, which are of comparable magnitude in all four penetrations. The relative humidity is uncertain; the four available water vapor measurements differ considerably (Lawson et al., 2008). The water data from WB-57's NOAA frost point measurements show the lowest values with subsaturation outside the contrail and high supersaturation inside the contrail, but apparently with some timing uncertainty. The $\mathrm{H}_{2} \mathrm{O}$ peaks fit the other peaks better when shifted by $60 \mathrm{~s}$ forward in time. The peaks agree with expected $\mathrm{CO}_{2}$ and $\mathrm{H}_{2} \mathrm{O}$ molar mixing ratio increases $\Delta c=(29 / 44) \mathrm{EI}_{\mathrm{CO}_{2}} / N_{\text {dil }}$ and $(29 / 18) \mathrm{EI}_{\mathrm{H}_{2} \mathrm{O}} / N_{\text {dil }}$ of the order of $1 \mathrm{ppm}$ for the given plume ages and dilution as in Eq. (1). For a fuel flow per flight distance of $m_{\mathrm{F}}=2 \mathrm{~g} \mathrm{~m}^{-1}$, this implies a cross-sectional area $A_{\mathrm{c}}=m_{\mathrm{F}} /\left(\rho N_{\text {dil }}\right)$ of about $0.025 \mathrm{~km}^{2}$ (e.g., $W=500 \mathrm{~m}$ and $D_{\text {eff }}=50 \mathrm{~m}$ ).

The CAPS instrument shows low $n_{\text {ice }}$ of rather large ice particles in the ambient air and, as the contrail was penetrated, clear $n_{\text {ice }}$ peaks, mainly of small ice particles $(90 \%$ of the particles were smaller than $2 \mu \mathrm{m}$ diameter, maximum diameter $25 \mu \mathrm{m}$ ). The $n_{\text {ice }}$ at $1 \mathrm{~s}$ time resolution (Flores et al., 
2006) reach maximum values of $250 \mathrm{~cm}^{-3}$. As derived from the forward to backscatter ratio from the CAS (one component of the CAPS), approximately $40 \%$ of the particles have a refractive index between 1.35 and 1.40 , suggesting the presence of sulfuric acid. The habits were $15 \%$ spherical and $50 \%$ with aspect ratios between 1.3 and 1.5 (also derived from the CAS forward to backscatter ratios). The spatial distributions of particles in the contrail are non-Poissonian and suggest smaller-scale contrail cloud structures with unknown origin. From the $30 \mathrm{~s}$ mean values available in the database (65 679 to $65709 \mathrm{~s}$ ), the contrail contributes $n_{\text {ice }}$ of $0.51 \mathrm{~cm}^{-3}$ in the first channel, a total of $0.78(<2.5) \mathrm{cm}^{-3}$ in all channels, IWC of $0.20 \mathrm{mg} \mathrm{m}^{-3}\left(r_{\mathrm{vol}}=4 \mu \mathrm{m}\right)$, and $\beta_{\mathrm{ext}}$ of $0.11 \mathrm{~km}^{-1}\left(r_{\mathrm{eff}}=3 \mu \mathrm{m}\right)$.

Particle size distributions and images of the contrail ice particles from the measurements in the contrail were shown in comparison to subvisible cirrus (SVC) (Lawson et al., 2008). In the SVC, the average $n_{\text {ice }}\left(0.066 \mathrm{~cm}^{-3}\right), \beta_{\text {ext }}$ $\left(0.009 \mathrm{~km}^{-1}\right)$, and IWC $\left(0.055 \mathrm{mg} \mathrm{m}^{-3}\right)$ were far lower than in the contrail.

\subsubsection{PAZI-2: contrail optical particle properties}

As part of the DLR project Particles and Cirrus-2 (PAZI-2), the Falcon was used to measure a persistent contrail formed by an Embraer E170 mid-sized jet aircraft (Febvre et al., 2009). The contrail formed near Berlin, Germany, at about $11900 \mathrm{~m}$ altitude, at $-60^{\circ} \mathrm{C}$, and at $\mathrm{RH}_{\mathrm{i}}$ of $108-131 \%$, $>8 \mathrm{~K}$ below the contrail threshold temperature. Mean ambient shear perpendicular to the flight direction, derived from in situ wind measurements, varied within $\mathrm{Sh}=0.005-0.01 \mathrm{~s}^{-1}$, with local thin shear layers, and $N_{\mathrm{BV}} \sim 0.011 \mathrm{~s}^{-1}$. The contrail was penetrated several times at two evolving stages, first at about $150 \mathrm{~s}$ contrail age, just after the vortex phase, and later for 660 and $1200 \mathrm{~s}$ contrail ages, in the dispersion phase. The $D$ and $W$ evolved from 120 and $350 \mathrm{~m}$ estimated for the young contrail to be about 150 and $1800 \mathrm{~m}$ in the aged contrail. Many of the later measurements were likely taken in the secondary wake above the sinking primary wake core. The number of ice particles larger than $1 \mu \mathrm{m}$ from FSSP-300 data was $68.3 / 18.3 \mathrm{~cm}^{-3}$ for the young/aged contrail regions. The IWC was low, near $1 \mathrm{mg} \mathrm{m}^{-3}$. Optical extinction was measured with a polar nephelometer (Gayet et al., 1998) at $804 \mathrm{~nm}$ wavelength, decreasing with contrail age from 0.48 to $0.29 \mathrm{~km}^{-1}$. Particles smaller than $10 \mu \mathrm{m}$ contribute about $80 \%$ of the $\beta_{\mathrm{ext}}$ and therefore dominate the optical properties. From IWC and $\beta_{\text {ext }}, r_{\text {eff }}$ was derived to yield 3 and $5.5 \mu \mathrm{m}$ for the young and the aged contrail. The asymmetry parameter $g$ derived from the nephelometer data decreased from 0.827 to 0.787 with age, revealing quasi-spherical ice particles in the young contrail and more aspherical crystals later. Nearby thin frontal cirrus contained larger and more aspherical crystals with $g \approx 0.7, r_{\mathrm{vol}}>20 \mu \mathrm{m}$.

\subsubsection{SCOUT-O3: contrails and cirrus above tropical convective clouds}

Contrail observations at low temperatures were derived from past Geophysica measurements. The Russian M-55 Geophysica is a reconnaissance aircraft converted into an atmospheric research aircraft equipped with a large set of in situ and remote sensing instruments, similar to NASA's ER-2 and WB-57. The M-55 reaches maximum pressure altitudes of $20 \mathrm{~km}$. Measurements in the tropical stratosphere within and above clouds were performed with the M-55 as part of various European projects (Stefanutti et al., 2004; Corti et al., 2008; Vaughan et al., 2008; Brunner et al., 2009; de Reus et al., 2009; Weigel et al., 2009; Cairo et al., 2010). We found several indications for measurements in self-induced contrails for stratospheric conditions (Schumann et al., 2016b). Measurement periods with Geophysica exhaust and contrail contributions were found near and above deep tropical convection in the tropics, during the project StratosphericClimate Links with Emphasis on the Upper Troposphere and Lower Stratosphere (SCOUT-O3) flights over the Tiwi Islands $\left(131^{\circ} \mathrm{E}, 11.5^{\circ} \mathrm{S}\right)$, near Darwin, Australia, in November 2005. The measurements were performed with the M-55 in coordinated flights with other research aircraft, e.g., the DLR Falcon, carrying an upward-looking lidar (Poberaj et al., 2002; Kiemle et al., 2008; Wirth et al., 2009). The analysis provides remote sensing results based on photography, lidar, and NOAA Advanced Very High Resolution Radiometer (AVHRR) satellite data as explained in Sect. 3.2.11.

From in situ measurements during three flights of SCOUTO3 near Darwin (29 and 30 November morning and afternoon, 2005), several potential contrail self-encounters in cirrus were identified from trajectory analyses. Potential encounters are those for which the flight path crosses computed plume positions within $\pm 100 \mathrm{~m}$ vertical distance. The mean measured cirrus properties at these times were taken as being representative of contrails at those positions. Since there is no proof that these cirrus clouds were actual contrails, these results should be interpreted with caution. We include these data in COLI with this annotation.

During the "golden day" of the SCOUT-O3 project, 30 November 2005, six ice events longer than 30 s measurement duration were found in the morning flight above a deep convective cloud, "Hector", over the Tiwi Islands near Darwin, at altitudes up to $18.7 \mathrm{~km}$, in the lower stratosphere, as documented in detail by de Reus et al. (2009). Several indications suggest that these ice events were influenced by nonvolatile aircraft aerosol and contrails (Schumann et al., 2016b). COLI includes the measured data with trajectorybased age estimates. The SCOUT-O3 and CR-AVE results are essential in extending the set of observations to lower temperatures. The conclusions of this study do not change significantly when the potential-contrail data from SCOUT$\mathrm{O} 3$ are omitted (see Sect. 4). 


\subsubsection{CONCERT-2008: aircraft influence on contrails}

The Contrail and Cirrus Experiment (CONCERT) determined aircraft-dependent contrail properties (Voigt et al., 2010). Line-shaped contrails were measured with the Falcon for contrail ages of several minutes. Contrails from different aircraft were probed in the upper troposphere at temperatures of -57 to $-51^{\circ} \mathrm{C}$. Here, we include results for four airliners of different types (CJ-2, A319, A340, A380), all in near-ice-saturated conditions. Particle sizes, $\beta_{\mathrm{ext}}$, and IWC were measured in the size range $0.45-17.7 \mu \mathrm{m}$ with an FSSP300 , and the scattering phase function and $\beta_{\text {ext }}$ with a polar nephelometer. OAPs detected larger ice particles. In addition, various chemical species were measured $\left(\mathrm{SO}_{2}, \mathrm{NO}, \mathrm{NO}_{y}\right.$, $\mathrm{HNO}_{3}, \mathrm{HONO}, \mathrm{HCl}, \mathrm{O}_{3}$, and $\mathrm{CO}$ ) (Jurkat et al., 2011). Values of $\beta_{\mathrm{ext}}, \tau$, and IWC are given in Voigt et al. (2011). The aircraft impact on contrails was discussed for comparable ambient conditions for the A319, A340, and A380 aircraft by Jeßberger et al. (2013). Jeßberger et al. (2013) and Unterstrasser (2014) compare the measured results with model simulations. Schumann et al. (2013a) relate the measured $n_{\text {ice }}$ to dilution (from wake vortex scales and trace species concentrations) and estimate soot and ice number emissions. Gayet et al. (2012) find increasing asphericity of contrail particles during aging in the A380 contrail for plumes as old as $250 \mathrm{~s}$.

Some of the contrails were embedded in cirrus with low $n_{\text {ice }}$ of large ice particles (Kübbeler et al., 2011). The $\mathrm{RH}_{\mathrm{i}}$ observed outside the contrails was often slightly below ice saturation. Most contrails were optically thick, as documented in photos and data (Voigt et al., 2011), and the IWC values were far higher than explainable by the engine water emissions in subsaturated air. Hence, the ambient air must have been icesupersaturated during the time of contrail IWC growth (Voigt et al., 2011; Gayet et al., 2012; Jeßberger et al., 2013).

\subsubsection{CONCERT-2011: ice saturation inside contrails}

CONCERT 2011 was an extension of CONCERT (Voigt et al., 2014). Again several contrails were probed with the Falcon. Kaufmann et al. (2014) show that the measured humidity was fully consistent during these measurements, with the expected ice saturation inside the contrail. From these measurements, three contrails are included in the COLI set for contrail ages of 80-160 s. The cases include an A321 contrail with FSSP-300 and polar nephelometer (PN) data for 16 September 2011, and contrails from two B77W aircraft (freight version of B777) with PN data for 16 and 24 September 2011. The contrail ages (80-160 s) were determined from air traffic data, as well as radiosonde and Falconderived wind data. The measured high NO molar mixing ratios, exceeding $10 \mathrm{nmol} \mathrm{mol}^{-1}$, clearly identified the data as in-plume measurements.

\subsubsection{COSIC: self-induced spiral contrail sampled with improved optical size spectrometers}

Jones et al. (2012) present results from sampling a selfinduced "spiral contrail" over England and the North Sea using the FAAM BAe146 UK research aircraft as part of the Contrails Spreading Into Cirrus (COSIC) study. Similar spiral type contrails have been observed for reconnaissance aircraft (Schumann, 2002; Haywood et al., 2009). In contrast to the racetrack pattern flown by the DC- 8 during SUCCESS, in which the DC-8 followed the contrail position moving with the wind (Lagrangian profile), here the spiral results from flying in an orbit over the same ground position while wind blows the contrails downwind (Eulerian profile). The flight, named B587, took place in an ice-supersaturated area between $\sim$ 14:00 and 19:00 UTC on 19 March 2011. Several parts of the BAe146 contrail were sampled at contrail ages of 420 to $1800 \mathrm{~s}$. Contrails from other aircraft were also sampled, but for unknown ages. The microphysical properties were measured with newer optical size spectrometers (CASDPOL, 0.6-50 $\mu \mathrm{m}$ and CIP-GS, 15-900 $\mu \mathrm{m})$. The BAe146 is propelled by four turbofan engines. It would be interesting to know whether aircraft with turbofan engines emit the same number of soot particles as comparable jet engines.

The contrails were observed with remote sensing up to $2400 \mathrm{~s}$ age. The persistent contrails were found to consist of small $(\sim 10 \mu \mathrm{m})$ plate-like crystals where growth of ice crystals to larger sizes $(\sim 100 \mu \mathrm{m})$ was typically detected when higher water vapor levels were present. From the in situ data, $\beta_{\text {ext }}$ values were calculated and found to be 0.01 to $1 \mathrm{~km}^{-1}$. The high values may apply to fresh contrails and the low to aged contrails. Limited water vapor supply was thought to have suppressed ice crystal growth. A table in Jones et al. (2012) lists individual values of $n_{\text {ice }}$ from the two instruments for contrail ages of 80 to $1800 \mathrm{~s}$, together with $T$ and $\mathrm{RH}_{\mathrm{i}}$ values, which we include into the COLI table, but no IWC and $\beta_{\text {ext }}$ values are provided for the specific contrail events.

\subsubsection{ML-CIRRUS: aged contrails and cirrus in the North Atlantic traffic corridor}

Many aged contrails were sampled on the High Altitude and Long Range Research Aircraft (HALO) during the MidLatitude Cirrus (ML-CIRRUS) campaign in 2014 (Voigt et al., 2016). One specific example is reported here. The contrail was identified from enhanced $\mathrm{NO}_{x}$ emissions $\left(\Delta \mathrm{NO}_{y}=\right.$ $40 \mathrm{pmol} \mathrm{mol}{ }^{-1}$ ) at $p=215 \mathrm{hPa}, T=-62{ }^{\circ} \mathrm{C}, \mathrm{RH}_{\mathrm{i}}=102 \%$, along a $18 \mathrm{~s}$ long segment during a flight at FL 370 crossing the North Atlantic flight corridor in a southbound direction, west of Shannon at $14.0^{\circ} \mathrm{W}, 53.7^{\circ} \mathrm{N}$ at $36150 \mathrm{~s} \mathrm{UTC}$ on 26 March 2014. For a TAS of $220 \mathrm{~m} \mathrm{~s}^{-1}$, the segment length corresponds to $W=4000 \mathrm{~m}$ if perpendicular to the contrail direction. The measured wind components are $(6,20) \mathrm{m} \mathrm{s}^{-1}$ in (east, south) directions. The contrail was found to have 
still higher $n_{\text {ice }}$ of relatively small ice particles than ambient cirrus. The CAS data imply an IWC of $0.9 \mathrm{mg} \mathrm{m}^{-3}$, and $r_{\mathrm{eff}}=9.5 \mu \mathrm{m}$ and $r_{\mathrm{vol}}=6.5 \mu \mathrm{m}$. Due to the presence of larger particles $(>50 \mu \mathrm{m})$ in the contrail cirrus, these data can be interpreted as lower limits. The $\beta_{\text {ext }}$ derived from the planar particle cross section of CAS and CIP data is $0.13 \mathrm{~km}^{-1}$, significantly larger than the $\beta_{\text {ext }}$ from the surrounding cirrus of $0.07 \mathrm{~km}^{-1}$, mainly due to the presence of higher number densities of small particles.

Based on radar-observed traffic data from EUROCONTROL for the UK air space, and from trajectory analysis using ECMWF wind data, one finds two possible source aircraft for the measured contrail. The observed contrail may have been generated by a B772 flying along a route from North America to Europe at FL 380 , near $14.37^{\circ} \mathrm{W}$, $55.77^{\circ} \mathrm{N}$, at $29627 \mathrm{~s}(08: 14) \mathrm{UTC}, 1.8 \mathrm{~h}(6533 \mathrm{~s})$ before the measurements. At the measurement time, the contrail from this flight crosses the HALO flight path nearly perpendicularly. This conclusion derives from analyzing the nominal ECMWF winds and also when the horizontal wind speed components are increased by $2 \mathrm{~m} \mathrm{~s}^{-1}$, which yields a better match between the ECMWF and in situ-measured winds. The ECMWF $\mathrm{RH}_{\mathrm{i}}$ values exceed $90 \%$ along the whole trajectory. The fact that the contrail was measured $1000 \mathrm{ft}$ $(\sim 300 \mathrm{~m})$ below the flight path of the B772 is explained by some subsidence (as indicated by the ECMWF data) and the contrail descent; however, this makes an alternative explanation more likely: the contrail could have been generated by a Falcon-900 (F900) aircraft on a similar eastbound route, but at FL 370 , near $18.61^{\circ} \mathrm{W}, 55.72^{\circ} \mathrm{N}$, at $10380 \mathrm{~s}$ (02:53) UTC, $7.16 \mathrm{~h}(25780 \mathrm{~s})$ before the measurements. The trajectory analysis for this alternative contrail matches the HALO position only for $2 \mathrm{~m} \mathrm{~s}^{-1}$ enhanced wind speeds and the computed contrail cuts the HALO flight path at an angle of about $45^{\circ}$ (implying $W=2800 \mathrm{~m}$ ). Here, the ECMWF $\mathrm{RH}_{\mathrm{i}}$ along the trajectory was $>97 \%$, and possibly the uppermost parts of the F900 contrail (generated at the same flight level) were measured.

For the given ages and an estimated emission index $\mathrm{EI}_{\mathrm{NO}_{x}}=20 \mathrm{~g} \mathrm{~kg}^{-1}$, one would expect $\mathrm{NO}_{y}$ increases of $1600 \mathrm{pmol} \mathrm{mol}^{-1}$ (B772) or $533 \mathrm{pmol} \mathrm{mol}^{-1}$ (F900) if the dilution followed Eq. (1). The computed $\mathrm{NO}_{y}$ concentrations are far higher than measured $40 \mathrm{pmol} \mathrm{mol}^{-1}$. An alternative dilution law,

$N_{\text {dil }}=20\left(t / t_{\text {dil }}\right)^{1.7}, t_{\text {dil }}=1 \mathrm{~s}$,

produces $\mathrm{NO}_{y}$ increases of $206 \mathrm{pmol} \mathrm{mol}^{-1}$ (B772) or $20 \mathrm{pmol} \mathrm{mol}^{-1}$ (F900). Since the dilution laws are accurate at best to a factor of 3, both results are approximately consistent with the observations, so that the older F900 contrail appears to be more plausible. Figure 1 shows that both results extend the set of available in situ data to higher ages, and both are approximately consistent with $\mathrm{CoCiP}$ and other data.

\subsection{Remote sensing}

\subsubsection{CIAP: contrails in the jet and wake-vortex phases}

During the Climatic Impact Assessment Program (CIAP), considering the impact of supersonic transport on the ozone layer and on climate, the vertical and lateral dimensions of a B-59 jet aircraft contrail were determined from ground-based camera observations near San Francisco, likely in fall 1972. The contrail formed in the upper troposphere at $12.77 \mathrm{~km}$ and lasted for about $1800 \mathrm{~s}$ (Conti et al., 1973). The contrail scales were derived during the wake phase and until the early dispersion phase (about $600 \mathrm{~s}$ ), with maximum $W$ and $D$ of 500/400 m (Hoshizaki et al., 1975). Sounding data and the day of measurements were not reported.

\subsubsection{ICE-1989: combined lidar and satellite observations of contrails}

In addition to in situ measurements during ICE (Sect. 3.1.3), four contrails were observed by an airborne lidar during the ICE-216 flight over the German Bay of the North Sea on 18 October 1989. The contrails were oriented about parallel in the east-west direction and embedded in optically thin $(0.01$ to 0.1$)$ cirrus. The aircraft flew a butterfly pattern near $7^{\circ} \mathrm{E}, 54^{\circ} \mathrm{N}$ (Hennings et al., 1990). The upward looking backscatter lidar ALEX-F (1064 nm) was flown on a DO 228 at $3.55 \mathrm{~km}$ altitude with $100 \mathrm{~m} \mathrm{~s}^{-1}$ TAS, southbound. The DLR Falcon, equipped with a counterflow virtual impactor (CVI) and a PMS 2D-C, sampled in the cirrus above FL 300 and found cirrus particles, predominantly smaller than $50 \mu \mathrm{m}$, over Norderney between 13:00 and 14:00 UTC (Ansmann et al., 1993; Ström et al., 1994). The Helgoland radiosonde indicated ice saturation at $8-12 \mathrm{~km}$. A combined Raman elastic-backscatter lidar observed the cirrus from Norderney $\left(7^{\circ} 13^{\prime} \mathrm{E}, 53^{\circ} 43^{\prime} \mathrm{N}\right)$ and data were reported for 10:45-16:30 UTC that day (Ansmann et al., 1992). The observations show a cirrus layer extending from 9 to $11.8 \mathrm{~km}$ altitude with $\tau \approx 0.2(0.1-0.4)$, extinction-to-backscatter ratios of 5 to $10 \mathrm{sr}$, and backscatter coefficients mostly at $0.1 \mathrm{~km}^{-1} \mathrm{sr}^{-1}$, with $150 \mathrm{~s}$ peaks up to $0.6 \mathrm{~km}^{-1} \mathrm{sr}^{-1}$, possibly because of contrails. Inside this cirrus, three contrails were observed by the ALEX-F lidar at 12:21, 12:23, and 12:26 UTC, nearly coincident with a NOAA satellite overpass at $7.3^{\circ} \mathrm{E}, 53.6^{\circ} \mathrm{N}$ at 12:26 UTC (Kästner et al., 1993).

Betancor Gothe and Graßl (1993) applied the split window technique (Inoue, 1985) and compared measured brightnesstemperature differences near 11 and $12 \mu \mathrm{m}$ of the NOAA-11 AVHRR scene of this day over the North Sea with radiative transfer model results and deduced the $r_{\text {eff }}$ and $\tau$ of contrail cirrus over the North Sea. Linear parts of the cirrus contained smaller ice particles $\left(r_{\text {eff }}<25 \mu \mathrm{m}\right)$ with larger $\tau(<0.2)$ compared to ambient cirrus, roughly consistent with the abovementioned lidar results. 
A remarkably thick contrail was observed at low altitude below a thin cirrus deck, along the same flight near $6.8^{\circ} \mathrm{E}$, $53.4^{\circ} \mathrm{N}$, at 13:14 UTC (Schumann and Wendling, 1990). The value of $\tau$ was derived from lidar using a shadow technique (Ruppersberg and Renger, 1991) and from the radiances measured in five channels (two visible, three infrared) of the NOAA-11 AVHRR satellite data. The contrails were observed with $W=1.2,1.8,3.0$, and $3.0 \mathrm{~km}$, within 8.8-9.1, 10.0-10.2, 8.1-8.5, and 7.6-8.3 km altitudes, with 200/300, 150/200, 250/400, and 400/700 m mean/maximum $D$, at the clock times 12:21, 12:23, 12:26, and 13:14 UTC, respectively. The maximum values of $\tau$ (at $1064 / 530 \mathrm{~nm}$ ) derived from the lidar/AVHRR data are $0.35 / 0.41,0.36 / 0.30$, $0.50 / 0.34$, and $1 / \mathrm{NA}$. The mean $\tau$ may be $50-70 \%$ of these values, consistent with an analysis of AVHRR data for the same cases by Betancor Gothe and Graßl (1993). Nearby radiosondes at 13:00 UTC (Quante, 2006) reveal temperatures of $-43,-51,-41$, and $-37.4^{\circ} \mathrm{C}$, a wind speed of $10 \mathrm{~m} \mathrm{~s}^{-1}$ from $210^{\circ}$, weak shear, $N_{\mathrm{BV}} \approx 0.007 \mathrm{~s}^{-1}$, and $\mathrm{RH}_{\mathrm{i}}$ up to $90 \%$ above $8 \mathrm{~km}$.

The life cycle of the cirrus clouds (up to $60 \mathrm{~h}$ ) was observed with imagery of the geostationary satellite Meteosat, radiosondes, and several ground-based lidar observations, indicating that cirrus particles have shorter lifetimes than cirrus clouds (Szantai et al., 2001). Fallstreaks and broadened contrails were observed during the whole day, starting from thin cirrus at the tropopause (Ansmann et al., 1993). The large contrail widths in low-shear environment suggest large ages. The wind derived from the Falcon data was near $10 \mathrm{~m} \mathrm{~s}^{-1}$ from $200^{\circ}$ (about southwest) (Quante, 2006). Based on the distance $(50-100 \mathrm{~km})$ to upper air traffic air routes passing Emden $\left(53.39^{\circ} \mathrm{N}, 7.24^{\circ} \mathrm{E}\right)$ in the east-west directions, and for given wind speed, we estimate the age as $1 \pm 0.5 \mathrm{~h}$. During that same day, cirrus was measured over Scotland (Francis et al., 1994) and an extensive contrail-cirrus deck was observed over southern Germany (Schumann and Wendling, 1990) and the northern Adriatic Sea (Betancor Gothe and Graß1, 1993), to be discussed with other contrail-cirrus cases. The original measurement data are no longer available.

\subsubsection{SiL: lidar-measured wake contrails of a large commercial aircraft}

Baumann et al. (1993) measured contrail properties using the airborne lidar ALEX-F on the Falcon and determined $W$ and descent speed of the contrail in the wake vortex behind a B747-200 cruising (TAS $=225 \mathrm{~m} \mathrm{~s}^{-1}$ ) in clear air close to the tropopause near $49^{\circ} \mathrm{N}, 12^{\circ} \mathrm{E}$ (Munich, Germany) for ages of 19 to $49 \mathrm{~s}$ at 12:25 UTC on 9 April 1991. The two counter-rotating vortices contained separate contrail lines $12 \mathrm{~m}$ wide and separated by $43 \mathrm{~m}$ laterally, implying $W \approx 55 \pm 4.7 \mathrm{~m}$ (data listed in Schumann, 1994). The optically effective depth measured from lidar backscatter plots was $D_{\text {eff }} \approx 35 \pm 3 \mathrm{~m}$, slightly decreasing with age because of sublimation in subsaturated air (Busen et al.,
1994). The mean descent speed was $2.5 \mathrm{~m} \mathrm{~s}^{-1}$, causing a wake depth $D$ of $125 \mathrm{~m}$ after $50 \mathrm{~s}$. For the given flight level $(350, p=238 \mathrm{hPa}), T=-63.3^{\circ} \mathrm{C}$, ambient humidity $\left(\mathrm{RH}_{\mathrm{i}}=39 \%\right)$, wind shear $\left(0.002 \mathrm{~s}^{-1}\right)$, and stratification $\left(N_{\mathrm{BV}}=0.027 \mathrm{~s}^{-1}\right)$ were derived from the nearby Munich radiosonde at that time. The SAC threshold is $T_{\mathrm{LC}}=-50.4^{\circ} \mathrm{C}$ for these values. Data on the Falcon flight path are available from the COLI data bank.

\subsubsection{IFU-Lidar: ground-based lidar observations of contrail geometry and optics}

Freudenthaler et al. (1994) developed a ground-based lidar (at the Institut für Umweltforschung, IFU, Garmisch, Germany) for remote sensing of contrails. Contrails from commercial aircraft at cruise in the upper troposphere passing over Garmisch, Germany $\left(47.5^{\circ} \mathrm{N}, 11^{\circ} \mathrm{E}\right)$, were observed between 1993 and 1996. The first paper describes a contrail, $\sim 1 \mathrm{~h}$ old, moving with northerly winds roughly perpendicular to the flight path through the fixed vertically pointing lidar beam at 16:00 UTC on 1 April 1993. (The given time of 17:00 may by 16:00 or 17:00 UTC.) The data imply $W \approx$ $1350 \pm 50 \mathrm{~m}, D \approx 250 \pm 20 \mathrm{~m}, A_{\mathrm{c}}=0.164(0.15-0.18) \mathrm{km}^{2}$, $\tau=0.15(0.1-0.4)$, and $\beta_{\text {ext }}=0.8(0.16-1) \mathrm{km}^{-1}$. Data from the twice-daily Schleissheim radiosonde (about $100 \mathrm{~km}$ north of Garmisch) were used to estimate $T, p, \mathrm{Sh}_{\mathrm{T}}$, and $N_{\mathrm{BV}}$. The sounding reports $\mathrm{RH}_{\mathrm{i}} \sim 60 \%$, but the contrail was growing in size and was hence likely in ice-supersaturated and possibly uplifting air near the Alpine foothills.

Freudenthaler et al. (1995) report measurements from a set of contrails observed with the scanning version of the same lidar for contrail ages of 60 to $3600 \mathrm{~s}$ and derived mean vertical and horizontal spread rate of contrails of 0.3 and $2.3 \mathrm{~m} \mathrm{~s}^{-1}$, respectively. The areal spread rate was 60 to $420 \mathrm{~m}^{2} \mathrm{~s}^{-1}$, mostly driven by shear. The ratio $A_{\mathrm{c}} /(W D)$ decreases from about 0.6 for the lowest width to 0.4 at $4 \mathrm{~km}$ width, and the lidar showed increasing shear-driven inclination of the contrail cross sections with time.

Figure 2 shows that the width $(\sim 80$ to $150 \mathrm{~m})$ increases slowly for low ages $<200 \mathrm{~s}$ and then linearly with longer age. The vertical growth was often limited by the depth of the humid layers within the flight levels, as later found also in large-eddy simulations (Unterstrasser and Gierens, 2010a, b; Lewellen, 2014).

Freudenthaler et al. (1996) derived $\tau$ and depolarization values from the lidar observations. Data from this work in 1994 to 1996 (69 individual observations with contrail $D$, $W, A_{\mathrm{c}}, p, T$, and $\mathrm{RH}_{\mathrm{i}}$, including $\tau$ for 48 observations) were made available for this paper. Those for 1995 and 1996 were partially reanalyzed for this purpose. The contrail identification and error analysis methods used are described in Freudenthaler (2000). Contrail age is provided for all of these data, but the aircraft types were not recorded. The data for 1994-1995 were obtained within the project SiL and a German Science Foundation (DFG)-funded project (Schumann, 
1998), while those for 1996 are from the project AEROCONTRAIL (Ström and Ohlsson, 1998) and include observations reported by Sussmann (1999).

At $T<-60^{\circ} \mathrm{C}$, the observed depolarization values inside the contrails increase from about 0.1 to 0.5 with age, whereas for higher temperatures, $T \approx-50^{\circ} \mathrm{C}$, the youngest contrails exhibit depolarization values of about 0.5 , suggesting quicker formation of aspherical ice particles at higher temperatures. The $\tau$ results fit into the range of other results (Kärcher et al., 2009a).

Within AEROCONTRAIL, the contrail of a B747-400 aircraft, in rather turbulent ambient air in the upper troposphere, was measured with the IFU-Lidar and from a ground-based digital camera at lifetimes of 5.7 to $50.3 \mathrm{~s}$, together with turbulence measurements obtained on the Falcon (Sussmann, 1999; Sussmann and Gierens, 1999). The contrail was observed from the surface near Augsburg $\left(48.3^{\circ} \mathrm{N}, 10.7^{\circ} \mathrm{E}\right)$, Germany, at 12:37 UTC on 22 April 1996. The contrail formed at $p=236.7 \mathrm{hPa}$ and $T=-52.3{ }^{\circ} \mathrm{C}$ in a slightly unstably stratified atmosphere $\left(N_{\mathrm{BV}}^{2}=-(3 \pm 2.4) 10^{-5} \mathrm{~s}^{-2}\right)$. A secondary wake was identified above the primary part of the wake in photos and lidar data. The humidity was not measured but the analysis suggests slightly ice-supersaturated ambient air, possibly $\mathrm{RH}_{\mathrm{i}}=101 \%$ (Sussmann and Gierens, 1999). The shear was highly variable, but low on average. The lidar identified cross-sectional areas for the primary and secondary wakes of about $4500 \pm 100 \mathrm{~m}^{2}$ each, at $50 \mathrm{~s}$ contrail age. The contrail depth was $D=160 \mathrm{~m}$ and $W=90 \mathrm{~m}$ at this age. The $\tau$ derived from the lidar data is 1.18 and 0.24 for the primary and secondary wakes, respectively. Apparently, for another contrail, the primary-wake contrail sublimated at 170 s age and the contrail in the secondary wake was slightly inclined by shear with a depth $D=160 \mathrm{~m}$ and $W=100 \mathrm{~m}$ (Sussmann and Gierens, 1999). Nearly simultaneous $100 \mathrm{~Hz}$ turbulence data reveal a dissipation rate of turbulent kinetic energy of $(7.4 \pm 0.5) \times 10^{-5} \mathrm{~m}^{2} \mathrm{~s}^{-3}$ and yield the rms values of horizontal $\left(0.9 \mathrm{~m} \mathrm{~s}^{-1}\right)$ and vertical $\left(0.5 \mathrm{~m} \mathrm{~s}^{-1}\right)$ turbulent velocity fluctuations. Follow-on studies, including numerical simulations of the contrails, showed that the ambient humidity level and adiabatic warming of the primary wake during descent determines when a secondary wake is visible above a vortex pair and when it is not (Sussmann and Gierens, 1999, 2001).

\subsubsection{SUCCESS: long-lived racetrack contrail in satellite images}

The contrail observed during SUCCESS on 12 May 1996 was generated while the DC-8 was flying a racetrack causing an oval contrail pattern. The oval was visible in geostationary satellite imagery ( $4 \mathrm{~km}$ resolution GOES-9) for $7 \mathrm{~h}$ (Jensen et al., 1998a; Lawson et al., 1998; Minnis et al., 1998). Additional data were derived from $1 \mathrm{~km}$ resolution polar-orbiting NOAA-12 AVHRR data. The contrail visible $\tau$, the effective radius $r_{\text {eff }}$, and the temperature $T$ of the contrails were de- rived from multispectral satellite data (Minnis et al., 1998). Data derived from these studies for contrail ages of 14400 (3600-25 200) $\mathrm{s}$ in Fig. 2 are $W=5-10 \mathrm{~km}, \tau=0.5 \pm 0.25$, and $r_{\text {eff }}=30(15-40) \mu \mathrm{m}$. The study showed high variability in the results with time.

Besides the 12 May case, contrail clusters were observed with ages up to $17 \mathrm{~h}$ and $\tau$, on average, from 0.2 to 0.5 over the cloud lifetime. In all cases, cloud particle sizes increased as the contrails developed into cirrus clouds. The contrail clusters include several individual contrails and, hence, are not included in COLI.

\subsubsection{SUCCESS-ER2: remote sensing of microphysics and integral contrail properties}

During the SUCCESS campaign, a multispectral thermalinfrared imaging spectroradiometer, an airborne Moderate Resolution Imaging Spectroradiometer (MODIS) simulator with about $100 \mathrm{~m}$ spatial resolution, and a $532 \mathrm{~nm}$ backscatter lidar (40 and $7.5 \mathrm{~m}$ resolution in horizontal and vertical directions) (Spinhirne and Hart, 1990) were flown onboard the NASA ER-2 aircraft (Duda et al., 1998; Spinhirne et al., 1998). A young and an aged contrail were observed over northeastern Oklahoma at 15:56 and 16:43 UTC on 20 April 1996. The source aircraft and the contrail ages were not determined, but both contrails originated within $10 \mathrm{~km}$ of each other, and the aged contrail was observed $3000 \mathrm{~s}$ later than the younger one. In order to correlate the results with other data, we estimate contrail ages $(900 \pm 300$ and $3900 \pm 900 \mathrm{~s})$. Pressure $(302-335 \mathrm{hPa})$, temperature ( -40 to $-45^{\circ} \mathrm{C}$ ), ambient humidity (near ice saturation), $N_{\mathrm{BV}}$ (near $0.008 \mathrm{~s}^{-1}$ ), and shear (low) are estimated from the Springfield, Missouri $\left(83.37^{\circ} \mathrm{W}, 37.22^{\circ} \mathrm{N}\right)$, radiosonde observations at 00:00 UTC on 21 April 1996, which is selected because it shows the highest humidity relative to the radiosondes in the neighborhood of northeastern Oklahoma.

This is the only study that determined the local and total ice water contents (IWC and TWC) and local and total number concentrations of ice particles $\left(n_{\text {ice }}\right.$ and $\left.N_{\text {ice }}\right)$ in contrails per volume and per unit length by remote sensing. The method is complementary to the in situ method of Knollenberg (1972). The method relates the IWC to $\beta_{\text {ext }}$ and $r_{\text {eff }}$ observable by remote sensing:

$\mathrm{IWC}=(2 / 3) \rho_{\text {ice }} \beta_{\text {ext }} r_{\text {eff }}$,

and

IWC $=C^{3} n_{\text {ice }}(4 / 3) \pi \rho_{\text {ice }} r_{\text {eff }}^{3}, C=r_{\mathrm{vol}} / r_{\mathrm{eff}}$.

The values of

$N_{\text {ice }}=n_{\text {ice }} A_{\mathrm{c}}, \quad \tau=\beta_{\text {ext }} D_{\text {eff }}, \quad \mathrm{EA}=\beta_{\text {ext }} A_{\mathrm{c}}$,

$\mathrm{TWC}=\operatorname{IWC} A_{\mathrm{c}}, \quad A_{\mathrm{c}}=W D_{\text {eff }}$

follow from the lidar data. Spinhirne and Hart (1990) implicitly assumed $C=1$, although they noted that $r_{\mathrm{vol}} / r_{\mathrm{eff}}$ may be 
as small as 0.5 . Values for $\tau, r_{\mathrm{eff}}$, and $T$ of the contrail were derived by comparing measured brightness temperatures of contrails at several bands in the infrared window to radiative transfer simulations of the clouds (Duda et al., 1998). The $\beta_{\text {ext }}$ profile is obtained from the lidar data, assuming an extinction-to-backscatter ratio of $18 \mathrm{sr}$, giving a similar $\tau$. The integrals of these variables over the contrail cross section are used to evaluate $A_{\mathrm{c}}, W$, and EA.

The results show that the ice particles in the young contrail are generally smaller $(7 \mu \mathrm{m})$ than those in the older one (20 $\mu \mathrm{m})$, as expected, while $N_{\text {ice }}$ stayed nearly constant, decreasing from 26 to $23 \times 10^{11} \mathrm{~m}^{-1}$ with age (Spinhirne et al., 1998). The derived $N_{\text {ice }}$ would be $>3$ times larger for $C<0.7$. The method would be less suitable for thick cirrus with far lower $C$ values.

\subsubsection{Spiral: a spiral contrail spreading in clear air}

An unusual example of a spiral contrail forming from a circling military aircraft was observed in NOAA-14 AVHRR data west of Denmark 14:45 UTC on 22 May 1998. A B707 aircraft, with four CFM 56 engines, was cruising at a speed of 660 to $720 \mathrm{~km} \mathrm{~h}^{-1}$, at flight level FL290 $(8.84 \mathrm{~km})$. Schleswig radiosonde data at 12:00 UTC on 22 May 1998 indicate that the contrail formed above $9 \mathrm{~km}$ altitude $(p<$ $300 \mathrm{hPa}, T<-47^{\circ} \mathrm{C}$ ) at levels with moderate stratification $\left(N_{\mathrm{BV}}=0.011 \mathrm{~s}^{-1}, \mathrm{Sh}_{\mathrm{T}}=0.001 \mathrm{~s}^{-1}\right)$, where the mean wind blew at more than $110 \mathrm{~km} \mathrm{~h}^{-1}$ from $330^{\circ}$. The contrail was $1500 \mathrm{~km}$ along nine circles of $60 \mathrm{~km}$ diameter along the spiral. This is the largest length identified in this study. $W$ varied between 5 and $10 \mathrm{~km}$. From the aircraft speed and from the spiral shift by $195 \mathrm{~km}$ with the $110 \mathrm{~km} \mathrm{~h}^{-1}$ wind, an age of $2(1.7-3) \mathrm{h}$ is estimated. The mean/maximum contrail $\tau$ increases linearly from $0.1 / 0.5$ to $0.3 / 0.9$ with age, while $\tau$ in the background air along the spiral increased up to 0.1 (Schumann, 2002; Kästner, 2003).

\subsubsection{Cluster: contrails merging into clusters}

Duda et al. (2004) observed the merging of several contrails into a contrail cluster over the Great Lakes (Wisconsin and Michigan) using a combination of geostationary (GOES-8) satellite, NWP, and traffic data for 14:00 to 19:00 UTC on 9 October 2000. They identified individual contrails in the upper troposphere (FL 350 to $390, p=240$ to $200 \mathrm{hPa}$ ), at high humidity. The $\tau$ of the contrails (and contrail clusters) was about $0.25(0.14-0.55)$. Normal ambient shear was low, at $(1.5-2.8) \times 10^{-3} \mathrm{~s}^{-1}$. Nevertheless, high lateral contrail spreading rates were found. The trails were about $6 \mathrm{~km}$ wide at $2.25 \mathrm{~h}$ age and $10 \mathrm{~km}$ wide at $3.75 \mathrm{~h}$ age - i.e., the mean spreading rate was $0.75 \mathrm{~m} \mathrm{~s}^{-1}$. The growth rates were explained for given shear by contrail depth increase with time from ice particle sedimentation, and the mean fall speeds of the ice particles were estimated from this connection. Still, the derived rate is 3 times smaller than that found by Freudenthaler et al. (1995) for younger contrails. Perhaps the shear was below average in the observations of Duda et al. (2004). Also, the estimated width-spreading rates may be affected by the relatively coarse resolution of GOES data. The contrail spreading results were found helpful to test global contrail modeling (Burkhardt and Kärcher, 2009).

\subsubsection{Shutdown: life cycle of isolated long-lived contrails}

Starting at about 16:00 UTC on 11 September 2001, air traffic over USA was halted for a period of more than $36 \mathrm{~h}$, in the aftermath of terrorist attacks. Instead of the approximately 30000 flights per day (Garber et al., 2005), only a few state or military aircraft operated over the USA, forming a few isolated, wide and well-observable contrails between 37 and $42^{\circ} \mathrm{N}$, and 73 and $90^{\circ} \mathrm{W}$, on 12 September. Here we report results from two ad hoc projects, "Shutdown 1" and "Shutdown 2".

In a previous study ("Shutdown 1"), Minnis et al. (2002) identified seven contrails in a sequence of multispectral images of geostationary and polar-orbiting satellites, including $4 \mathrm{~km}$ resolution data from GOES- 8 at $75^{\circ} \mathrm{W}$ and GOES10 at $135^{\circ} \mathrm{W}$, and $1 \mathrm{~km}$ data from the MODIS on the EOS Terra satellite and the AVHRR on NOAA-14, 15, and 16 after 10:14 UTC on 12 September 2001. One of the contrails was followed over a time period up to $11.5 \mathrm{~h}$ in a sequence of satellite images. This is the oldest individual contrail identified in this study. The actual flight routes of the contrail-forming aircraft are unknown. In routine mode, the GOES observation times over the continental USA are every $15 \mathrm{~min}$, at $02,15,32,45$ after the hour. The contrail might have formed prior to the first observation, in the $15 \mathrm{~min}$ time interval between two subsequent GOES scenes. Thus, even higher ages cannot be excluded. Contrail $W, L$, and $\tau$ values of the contrails were determined from the satellite images at various contrail ages ( 23 data points). The contrail $\tau$ is derived using the shortwave-infrared infrared split-window technique (SIST; Minnis et al., 2011). The SIST is daytimeindependent since it uses only the $3.7,11$, and $12 \mu \mathrm{m}$ brightness temperatures and solves for cloud optical depth, contrail temperature, and particle size. Longwave radiative forcing is computed as in Palikonda et al. (2005). The results show a mean $\tau \approx 0.23 \pm 0.14$. Most of the trails spread at $7-8 \mathrm{~km} \mathrm{~h}^{-1}$ with maximum $W$ after $2-4 \mathrm{~h}$. The mean $W$ is $(14.5 \pm 9) \mathrm{km}$, and the mean $L$ is $(205 \pm 121) \mathrm{km}$. For a subset of the contrails, with nearly coincidental GOES-8 and NOAA-14 and 15 observations near 11:09 and 12:45 UTC on 12 September, the geometric contrail altitudes were estimated from stereography. Many of the contrails had altitudes between 9 and $12 \mathrm{~km}$ above mean sea level, with extreme values of 6.5 and $13 \mathrm{~km}$.

As a supplement to that paper, the dataset has been expanded in a new study ("Shutdown 2") by analyzing additional AVHRR and MODIS observations between 00:11 and 
16:00 UTC the same day, using the methods described in Bedka et al. (2013). In addition to contrail $W, L, \tau$, and altitude, $r_{\text {eff }}$ values are also derived for 15 contrails, of which 7 overlap the observations in the Shutdown 1. One or more of the earlier contrails was likely produced by the US Air Force One aircraft (a B747 variant) and its fighter escorts, but details are unknown. Contrail temperature was derived and converted to altitude using NWP data. Contrail ages were estimated by visually searching for the first appearance of contrail traces in sequential $1 \mathrm{~km}$ visible-channel GOES scenes. GOES data between 23:45 UTC on 11 September and 01:02 UTC on 12 September and between 03:45 and 06:45 UTC were missing, while others were incomplete. Because of the low resolution of the thermal infrared GOES imagery available, RGB data were used (i.e., a combination of visible (0.65), 3.9-11, and $11 \mu \mathrm{m}$ data during the day, and 3.9, 11, and 3.9-11 $\mu \mathrm{m}$ data at night). The detectability of the contrails in the RGB data may be slightly later in the contrail's life cycle than for 11-12 $\mu \mathrm{m}$ imagery. This is especially true for contrails that are embedded in or extend from cirrus decks, and therefore some of the contrail ages given in this study may be underestimated.

The mean results are plotted versus contrail age in Fig. 2. The mean values with error bars depict the age, i.e., the difference between the actual observation time and the time of first observability, with $0.5 \mathrm{~h}$ added uncertainty for the Shutdown 1 and $1 \mathrm{~h}$ for Shutdown 2 results. The values plotted for $\tau$ and $r_{\text {eff }}$ are the median values with 10th to 90th percentiles. The uncertainty of $W$ and $L$ are estimated as \pm 30 and $20 \%$. The total extinction EA (the integral of the optical depth over contrail width) is estimated from the product of $W$ and $\tau$ based on the respective median values and uncertainty ranges from $\tau$ and $W$. The results show reasonable variations. In particular, particle sizes seem to grow systematically with age. One (Shutdown 1) contrail result stands out, likely because of underestimated contrail age.

For those contrails which were treated in both analyses, the Shutdown 2 results for $\tau, W$, altitude and $L$ differ by about 20 to $50 \%$ from the Shutdown 1 results. These deviations are essentially within the error bars, but the Shutdown 1 results tend to have larger $\tau$ and $W$, while the $L$ values are similar and correlated within $90 \mathrm{~km}$ for most cases. The differences between the two analyses demonstrate the general uncertainties involved in satellite retrieval of contrail $\tau$ and $r_{\text {eff }}$ in addition to technical differences. Several factors contribute to these differences. The two methods identified contrail pixels differently. For the MODIS retrievals, the mask $C$ from the automated contrail detection algorithm is used (Bedka et al., 2013), while the AVHRR retrievals were done with the splitwindow technique for 11-12 $\mu \mathrm{m}$ brightness-temperature difference (BTD) thresholds (Mannstein et al., 1999), subjectively throwing out non-contrail pixels by hand. The contrail pixels in most of the images were determined subjectively (except for the new MODIS analyses at 04:00 and 16:00 UTC where the automated mask $C$ was used). Thus, the contrail property statistics are expected to vary. Secondly, a different retrieval scheme was used in the two analyses (SIST or BTD). Thirdly, the contrail height was estimated differently in the two studies. Although the contrail heights from the later analyses are generally consistent with the stereoscopic determinations from the first analysis (with the potential exception of the MODIS results), even minor differences will lead to added uncertainty in retrieved contrail properties.

We also compared the Shutdown 2 contrail results to coincident NWP data from ERA-Interim (Dee et al., 2011). The validity of the NWP data for this case was checked by comparison to two weather-balloon soundings. The temperature profiles exhibit a double tropopause for that day, one near $12 \mathrm{~km}$ and another near $17 \mathrm{~km}$, with high humidity in layers of 1 to $2 \mathrm{~km}$ thickness partially exceeding ice saturation at 12 and $9 \mathrm{~km}$ altitude. Wind speed reached $20 \mathrm{~m} \mathrm{~s}^{-1}$ from west between 12 and $14 \mathrm{~km}$ attitude. In the NWP data, temperature is rather homogeneous horizontally and slowly decreased with time during that day. Vertical profiles of temperature, wind, geopotential altitude, and even relative humidity over ice in the mid troposphere from NWP data agree quite well with the radiosonde data. Although $\mathrm{RH}_{\mathrm{i}}$ from radiosondes and NWP may have limited accuracy at low temperatures, some altitudes $(>13 \mathrm{~km}$ ) derived from the contrail analysis appear as possibly too high because the air masses were dry $\left(\mathrm{RH}_{\mathrm{i}}\right.$ below $\left.30 \%\right)$ at those altitudes in the NWP analysis. Accurate height and related temperature analysis is important since a $5 \mathrm{~K}$ decrease in contrail $T$ could lead to a 0.05 decrease in the retrieved $\tau$ and a $1 \mu \mathrm{m}$ increase in $r_{\mathrm{eff}}$ (Bedka et al., 2013).

The NWP data were also used to check for source identity of contrails at various ages. Air parcel trajectories were computed using linearly interpolated winds and a second-order numerical integration scheme with about 20 min time steps, which is fully sufficient for NWP data having $3 \mathrm{~h}$ resolution. Starting with an observed contrail at a known position (longitude, latitude and altitude) at one time, the expected position of the same contrail at a later time is taken from this trajectory analysis. By comparing computed and observed positions at the later time, it can be determined whether two contrails observed at two subsequent times have identical sources or not. With this analysis we confirmed that some of the contrails originated from the same source, while others, in apparently close proximity with similar morphology, had, in fact, different sources.

Atmospheric parameters $\left(p, T, \mathrm{RH}_{\mathrm{i}}, \mathrm{Sh}_{\mathrm{T}}, N_{\mathrm{BV}}\right)$ at contrail positions were derived from the NWP data. The atmosphere was stably stratified $\left(N_{\mathrm{BV}}=0.017 \mathrm{~s}^{-1}\right.$ on average), typical for the upper troposphere. Shear was rather low $\left(\mathrm{Sh}_{\mathrm{T}} \approx 0.0012 \mathrm{~m} \mathrm{~s}^{-1}\right)$, and can explain the large observed $W$ only for large $D$, again suggesting possible enhancement by sedimentation. 


\subsubsection{Fallstreaks: fallstreak formation for a sequence of contrails}

Atlas et al. (2006) observed individual contrails for ages up to $2 \mathrm{~h}$. The first set of contrails was observed between 15:30 and 18:00 UTC on 7 September 2003 with a camera from the ground, with a lidar at Goddard Space Flight Center $\left(39^{\circ} \mathrm{N}, 76.9^{\circ} \mathrm{W}\right)$, and in MODIS images. The generating airliner flights were identified and used to estimate the contrail ages (1000 to $7100 \mathrm{~s}$ ). The corresponding aircraft types are listed in the Supplement. Flight information is available from a flight track database (Garber et al., 2005), ready for a simulation of this case with proper NWP data. The observations showed contrails producing cirrus uncinus and fallstreaks. The $\tau$ was estimated as 0.35 , with a maximum of 2 . The TWC per contrail length was $10^{3}$ to $10^{4}$ times the water mass emitted by a typical airliner.

The second set of data was observed between 12:00 and 22:45 UTC on 5 December 2008 at the same place, again with lidar and GOES images, and analyzed using radiosonde and NWP data (Atlas and Wang, 2010). About 200 thin contrails were observed, while one contrail of about $1 \mathrm{~h}$ age, clearly visible with $W=10 \mathrm{~km}$ in GOES images, and $D=$ $1.5 \mathrm{~km}$ in lidar data, reached $\tau=2.3$. The data show the large range of variability in IWC, $\beta_{\mathrm{ext}}, \tau$, and $D$. The NWP data allow specification of wind, $T, p$, Sh, and $N_{\mathrm{BV}}$. The $n_{\text {ice }}$ and the aircraft types were not determined.

\subsubsection{SCOUT-03: long-lived contrails in the tropical stratosphere and above Hector}

In addition to the in situ data taken for Geophysica contrails as described in Sect. 3.1.11, contrail data are derived from a photo and from Falcon lidar taken during SCOUTO3 (Schumann et al., 2016b). The photo was taken from the Falcon cockpit at $11.9 \mathrm{~km}$ altitude and shows the Geophysica contrail at 17 to $19 \mathrm{~km}$ altitude in the stratosphere at 08:35 UTC on 16 November 2005 west of the Tiwi Islands. The position of the Geophysica exhaust plume responsible for the observed contrail could be reproduced from the Geophysica flight path and wind data. The Geophysica was descending along a flight path with several curves from about $19 \mathrm{~km}$ in the stratosphere to $17 \mathrm{~km}$ altitude at the tropopause while it formed a visible contrail in clear air. Two contrail segments, above and below $18 \mathrm{~km}$ altitude, were distinguished in the photo. The optically thin persistent contrail segments were 1200 to $3200 \mathrm{~s}$ old, $1-3 \mathrm{~km}$ wide, each about $200 \mathrm{~km}$ long, and originated in ambient air with mean $T$ and $\mathrm{RH}_{\mathrm{i}}$ values and standard deviations along the flight paths of $T=(-82 \pm 0.6)^{\circ} \mathrm{C}$ and $(-85 \pm 2)^{\circ} \mathrm{C}$ and $\mathrm{RH}_{\mathrm{i}}=(64 \pm 7) \%$ and $(87 \pm 23) \%$.

Lidar data were obtained with an upward-looking backscatter lidar on the DLR Falcon for the "Golden Hector" day of 30 November 2005. The lidar observed two cirrus layers from the anvil of a deep convective cloud, containing
Geophysica exhaust, in particular in the upper of these two cirrus layers. The anvil is also seen in two NOAA AVHRR scenes, but line-shaped contrail structures were not identifiable. The geometrical and optical thickness of the cirrus layers and their geometrical width as well as EA (integral of optical depth over width along the Falcon flight path) was derived. The atmospheric conditions for these cirrus layers were taken from the in situ measurements on the Geophysica at the time of contrail generation. The age of the contrails was derived from trajectory analysis. The observations represent mixtures of natural cirrus with contrails.

\subsubsection{ACTA: life cycle and radiative properties of satellite-observed contrails}

Vázquez-Navarro et al. (2010) developed the Automatic Contrail Detection Algorithm (ACTA) to identify contrails in simultaneous MODIS and METEOSAT satellite scenes and to subsequently trace the contrail history forward and backward in time in rapid scan (5 min) METEOSAT images with $3 \mathrm{~km} \times 3 \mathrm{~km}$ spatial resolution at nadir. ACTA was developed within DLR projects (CATS and WeCARE). A total of 2400 contrails was observed with the ACTA method, at multiple times during their life cycles, mainly over the Atlantic and Europe at northern midlatitudes, from August 2008 to July 2009 , yielding more than 25000 data entries for contrail $L, W, \tau$, height, shortwave and longwave local radiative forcing, and energy forcing (Vázquez-Navarro et al., 2015). The given ages do not include any dwell time needed to make the contrails visible in the coarse Meteosat scenes (about 0.5 to $1 \mathrm{~h})$. Mean (maximum) values retrieved are $1 \mathrm{~h}(17 \mathrm{~h})$ duration, $130 \mathrm{~km}(>400 \mathrm{~km})$ length, $8 \mathrm{~km}(14 \mathrm{~km})$ width, $11.7 \mathrm{~km}$ $(14 \mathrm{~km})$ altitude, and 0.34 (2) optical thickness. A table with the ACTA results and the percentiles of the $\tau$ data is included in the Supplement.

Figure 2 includes a graph of the median values and the $\tau$ percentiles. The optical depths in the ACTA data are within the upper range of other observations, as to be expected (Schumann et al., 2015). The derived width values are not plotted; they are also large for young ages and seem to suffer from the coarse satellite pixel resolution. The data would allow extraction of the relevant meteorological parameters from NWP data. The individual aircraft causing the contrail have not been identified, because air traffic data are missing. The local RF values are of the order of $\pm 20 \mathrm{~W} \mathrm{~m}^{-2}$, consistent with other observations and model results (Duda et al., 2001; Haywood et al., 2009; Schumann et al., 2015).

\subsubsection{Cameras: contrails observed with several ground-based cameras}

Four individual persistent contrails behind well-identified aircraft (small and large ones) were tracked in clear air with several ground-based video cameras 23 to $37 \mathrm{~km}$ apart (Schumann et al., 2013b), as a contribution to the DLR project 
WeCARE. Contrail properties in terms of altitude and visible width $W$ were derived up to a maximum age of $2700 \mathrm{~s}$. The data fit well with the other $W$ results (Fig. 2). The ambient meteorology was characterized with radiosonde and NWP data. The contrails were compared with individual CoCiP contrail simulations, and it was found that the $W$ (e.g., $1500 \mathrm{~m}$ at $1400 \mathrm{~s}$ age) was roughly simulated as observed. One of the contrails formed during aircraft climb in clear air at a temperature, derived from ECMWF data, in agreement with the radiosonde data, of about $-39^{\circ} \mathrm{C}$, more than $7 \mathrm{~K}$ above the SAC threshold temperature.

\section{Discussion}

\subsection{Contrail properties versus age}

Figure 3 depicts the data from all observations collected in COLI for various local contrail properties together with results from CoCiP as a function of contrail age. Nearly $90 \%$ of the contrail cases occurred at temperatures between -60 and $-40{ }^{\circ} \mathrm{C}$, but the dataset includes contrails at temperatures as cold as $-88^{\circ} \mathrm{C}$ (CR-AVE) to as warm as $-31^{\circ} \mathrm{C}$ (ICE-1989), and at altitudes between 7.5 and $18.7 \mathrm{~km}$. The observed jet aircraft are of different sizes, with 12 to $79.8 \mathrm{~m}$ wing span, 2.5 to $508 \mathrm{Mg}$ mass, and 0.57 to $16 \mathrm{~g} \mathrm{~m}^{-1}$ fuel consumption per flight distance.

When discussing trends in these data with age, one must note that the plots show the properties of the ensemble of contrail observations versus ages at the times of observations, i.e., in a quasi-Eulerian mode. Different trends may occur when observing single individual contrails during their evolution with time, in a quasi-Lagrangian mode. Only a few observations provide information on individual contrails in a Lagrangian mode. The CoCiP model results used here are also for an ensemble of contrails evaluated in the Eulerian mode. The ACTA data include data for individual contrails at a sequence of times and data for the ensemble of contrail observations.

Both the observations and the model results show a large range of variability in the contrail properties that increases with age. The results from the measurements and simulations agree on the mean magnitude. The observations may be biased somewhat to thicker contrails, because they are typically easier to observe. The trends are as expected (Schumann and Heymsfield, 2016). Ice particle number concentrations are high in the young exhaust and then decrease (with power -1.6 of age in these data), mainly because of dilution. The remote sensing results of Spinhirne et al. (1998) and Duda et al. (1998), blue points in Fig. 3a, are within the spread of the in situ data. The IWC (Fig. 3b) adjusts to the available supersaturation, which is temperature-dependent and appears to decrease slightly with age. The particle sizes (Fig. 3c) are initially small, but grow with age, depending on the number of particles competing for the available humidity. The value of $r_{\text {eff }}$ is often larger than the $r_{\mathrm{vol}}$, and $r_{\text {eff }}$ grows slightly faster with age (with power 0.5) than $r_{\mathrm{vol}}$ (power 0.33), presumably because the size distributions broaden with time with larger separation between sizes of maximum volume and maximum number densities for aged contrails. The ratio $C=r_{\mathrm{vol}} / r_{\mathrm{eff}}$ ranges from $0.8 \pm 0.2$ for young contrails to $0.6 \pm 0.4$ for about $1 \mathrm{~h}$ aged contrails. The optical depth (Fig. 3d) is largest for young contrails and then approaches a near-constant median value of about 0.3 . The contrail width $W$ (Fig. 3e), reaching up to $40 \mathrm{~km}$, is controlled by the aircraft wake in the first $\sim 100 \mathrm{~s}$ and then grows almost linearly over 2 orders of magnitude, mainly because of horizontal wind shear. The contrail depth in Fig. $3 \mathrm{f}$ is the maximum depth $D$ derived from the observations. It is larger than the effective depth $D_{\text {eff }}=A_{\mathrm{c}} / W$, controlling $\tau$ or ice water path. $D$ is controlled by vertical mixing in the wake vortex initially and then grows less strongly (power 0.3 , over 1 order of magnitude) mainly by turbulence and particle sedimentation when the particles reach a sufficiently large size. The $D / W$ ratio values vary over a wide range similar to those derived from a combination of satellite data from MODIS and the lidar CALIOP on the Cloud-Aerosol Lidar and Infrared Pathfinder Satellite Observations (CALIPSO) (Iwabuchi et al., 2012).

Figure 4 shows integral contrail properties (and length and $\left.\beta_{\text {ext }}\right)$ versus age. Integral properties have often been computed from models (Unterstrasser and Gierens, 2010a; Lewellen et al., 2014). This is the most complete set of integral contrail data derived from observations to date. The figure includes results from remote sensing and a few in situ measurements with estimated cross-sectional areas. The contrail cross-sectional area $A_{\mathrm{c}}$ in Fig. 4a grows with a power of 1.4 of age by turbulent mixing, enhanced by shear, ice particle sedimentation, and radiative heating. It could diminish when part of the contrail evaporates, but this effect is only weakly indicated in this collection (e.g., at large ages). The total number of ice particles $N_{\text {ice }}$ (Fig. 4b) is large initially because it is mainly controlled by exhaust particles and decreases slowly with age. This confirms earlier suggestions (Spinhirne et al., 1998) and is remarkable, because it suggests that any ice nucleation process contributes little to contrail ice particles at later ages. This does not exclude re-nucleation of ice particles from the aerosol released from the contrail after sublimation (Schumann and Heymsfield, 2016).

The particle losses at later ages certainly include ice sublimation in dry air and precipitation. More complex processes like aggregation (Kienast-Sjögren et al., 2013) or humidity fluctuations under the influence of the Kelvin effect (Lewellen, 2012) may be present but are not obvious in these observations. The TWC (Fig. 4c) varies strongly with large variability over about 6 orders of magnitude. Low TWC values may result when the ambient air dries (e.g., in subsiding air masses). Large TWC values develop in rising air masses with increasing relative humidity, for strong mixing with humid air masses, and for sufficiently large ice particles falling 

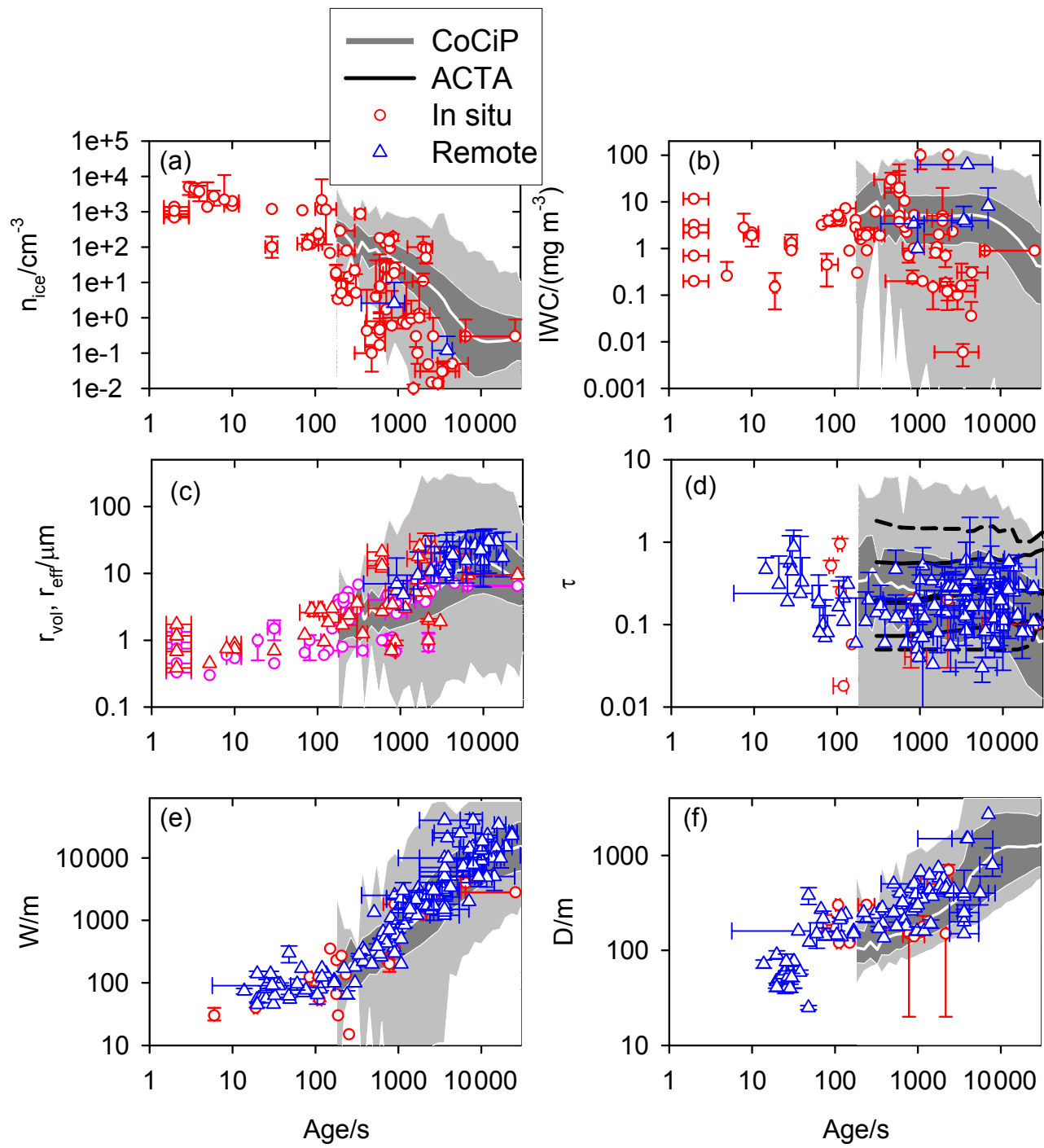

Figure 3. Local contrail parameters from all observations collected in COLI versus contrail age, together with results from a model simulation (CoCiP percentiles) as in Fig. 1. (a) $n_{\text {ice }}$, (b) IWC, (c) $r_{\text {vol }}$ (purple symbols), $r_{\text {eff }}$ (red and blue symbols), (d) $\tau$, (e) $W$, and (f) $D$. The red (and purple) symbols are from in situ measurements. The blue symbols are from remote sensing. The black lines in panel (d) are from ACTA.

into more humid layers. Sedimentation contributes to a dehydration of the upper troposphere (Burkhardt and Kärcher, 2011; Schumann et al., 2015).

EA (Fig. 4d) multiplied by lifetime or length controls the contribution of an individual contrail to warming or cooling the Earth atmosphere. EA grows about linearly with age. Hence, when multiplied with lifetime or length, the product (related to the product of $\tau$ and contrail coverage) varies over about 7 orders of magnitude. The amount of energy put into the atmosphere by a contrail (the energy forcing; Schumann et al., 2012) is proportional to EA but depends further on radiative boundary conditions and hence varies in sign, and its magnitude varies over an even larger range than the local contrail properties.
The contrail length (Fig. 4e) reaches $620 \mathrm{~km}$ for the linear contrails and $1500 \mathrm{~km}$ for the spiral contrail in this collection. The length is of course limited by aircraft speed and age, as well as by the meteorological variability along the flight path. Length values have rarely been derived from in situ observations. Remote sensing studies (Iwabuchi et al., 2012; Vázquez-Navarro et al., 2015) provide more extensive databases for length, with a similar maximum value of $1200 \mathrm{~km}$.

The $\beta_{\text {ext }}$ values included in this plot show a quite consistent picture, with values, in general, decreasing slowly with age. The $\beta_{\text {ext }}$ values (Fig. 4f) should increase for growing ice particles sizes and decrease for decreasing ice particle concentrations. In addition, they depend on the particle habit, which may be quasi-spherical in young contrails (at least at 

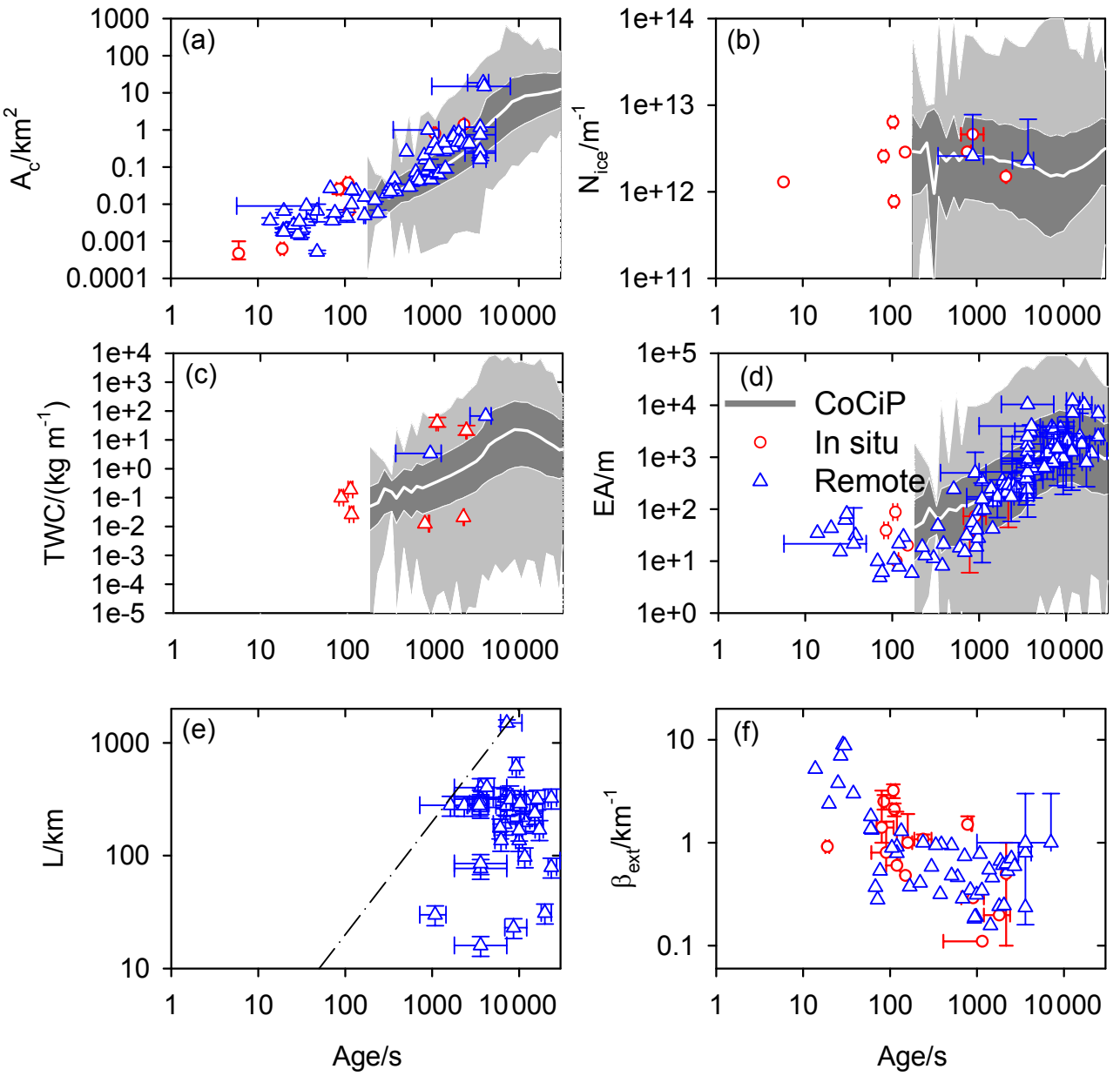

Figure 4. Integral contrail parameters (together with length and extinction) from all observations collected in COLI versus contrail age, together with results from a model simulation (CoCiP percentiles) as in Fig. 1. (a) Contrail cross-section area $A_{\mathrm{c}}$, (b) total number of ice particles per length $N_{\text {ice }}$, (c) total ice water content per length TWC, (d) total extinction EA (i.e., integral of optical depth over contrail width $=$ integral of extinction over contrail area), and (e) length $L$, (f) optical extinction $\beta_{\text {ext }}$. The red symbols are from in situ measurements. The blue symbols are from remote sensing. The dash-dotted line in panel (e) depicts the maximum length to be expected for $200 \mathrm{~m} \mathrm{~s}^{-1}$ aircraft speed.

low temperatures; Freudenthaler et al., 1996) and become more complex in aged contrails. Apparently, the dilution effect dominates the $\beta_{\text {ext }}$ change with age.

Some of the mean contrail properties are specifically sensitive to one set of observations only. In particular, this is the case for remote sensing of $\tau$ and of $r_{\text {eff }}$, which are determined mainly by the IFU-Lidar data for ages $<1 \mathrm{~h}$ and by the Shutdown data for larger ages.

\subsection{Humidity and contrail ice water content versus temperature and contrail threshold}

Figure 5 (upper panel) shows that the IWC in contrails scatters over a wide range of values and varies strongly with temperature, as expected. The linear regression for the in situ data is close to an early parameterization by Schumann (2002). Relative to the regression line, the logarith- mic IWC values vary with a standard deviation which corresponds to a factor of 3.8 for linear IWC values. The thin black curves represent maximum, median, and minimum IWC values from a large set of in situ measurements in cirrus (Schiller et al., 2008). Extreme values of contrail IWC have been observed rarely, with minimum/maximum values reasonably within the range of IWC measured for other cirrus. The results from SCOUT-O3 and CR-AVE nicely extend the previous results for CRYSTAL-FACE to lower temperatures, without any notable outliers. In fact, the extreme values are quite understandable. The high in situ value at $235 \mathrm{~K}$ is from the PMS results (Knollenberg, 1972) for a contrail resulting in cirrus uncinus. Similarly, the high remote sensing value at $215 \mathrm{~K}$ in Fig. 5 applies for a thick fallstreak contrail (Atlas and Wang, 2010). The high in situ values between 185 and $192 \mathrm{~K}$ are from the ice events measured during SCOUT-O3 

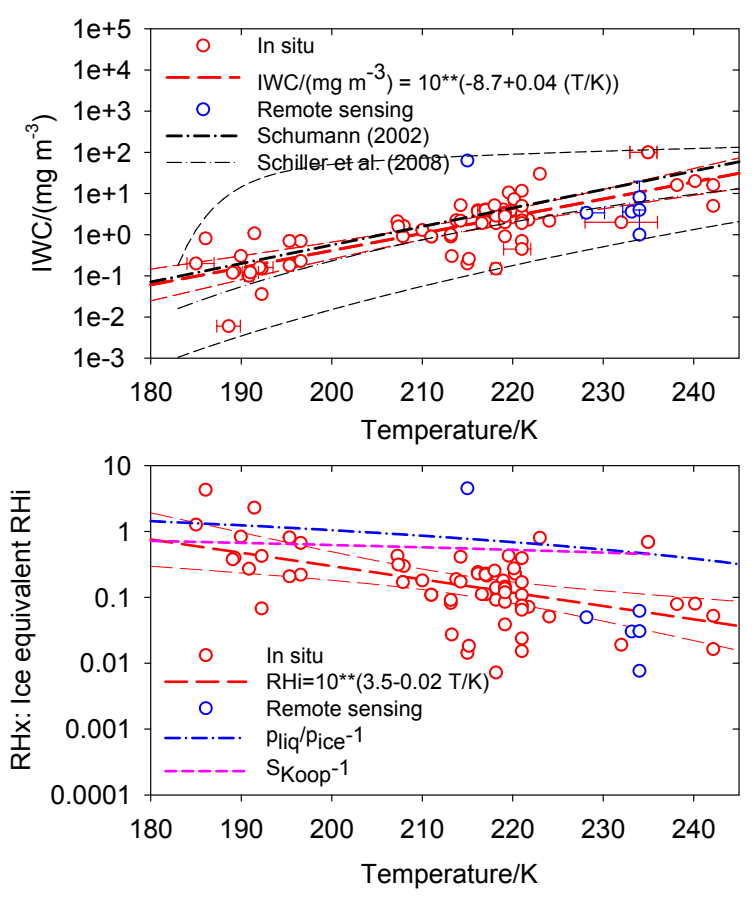

Figure 5. Top: Ice water content (IWC) versus temperature $T$ from in situ (red) and remote sensing observations (blue symbols) with a regression line for the in situ data (red; with given formula and with $99 \%$ confidence ranges, red dashed). The thick black dash-dotted line depicts an earlier parameterization (Schumann, 2002). The thin black lines represent median (dash-dotted) and maximum/minimum values (dashed curves) from in situ measurements in cirrus (Schiller et al., 2008). Bottom: ice-equivalent relative humidity $\left(\mathrm{RH}_{x}\right)$ over ice versus temperature $(1=100 \%)$, with a regression line (red dashed; with $99 \%$ confidence ranges, thin red dashed), and with expected $\mathrm{RH}_{x}$ values for ice forming from ambient supersaturation at liquid saturation (blue dash-dotted) and at the critical humidity for homogenous nucleation (Koop et al., 2000; Kärcher and Lohmann, 2002) (purple dashed line).

(de Reus et al., 2009), which might be contrail cirrus. These ice events contain many small ice particles and aerosol particles, possibly from the Geophysica aircraft exhaust, as well as a few large ice particles, that dominate the IWC, due to deep overturning convection. The two sets of IWC values for CRYSTAL-FACE contrails, larger from Mullins (2006) and smaller from Gao et al. (2006), are both within the range of other data. In some studies (Knollenberg, 1972), the IWC is higher than to be expected from deposition of ambient ice supersaturation if the ambient air was saturated with respect to liquid water. This may come from non-adiabatic effects, like particle growth during sedimentation, uplifting motions, or mixing with ambient cirrus.

The lower panel of Fig. 5 shows the ice-equivalent relative humidity over ice,

$\mathrm{RH}_{x}=\left(M_{\text {air }} / M_{\mathrm{H}_{2} \mathrm{O}}\right)(\mathrm{IWC} / \rho) /\left(p_{\text {ice }}(T) / p\right)$,
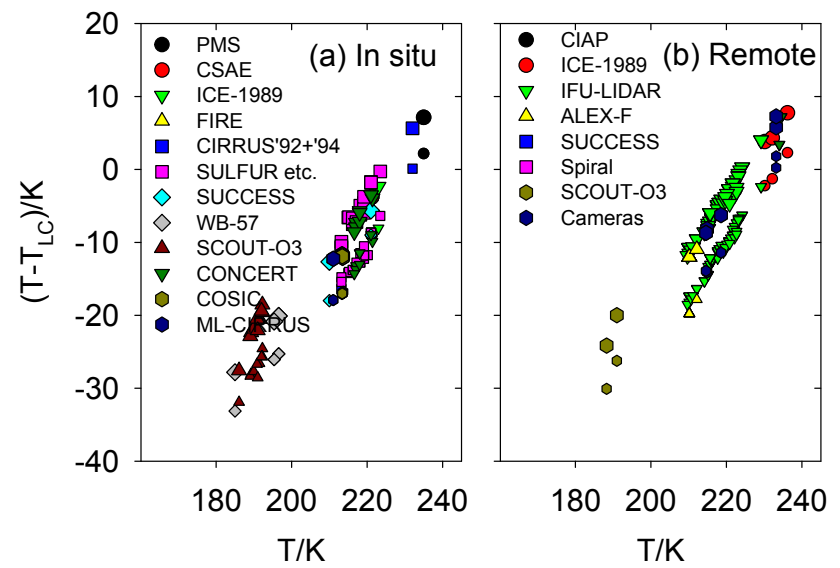

Figure 6. Difference between ambient temperature $(T)$ and the threshold temperature $\left(T_{\mathrm{LC}}\right)$ versus $T$ for $(\mathbf{a})$ in situ and for $(\mathbf{b})$ remote sensing contrail observations. The larger symbols depict $T-$ $T_{\mathrm{LC}}$ when $T_{\mathrm{LC}}$ is computed for the measured or estimated humidity, and the smaller symbols when computed for assumed liquid saturation. The symbols refer to the same projects as in Figs. 1 and 2 (WB-57 refers to CRYSTAL-FACE and CR-AVE, which both used this aircraft).

for given molar masses of air and water, ice water mass per unit air volume, air density, ice saturation pressure for given temperature and pressure. We see that $\mathrm{RH}_{x}$ is larger at low temperatures than at high temperatures. This is to be expected (Schumann, 2002) because the humidity difference between liquid saturation and ice saturation decreases with increasing temperature and is zero near $0{ }^{\circ} \mathrm{C}$. The $\mathrm{RH}_{x}$ difference between homogeneous ice nucleation and ice saturation is smaller and zero above $-38^{\circ} \mathrm{C}$ (Koop et al., 2000). In a few cases, the observed $\mathrm{RH}_{x}$ values are very large. These are cases with strong diabatic ice formation, as discussed before.

Figure 7 shows histograms of $\mathrm{RH}_{\mathrm{i}}$ in the ambient air for all the data (including remote sensing data, with $\mathrm{RH}_{\mathrm{i}}$ from radiosondes or NWP data) and for the in situ data only. We see maximum values of $165 \%$ and many cases near ice saturation, but also many cases where the available information suggests ice subsaturation. Certainly, the accuracy of the given $\mathrm{RH}_{\mathrm{i}}$ data varies. Contrails (and cirrus) are observed frequently in apparently subsaturated air (Jensen et al., 2001; Ovarlez et al., 2002; Krämer et al., 2009; Kübbeler et al., 2011). The common explanation is that these are clouds with large ice particles that have been formed under supersaturated conditions, have sedimented to lower and drier levels, and are sublimating slowly. A process-oriented study of measured contrail ice in subsaturated air is missing. Contrail model simulations often depend strongly on accurate ambient humidity data (Sussmann and Gierens, 2001). If such data are missing, one may consider adjusting ambient humidity such that the simulated contrails reach the observed IWC.

The mean IWC and $\mathrm{RH}_{x}$ trends are most sensitive to the observations at the highest (ICE-1989) and lowest (CR-AVE 
and SCOUT-O3) temperatures. If these data are excluded from Fig. 7, the mean trends in both panels stay about unchanged but the confidence ranges double.

\subsection{Consistency with the Schmidt-Appleman criterion}

Figure 6 shows the temperature difference between ambient temperature $T$ and the SAC threshold temperature $T_{\mathrm{LC}}$ (Schumann, 1996; Jensen et al., 1998c). The threshold temperature is computed for given pressure, best estimate of propulsion efficiency (aircraft- and operationdependent, between 0.1 and 0.4 , mostly 0.3 ), combustion heat of $43.2 \mathrm{MJ} \mathrm{kg}^{-1}$, and $\mathrm{H}_{2} \mathrm{O}$ emission index of 1.24 . The figure shows two sets of results, one for observed relative humidity and one for liquid saturation; the latter are the lower values. For warm air with $T>-40^{\circ} \mathrm{C}$, we see that 15 of the contrails were observed at ambient conditions above the SAC threshold. Assuming liquid saturation, this number reduces to 7 . The differences reach up to $12 \mathrm{~K}$ ( $7 \mathrm{~K}$ for liquid saturation), and can hardly be explained with instrument errors. Sometimes the temperature may have been measured at the contrail level while the contrail formed at higher altitude with lower temperature. Also, added humidity from ambient cirrus particles entrained into the young exhaust plume from ambient air cannot explain all cases, because some of the cases were observed in clear sky (Sect. 3.2.13). There are a few other cases that were discussed in the literature for which contrails were observed at temperatures significantly above the SAC threshold in warm air (Gayet et al., 1996b; Mazin, 1996; Jensen et al., 1998c; Schumann et al., 2013b). These are, perhaps, aerodynamic contrails (Gierens et al., 2009), contrails forming on exhaust particles suitable for ice formation below liquid saturation at these temperatures (Mazin and Heymsfield, 1998), or contrails forming on pre-activated aircraft exhaust aerosol (Schumann and Heymsfield, 2016). On the other hand, there are several observations of aircraft in operation without forming a contrail, consistent with the Schmidt-Appleman criterion (and the requirement for liquid saturation in the plume), at least when one takes the effect of propulsion efficiency correctly into account (Busen and Schumann, 1995; Mazin, 1996; Schumann, 2000; Schumann et al., 2000).

\subsection{Measurement issues}

Some of the studies found systematically higher or lower ice number concentrations. This can be seen in Fig. 3a, but is more obvious in Fig. 8. The latter shows the $n_{\text {ice }}$ normalized by air density to mass concentrations and multiplied by dilution $N_{\text {dil }}$ (age) from Eq. (1), so that they can be interpreted as an apparent ice particle emission index (PEI). Note that an underestimate of dilution causes an underestimate of the computed PEI. Higher dilution may in fact have occurred for some of the cases observed, e.g., for strong shear and sedimentation-driven contrail widening. In principle, one

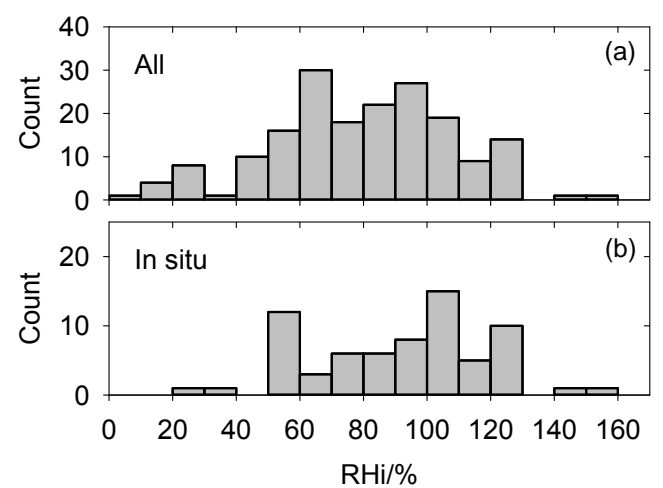

Figure 7. Histogram of relative humidity over ice $\left(\mathrm{RH}_{\mathrm{i}}\right)$ for all cases (top) and for in situ cases (bottom).
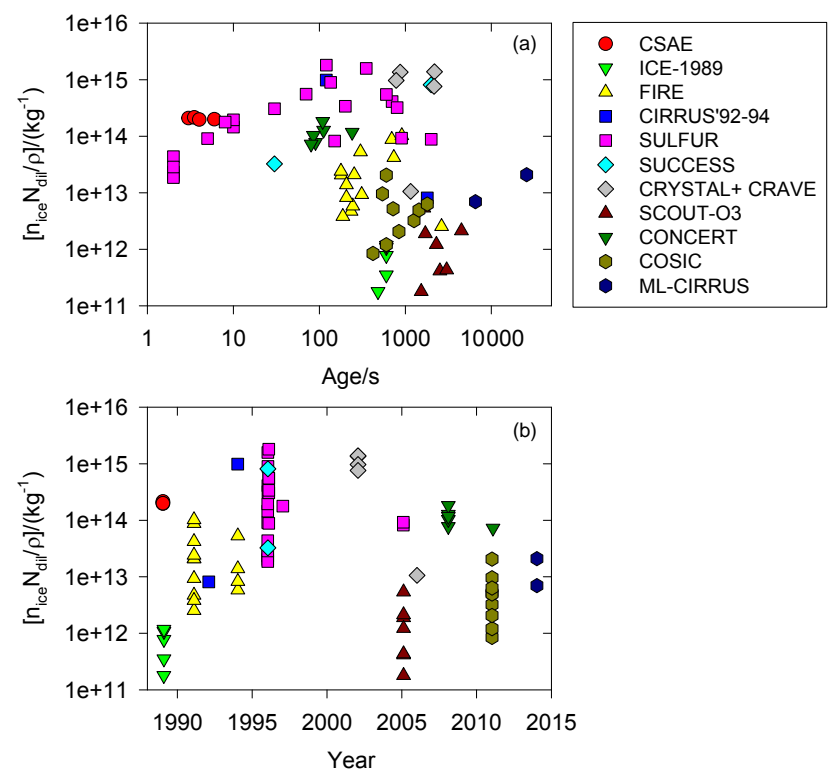

Figure 8. Particle concentrations $n_{\text {ice }}$ normalized to density and an empirical dilution law, approximating an apparent particle emission index, $\mathrm{PEI}_{\text {ice }}$ (the number of ice particles in the contrail per burnt fuel mass). (b) Same quantity versus year of measurement.

should normalize to the concentration of a fuel consumption tracer (such as $\mathrm{CO}_{2}$ ), but such data are rare in these observations. Here, the dilution formula is approximate, and hence these values approximate the PEI.

Rather high $n_{\text {ice }}$ and PEI values are found for SULFUR, in particular at $120 \mathrm{~s}$ age for case B1 of Schröder et al. (2000). Note that the high estimated PEI value may also result from an overestimate of dilution at this age. Low values are seen for younger contrails, likely because of instrument limitations in detecting high $n_{\text {ice }}$. Low $n_{\text {ice }}$ values are also seen for FIRE, ICE-1989, COSIC, CR-AVE, and SCOUT-O3. The first two of these experiments in 1989 and 1991 used FSSP100 , with a lower size threshold of $2 \mu \mathrm{m}$, which may have undercounted small ice particles. For young contrails, ice parti- 
cles may occur even below the size range of about $0.3 \mu \mathrm{m}$ presently feasible for modern instruments. The maximum measured $n_{\text {ice }}=7000 \mathrm{~cm}^{-3}$ at $3.5 \mathrm{~s}$ age still seems small for young contrails for which concentrations as high as $10^{4}$ to $10^{5} \mathrm{~cm}^{-3}$ are expected for $1 \mathrm{~s}$ old contrails, at least for soot number emission indices $>10^{15} \mathrm{~kg}^{-1}$, from model studies (see Fig. 2 in Kärcher and Yu, 2009). This may indicate an upper detection limit of the particle probes caused by coincidence.

Baumgardner et al. (2016) and McFarquhar et al. (2016) discuss the many issues that are associated with measuring ice particles with in situ instrumentation. For example, ice crystal shattering on probe inlets and extended arms (Korolev et al., 2011) is a potential issue for contrail measurements. Comparisons of in situ data with remote sensing data, however, indicate that not all cirrus with small sizes can be explained by shattering (Cooper and Garrett, 2011). Shattering has also been discussed for contrails (Febvre et al., 2009; Gayet et al., 2012). For example, Voigt et al. (2011) describe a contrail embedded in an optically thin cirrus cloud. Here, the ambient cirrus contributed less than $1 \%$ to the number, surface, and volume distributions detected in contrails. No significant difference in the particle size range of 0.4 to $12 \mu \mathrm{m}$ between in-cirrus and out-of-cirrus contrail observations was found. As explained in McFarquhar et al. (2016), techniques have been developed to decrease measurement uncertainties and to minimize errors. For example, in COSIC, Jones et al. (2012) used the measured particle inter-arrival times to eliminate high particle counts (above $50 \mathrm{~cm}^{-3}$ ) due to presumed shattering. They noted, however, that the high counts could be due to smaller aerosols from the aircraft plume mixed with the contrail, as well as that their low-timeresolution $\mathrm{NO}_{x}$ measurements did not provide enough evidence to decide whether these were plume encounters. If the non-filtered COSIC $n_{\text {ice }}$ data were included in our figures, they would fit better to the other observations. Shattering is not the only factor that can affect the measurements. Other factors include the size sensitivity of the probes (e.g., the effect of minimum detection threshold), the sample volume uncertainties in the OAPs, particularly for sizes $<50 \mu \mathrm{m}$, and the coincidences of particles in the sample volume given the very large concentrations, and many more.

The PEI results (Fig. 8) increased in the reported data between 1989 and 1993 (with the noteworthy exception of CSAE). The more recent measurements support a PEI value between $10^{14}$ and $10^{15} \mathrm{~kg}^{-1}$. The possible underestimate of dilution implies that the true values may well be a factor of 10 higher. Nevertheless, the consistency of these data with remote sensing observations and the other measured data (e.g., $\beta_{\text {ext }}$ and particle sizes) suggests that shattering is a minor issue in these measurements. The low PEI data for CR-AVE and SCOUT-O3 are based on measurements at the lowest temperatures with very low ambient humidity. Possibly, these measurements underestimate the number of small ice particles because they were too small. This is further supported by the fact that the highest $n_{\text {ice }}$ was measured during CRAVE in the oldest part of the plume almost $1000 \mathrm{~s}$ after it formed. Interestingly, the PEI values for CRYSTAL-FACE, at $10 \mathrm{~K}$ higher temperatures, are far higher, which is not easy to explain.

By definition, the IWC should be consistent with (4/3) $\pi \rho_{\text {ice }} n_{\text {ice }} r_{\text {vol }}^{3}$, within the expected uncertainties in assumed ice crystal volume and density (Baumgardner et al., 2016). This appears trivial but is not always the case. In particular, some early Falcon results (Schröder et al., 2000) deviate from this expectation by factors of up to 4. Baumgardner et al. (2016) suggest that the uncertainty of IWC derived from single-particle spectrometers may be as large as a factor of 3, but in contrails, where there is less variation in size, shape, and density, the uncertainty should be less than a factor of 2. Experimenters have, perhaps, estimated IWC, $n_{\text {ice }}$, and $r_{\text {eff }}$ using different approaches to correct for known observational deficiencies, like underestimated contributions in certain particle-size ranges or indications of particle shattering. Some authors may have used other radius definitions, e.g., with variable effective density (Heymsfield et al., 2002).

The few remote sensing data for $n_{\text {ice }}$ fit reasonably to the in situ data. In particular, the contrail properties derived from the Shutdown 2 analysis are consistent with the other observations. If one derives the number of ice particles per contrail length from $N_{\text {ice }}=\mathrm{EA} /\left(Q_{\text {ext }} \pi r_{\text {area }}^{2}\right)$ for these data, the $N_{\text {ice }}$ vary in the range of $(4-50) \times 10^{11} \mathrm{~m}^{-1}$, depending on the assumed ratio $r_{\text {area }} / r_{\text {eff }}=C^{3 / 2}$, with $C$ of about 0.5 to 0.7 . This range of scatter is small in view of the fact that very different aircraft sizes and types caused the contrails. The result is not much different from that of Spinhirne et al. (1998). Hence, these studies provide further evidence for a nearly constant number of ice particles in contrails.

Several of the contrail properties show systematic changes of mean values or trends with age or temperature, such as EA with age and IWC with temperature. The mean values and trends are sensitive to data from a few observation projects, such as the IFU-Lidar and Shutdown satellite analyses for the change of $r_{\text {eff }}$ and EA with age, and ICE-1989, CRYSTALFACE, CR-AVE, and SCOUT-O3 for the change of IWC with $T$. However, none of these results changes significantly when one data source is excluded. For SCOUT-O3, we repeat that these data are from potential contrail self-encounters.

\subsection{Model comparisons and open issues}

The observations generally agree well with the model results. Both show a large range of variability and changes with age and agree on the median magnitude. The observations are all within the range of model results, at least if we include the minimum and maximum values of the $\mathrm{CoCiP}$ results. Co$\mathrm{CiP}$ also reflects properties of thinner contrails, which are less easy to observe. Figures 1-4 compare contrails for very different aircraft and atmospheric conditions. A similar comparison, for ages up to $1200 \mathrm{~s}$ and for a subset of the ob- 
servations, shown by Naiman et al. (2011) for large-eddy simulation (LES) results, showed comparable, but not better, observation-model agreement. More demanding would be a comparison between simulated and observed results, case by case for fixed model properties. Tests for young contrails (Schumann, 2012) have shown that the agreement depends on details of ambient humidity, shear, and soot number emissions, and the remaining observations provide a weak model test when the open input is optimally adapted. Tests for young and old contrails with one set of model parameters might be more constraining. A case-by-case comparison can be done only when aircraft and atmospheric parameters are sufficiently well specified. As noted before, neither the contrail-generating aircraft nor the meteorology was identified for all cases. Most suitable for comparisons are those cases with a rich set of observations coupled with known aircraft and ambience properties. A notable example is found in the Falcon observations of the A380 case during CONCERT.

Substantial losses in the total number of contrail ice particles $N_{\text {ice }}$ have been predicted, for example, by LES, because of adiabatic warming in the sinking wake vortex (Greene, 1986; Sussmann and Gierens, 1999; Lewellen and Lewellen, 2001; Unterstrasser et al., 2008) at contrail ages up to about $300 \mathrm{~s}$ (Unterstrasser, 2016). These simulations assume that ice particles that have sublimated do not leave ice nuclei which can be reactivated when the ambient humidity increases. Therefore, we discuss below the observations in respect to these predicted losses.

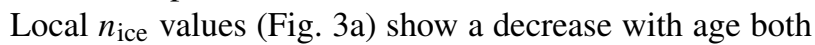
before and after the end of the wake vortex phase, but this does not reflect changes in $N_{\text {ice }}$. There are only a few observations of $N_{\text {ice }}$ available (Fig. 4b). The soot number emissions needed for an estimate of the initial $N_{\text {ice }}$ are also missing. More data are available for EA (Fig. 4d). The EA data show a gap between ages of 100 and $300 \mathrm{~s}$, which is interesting. A comparable plot from LES results, Fig. 2c of Lewellen et al. (2014), shows a similar but weaker minimum of EA (actually EA $/ Q_{\text {ext }}$ is plotted) near $100 \mathrm{~s}$ age for the LES case with maximum particle losses.

As explained in Jeßberger et al. (2013), EA scales as

$$
\begin{aligned}
\mathrm{EA}= & {\left[9 \pi /\left(16 \rho_{\mathrm{ice}}^{2}\right)\right]^{1 / 3} C Q_{\mathrm{ext}} m_{\mathrm{F}}\left[f_{\mathrm{s}} \mathrm{PEI}_{\mathrm{ice}}\right]^{1 / 3} } \\
& {\left[\mathrm{EI}_{\mathrm{H}_{2} \mathrm{O}}+\left(\mathrm{RH}_{\mathrm{i}}-1\right) N_{\mathrm{dil}} M_{\mathrm{H}_{2} \mathrm{O}} p_{\mathrm{s}}(T) /\left(M_{\mathrm{air}} p\right)\right]^{2 / 3} . }
\end{aligned}
$$

Most symbols were explained before: $\rho_{\text {ice }}$, ice bulk density; $C, r_{\mathrm{vol}} / r_{\mathrm{eff}} ; Q_{\mathrm{ext}}$, extinction efficiency, $m_{\mathrm{F}}$, fuel consumption per distance; $f_{\mathrm{s}}$, survival factor of ice particles; $\mathrm{PEI}_{\text {ice }}$, ice particle emission index; $\mathrm{EI}_{\mathrm{H}_{2} \mathrm{O}}$, water vapor emission index; $\mathrm{RH}_{\mathrm{i}}$, relative humidity over ice; $N_{\text {dil }}$, dilution factor; $M_{\mathrm{H}_{2} \mathrm{O}}$ and $M_{\text {air }}$, molar masses of water and air; $p_{s}(T)$, saturation pressure; and $p$, air pressure. $Q_{\text {ext }}$ may increase with age when the initially sub-micron sized ice particles grow much larger than the wavelength of light, $N_{\text {dil }}$ increases strongly with age, and $f_{\mathrm{s}}$ should decrease for strong particle

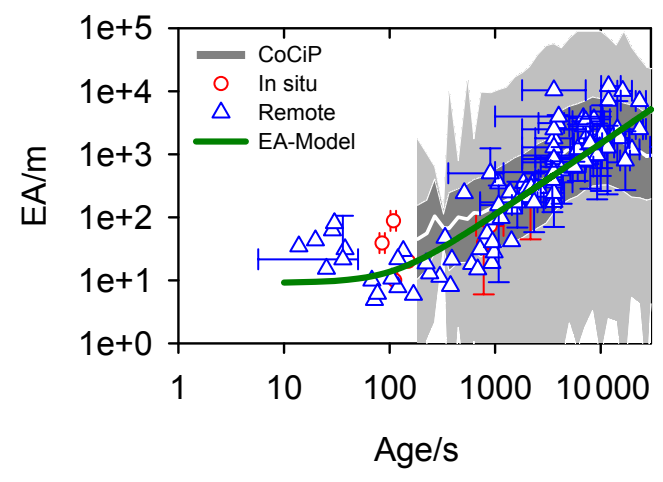

Figure 9. EA versus time: data (symbols as before) and a simple model (full dark-green curve).

losses. Thus, any decrease in EA with age during the wake vortex phase could be an indicator for particle losses.

The dark-green curve in Fig. 9 shows an evaluation of the above EA model versus age for $T=220 \mathrm{~K}, p=240 \mathrm{hPa}$, $C=0.7, m_{\mathrm{F}}=5 \mathrm{~g} \mathrm{~m}^{-1}$, and PEI $\mathrm{I}_{\text {ice }}=10^{15} \mathrm{~kg}^{-1}$, for constant survival factor $f_{\mathrm{s}}=0.7$, and a new contrail dilution model $N_{\text {dil }}=20\left(t / t_{\text {dil }}\right)^{1.7}, t_{\text {dil }}=1 \mathrm{~s}$, with coefficients (in particular exponent 1.7) fitted to the observed growth in cross-section area. The constant, $f_{\mathrm{s}}$, accounts for mean losses but does not describe any temporal evolution of particle losses. This EA model fits the remote sensing observations (mainly from IFU-Lidar for ages $<1 \mathrm{~h}$ and from Shutdown data for larger ages) reasonably well for constant $f_{\mathrm{s}}$, but without the gap or local minimum which seems to exist in the observations near 100-300 s. Hence, the observations may be sensitive to particle losses in the wake phase; however, a final conclusion is still not possible. A closer investigation should check for any other reason that may explain the gap (e.g., high EA in young contrails because of strong vertical mixing or high temperature, and high EA at large ages because of re-nucleation of residuals from sublimated ice particles in supersaturated air).

\section{Conclusions}

A "contrail library" (COLI) has been set up, collecting microphysical and geometric contrail properties from past measurements for individual jet aircraft contrails with known ages, together with information on the aircraft and atmosphere when available. The database includes 236 entries describing properties of contrails with known ages, including mean data for 100 cases of in situ measurements, more than 70 cases from ground-based and airborne lidar observations, 50 cases from satellites, and a few camera observations. The data come from 33 observation projects during the last 45 years.

The comparison of the data from various measurements shows notable differences among the various measurements from different instrumentations. But generally, the agreement 
among each other and between the in situ and remote sensing results, and also the agreement with the model results, shows that the basic properties of contrails are quite well documented. The comparisons provide some answers to the questions listed in the Introduction. For example, all results are consistent with the assumption that contrail ice particles form from exhaust in the young contrail, and the number does not change much later during the lifetime. The data show the high importance of cirrus uncinus formation with fallstreaks in ice-supersaturated environments. These cases are responsible for large $D, W, r_{\mathrm{eff}}$, and IWC. The comparison gives strong support for the general validity of the CoCiP model for the period after the wake vortex phase. The apparent emission index of ice particles may exceed $10^{15} \mathrm{~kg}^{-1}$, because the computed PEI values are dilution-dependent, and dilution in contrails was stronger than measured in exhaust plumes without contrails. The IWC in contrails, on average, follows a previously suggested negative correlation with temperature and higher ice-equivalent relative humidity for low temperatures, as expected thermodynamically and from homogeneous ice nucleation theory. The ratio of volume to effective mean radius decreases with time, which affects the optical depth and the radiative effectiveness of cirrus computed for given number density and ice water content. The optical extinction decreases with contrail age, mainly because of particle dilution. Surprisingly, several contrails were observed in warm air above the Schmidt-Appleman threshold, without full explanation.

There is no obvious indication that ice crystal shattering on instruments has significant effects on past contrail measurements. Shattering may still be important in warm contrails with a high number density of large ice crystals. In nascent contrails and at low temperatures, the measurements may have underestimated the concentration of sub-micrometer ice particles. The remote sensing contrail data, though also not without uncertainties, support the general consistency of the data obtained. More data, from various methods and regions, would allow reducing the sensitivity of mean results to single observation projects.
In view of the large variability, the total amount of data is still small. More data and more detailed comparisons of model results with the observations are needed for final answers to, for example, the questions raised. Models should be run for case studies of ensembles of contrails in an Eulerian mode at various ages and for individual contrails in a Lagrangian mode as a function of age, and measurements should be interpreted for these modes separately in order to see whether the derived correlations describe the full life cycle of contrails. A future study similarly could collect and compare contrail-cirrus data.

In many cases, the relative humidity inside and outside the contrails was low and not consistent with the measured ice water content, and the data missed accurate quantification of dilution. This database should be supplemented with future measurements providing "complete" datasets for individual contrails, with data on all the parameters listed in Tables 1-6. This includes data on contrail age and geometry, source aircraft, microphysics, tracers of dilution, ambient atmosphere parameters (temperature, humidity, shear, stratification, turbulence, radiation, ambient clouds), and the instrumentation. In addition, there remains the need for new instruments that can successfully measure the high concentration of small contrail crystals near the source, overcoming the current limitations of particle detection at wavelengths of visible light and coincidence in the sample volume.

\section{Data availability}

The COLI table is available from the Supplement. Other information is available as explained in Sect. 2 and in the references cited. 
Appendix A: Early measurements on the formation conditions of contrails

Early flight experiments on the formation condition of contrails were performed in several countries (Brewer, 1946; Weickmann, 1951; Appleman, 1953; Mazin, 1996; Schumann, 1996). The first in situ measurements in the exhaust plume of a contrail-forming aircraft were performed in Germany starting in 1939 (aufm Kampe, 1942, 1943). The aircraft was a single-propeller Henschel (Hs-126; span $14.5 \mathrm{~m}$, mass between 2 and $3.2 \mathrm{Mg}$ ), with a Bramo-Fafnir motor, flying with about $135 \mathrm{~kg} \mathrm{~h}^{-1}$ fuel consumption (87-octane aviation gasoline), at 8000 to $10000 \mathrm{~m}$ altitude, at $66 \mathrm{~m} \mathrm{~s}^{-1}$ speed. About $60 \%$ of the combustion energy was expected to heat the engine exhaust, so that the overall propulsion efficiency is about 0.4 . The water content of the fuel was higher than for kerosene, but the fuel is not burned completely, so that the effective water mass emission index was estimated to be $\sim 1.25$. Temperature above ambient air and air speed were measured in situ on a towed glider aircraft and at the wing. The plume excess temperature was maximal $(36 \mathrm{~K})$ about $1.5 \mathrm{~m}$ behind the engine exhaust exit, about $7 \mathrm{~m}$ before the aircraft tail, $14 \mathrm{~K}$ at the tail, and about $3 \mathrm{~K}$ at $60 \mathrm{~m}$ behind the tail. The measured propeller wake speed was $77 \mathrm{~m} \mathrm{~s}^{-1}$ (about $11 \mathrm{~m} \mathrm{~s}^{-1}$ higher than the aircraft speed) at a position $6 \mathrm{~m}$ behind the engine and $69 \mathrm{~m} \mathrm{~s}^{-1}$ at $60 \mathrm{~m}$ distance. Contrail formation was observed and documented in photos from escorting aircraft and from the ground. The humidity inside the exhaust plume was computed for the given fuel consumption, emission index, and measured wake diameter. The temperature was measured and used to compute relative humidity. Hence, aufm Kampe (1942) found that liquid saturation was reached in the propeller wake, about 10 to $20 \mathrm{~m}$ behind the tail. This is supported by the fact, that frost was observed on the towed glider and other aircraft following at distances of a few hundred meters, indicating the existence of liquid water in the young contrail during these experiments. The distance where contrails formed increased with ambient temperature, consistent with the thermodynamic theory (Schmidt, 1941). These and other studies at that time led to the important general conclusion that ice formation requires liquid water saturation (aufm Kampe, 1942; Weickmann, 1951).

From the observations of contrail persistence during 150 flights, it was concluded that ice supersaturation occurred frequently, while water supersaturation was not observed (aufm Kampe, 1943). The size and shape of contrail ice particles was derived from impactor collections in the contrails and contrail cirrus; see also Weickmann (1945). Some of the contrail particles grew large and formed fallstreaks. Halos were observed in the contrails, indicating unimodal hexagonal ice crystals, bullets, or plates (aufm Kampe, 1942, 1943; Weickmann, 1945).

We include one data line from these reports, listing the diameter of the contrail as $\sim 3 \mathrm{~m}$ at contrail formation, $20 \mathrm{~m}$ or $0.26 \mathrm{~s}$ behind the aircraft tail, but ambient conditions for these observations have to be estimated (about $-45^{\circ} \mathrm{C}$ ambient air temperature at $8 \mathrm{~km}$ altitude). The dilution in the propeller wake is about 10 times larger than expected for jet airliners from Eq. (1). Therefore, the data are not included in the plots which represent jet aircraft contrails.

\section{Appendix B: On the Contrail Cirrus Prediction Model (CoCiP)}

The plots include results from $\mathrm{CoCiP}$ as taken from the simulations described in Schumann et al. (2015). The method is documented in Schumann (2012). This appendix briefly summarizes the model and simulation parameters relevant for the comparison to observations.

CoCiP is a Lagrangian model that simulates contrail segments for each flight segment of a given aircraft flight trajectory and for the state of ambient atmosphere (temperature, humidity, wind, etc.) interpolated to the flight track waypoints in time and space. A contrail is initialized when the Schmidt-Appleman criterion is satisfied. The contrail life ends in the model when the contrail particles precipitate below the lower boundary of the computational domain (at about $450 \mathrm{hPa}$ ) or when the $\tau$ becomes smaller than a low threshold $\left(10^{-6}\right)$. Hence, most of the contrails analyzed formed in ice-supersaturated air, but contrails also occur in subsaturated air (either short-lived contrails or older contrails with large cross section and still finite IWC). The initial number of contrail ice particles corresponds to a modeled fraction ( $\sim 0.5$ to 1 , depending on aircraft, emissions, and ambient conditions) of the soot particles emitted. The simulation was performed for an assumed constant soot particle number emission index of $10^{15} \mathrm{~kg}^{-1}$, assuming that each soot particle nucleates one ice particle. The atmospheric parameters are taken as provided by the general circulation climate model CAM-3 with ice-supersaturation microphysics (Yun et al., 2013), except that humidity was increased by a factor of 1/0.9. The results shown were obtained in the coupled model version that includes exchange of humidity between the background atmosphere and contrails in both directions. The weather considered in the model is the weather for the last 30 years simulated in the climate model. For each flight, the aircraft type and the flight route is taken from the ACCRI traffic waypoint dataset for the year 2006. For each aircraft type, aircraft properties (span, mass, fuel consumption, speed, propulsion efficiency) are derived from BADA data for a given flight level (EUROCONTROL, 2009). A total of $3 \times 10^{7}$ contrail segments are simulated per year and analyzed hourly. The data were used to compute median values and percentiles for plotting. A table with the CoCiP percentiles as shown in Figs. 1-4 is included in the Supplement. 


\section{The Supplement related to this article is available online at doi:10.5194/acp-17-403-2017-supplement.}

Acknowledgements. We are grateful for input and comments from William A. Cooper, Ru-Shan Gao, Timothy Garrett, Kaspar Graf, Christian Kiemle, Andreas Minikin, Andrew Roberts, and Simon Unterstraßer. S. Bedka, D. Duda, and P. Minnis were supported by the FAA ACCRI Program. We gratefully acknowledge the wide set of data sources as explained in the text. The first author dedicates this work to his former colleague, Manfred E. Reinhardt (26 January 1927 to 1 October 2015), a reliable partner, for fruitful cooperation between 1982 and 1991, and for early contrail research with research aircraft.

The article processing charges for this open-access publication were covered by a Research

Centre of the Helmholtz Association.

Edited by: O. Möhler

Reviewed by: two anonymous referees

\section{References}

Alcala-Jornod, C., van den Bergh, H., and Rossi, M. J.: Can soot particles emitted by airplane exhaust contribute to the formation of aviation contrails and cirrus clouds?, Geophys. Res. Lett., 29, 1820, doi:10.1029/2001GL014115, 2002.

Andronache, C. and Chameides, W. L.: Interactions between sulfur and soot emissions from aircraft and their role in contrail formation, J. Geophys. Res., 102, 21443-21451, doi:10.1029/97JD01374, 1997.

Andronache, C. and Chameides, W. L.: Interactions between sulfur and soot emissions from aircraft and their role in contrail formation: 2. Development, J. Geophys. Res., 103, 10787-10801, doi:10.1029/98JD00173, 1998.

Ansmann, A., Wandinger, U., Riebesell, M., Weitkamp, C., and Michaelis, W.: Independent measurement of extinction and backscatter profiles in cirrus clouds by using a combined Raman elastic-backscatter lidar, Appl. Opt., 31, 7113-7131, doi:10.1364/AO.31.007113, 1992.

Ansmann, A., Bösenberg, J., Brogniez, G., Elouragini, S., Flamant, P. H., Klapheck, K., Linn, H., Menenger, L., Michaelis, W., Riebesell, M., Senff, C., Thro, P.-Y., Wandinger, U., and Weitkamp, C.: Lidar network observations of cirrus morphological and scattering properties during the International Cirrus Experiment 1989: The 18 October 1989 case study and statistical analysis, J. Appl. Meteor., 32, 1608-1622, 1993.

Appleman, H.: The formation of exhaust contrails by jet aircraft, B. Am. Meteorol. Soc., 34, 14-20, 1953.

Atlas, D. and Wang, Z.: Contrails of small and very large optical depth, J. Atmos. Sci., 67, 3065-3073, doi:10.1175/2010JAS3403.1, 2010.

Atlas, D., Wang, Z., and Duda, D. P.: Contrails to cirrus - Morphology, microphysics, and radiative properties, J. Appl. Meteorol. Clim., 45, 5-19, doi:10.1175/JAM2325.1, 2006. aufm Kampe, H. J.: Kondensation und Sublimation in der oberen Troposphäre, Deutsche Luftfahrtforschung, Deutsche Forschungsanstalt für Segelflug, FB 1491, 62 pp., available at: http://elib.dlr.de/107959/, 1942.

aufm Kampe, H. J.: Die Physik der Auspuffwolken hinter Flugzeugen, Luftwissen, 10, 171-173, 1943.

Baumann, R., Busen, R., Fimpel, H. P., Kiemle, C., Reinhardt, M., and Quante, M.: Measurements on contrails of commercial aircraft, Preprints of the Eighth Symposium on Meteorological Observations and Instrumentation, Anaheim, Ca., 17-22 January, 1993.

Baumgardner, D. and Cooper, W. A.: Airborne measurements in jet contrails: Characterization of the microphysical properties of aircraft wakes and exhausts, in: Impact of Emissions from Aircraft and Spacecraft upon the Atmosphere, edited by: Schumann, U. and Wurzel, D., Cologne, DLR, Mitt. 94-06, 418-423, 1994.

Baumgardner, D. and Gandrud, B. E.: A comparison of the microphysical and optical properties of particles in an aircraft contrail and mountain wave cloud, Geophys. Res. Lett., 25, 1129-1132, doi:10.1029/98GL00035, 1998.

Baumgardner, D., Dye, J. E., Gandrud, B. W., and Knollenberg, R. G.: Interpretation of measurements made by the Forward Scattering Spectrometer Probe (FSSP-300) during the Airborne Arctic Stratospheric Expedition, J. Geophys. Res., 97, 8035-8046, doi:10.1029/91JD02728, 1992.

Baumgardner, D., Dye, J. E., Gandrud, B., Barr, K., Kelly, K., and Chan, K. R.: Refractive indices of aerosols in the upper troposphere and lower stratosphere, Geophys. Res. Lett., 23, 749-752, doi:10.1029/96GL00707, 1996

Baumgardner, D., Miake-Lye, R. C., Anderson, M. R., and Brown, R. C.: An evaluation of the temperature, water vapor, and vertical velocity structure of aircraft contrails, J. Geophys. Res., 103, 8727-8736, doi:10.1029/98JD00205, 1998.

Baumgardner, D., Jonsson, H., Dawson, W., O'Connor, D., and Newton, R.: The cloud, aerosol and precipitation spectrometer: a new instrument for cloud investigations, Atmos. Res., 59-60, 251-264, 2001.

Baumgardner, D., Brenguier, J. L., Bucholtz, A., Coe, H., DeMott, P., Garrett, T. J., Gayet, J. F., Hermann, M., Heymsfield, A., Korolev, A., Krämer, M., Petzold, A., Strapp, W., Pilewskie, P., Taylor, J., Twohy, C., Wendisch, M., Bachalo, W., and Chuang, P.: Airborne instruments to measure atmospheric aerosol particles, clouds and radiation: A cook's tour of mature and emerging technology, Atmos. Res., 102, 10-29, doi:10.1016/j.atmosres.2011.06.021, 2011.

Baumgardner, D., Abel, S., Axisa, D., Cotton, R., Crosier, J., Field, P., Gurganus, C., Heymsfield, A., Korolev, A., Krämer, M., Lawson, P., McFarquhar, G., Ulanowski, Z., and Um, J.: In situ measurement challenges - Ice Formation and Evolution in Clouds and Precipitation: Measurement and Modeling Challenges: Chapter 9, Meteor. Monogr., in press, 2016.

Bedka, S. T., Minnis, P., Duda, D. P., Chee, T. L., and Palikonda, R.: Properties of linear contrails in the Northern Hemisphere derived from 2006 Aqua MODIS observations, Geophys. Res. Lett., 40, 772-777, doi:10.1029/2012GL054363, 2013.

Betancor Gothe, M. and Graß1, H.: Satellite remote sensing of the optical depth and mean crystal size of thin cirrus and contrails, Theor. Appl. Climat., 48, 101-113, doi:10.1007/BF00864917, 1993. 
Boin, M. and Levkov, L.: A numerical study of contrail development, Ann. Geophys., 12, 969-978, 1994.

Boucher, O., Randall, D., Artaxo, P., Bretherton, C., Feingold, G., Forster, P., Kerminen, V.-M., Kondo, Y., Liao, H., Lohmann, U., Rasch, P., Satheesh, S. K., Sherwood, S., Stevens, B., and Zhang, X. Y.: Clouds and Aerosols, in: Climate Change 2013: The Physical Science Basis, Contribution of Working Group I to the Fifth Assessment Report of the Intergovernmental Panel on Climate Change, edited by: Stocker, T. F., Qin, D., Plattner, G.-K., Tignor, M., Allen, S. K., Boschung, J., Nauels, A., Xia, Y., Bex, V., and Midgley, P. M., Cambridge University Press, Cambridge, UK, New York, NY, USA, 571-657, 2013.

Brasseur, G. P., Gupta, M., Anderson, B. E., Balasubramanian, S., Barrett, S., Duda, D., Fleming, G., Forster, P. M., Fuglestvedt, J., Gettelman, A., Halthore, R. N., Jacob, S. D., Jacobson, M. C., Khodayari, A., Liou, K.-N., Lund, M. T., Miake-Lye, R. C., Minnis, P., Olsen, S. C., Penner, J. E., Prinn, R., Schumann, U., Selkirk, H. B., Sokolov, A., Unger, N., Wolfe, P., Wong, H.-W., Wuebbles, D. W., Yi, B., Yang, P., and Zhou, C.: Impact of aviation on climate: FAA's Aviation Climate Change Research Initiative (ACCRI) Phase II, B. Am. Meteorol. Soc., 97, 561-583, doi:10.1175/BAMS-D-13-00089.1, 2016.

Brewer, A. W.: Condensation trails, Weather, 1, 34-40, doi:10.1002/j.1477-8696, 1946.

Brown, R. C., Miake-Lye, R. C., Anderson, M. R., and Kolb, C. E.: Aircraft sulfur emissions and the formation of visible contrails, Geophys. Res. Lett., 24, 385-388, doi:10.1029/97GL00107, 1997.

Brunner, D., Siegmund, P., May, P. T., Chappel, L., Schiller, C., Müller, R., Peter, T., Fueglistaler, S., MacKenzie, A. R., Fix, A., Schlager, H., Allen, G., Fjaeraa, A. M., Streibel, M., and Harris, N. R. P.: The SCOUT-O3 Darwin Aircraft Campaign: rationale and meteorology, Atmos. Chem. Phys., 9, 93-117, doi:10.5194/acp-9-93-2009, 2009.

Burkhardt, U. and Kärcher, B.: Process-based simulation of contrail cirrus in a global climate model, J. Geophys. Res., 114, 1-13, doi:10.1029/2008JD011491, 2009.

Burkhardt, U. and Kärcher, B.: Global radiative forcing from contrail cirrus, Nat. Climate Change, 1, 54-58, doi:10.1038/NCLIMATE1068, 2011.

Busen, R. and Schumann, U.: Visible contrail formation from fuels with different sulfur contents, Geophys. Res. Lett., 22, 1357 1360, doi:10.1029/95GL01312, 1995.

Busen, R., Baumann, R., Reinhardt, M. E., Fimpel, H., Kiemle, C., and Quante, M.: Measurements of physical properties in the wake of commercial aircraft, in: Impact of Emissions from Aircraft and Spacecraft upon the Atmosphere, edited by: Schumann, U. and Wurzel, D., Cologne, DLR Mitt. 94-06, 297-302, 1994.

Cairo, F., Pommereau, J. P., Law, K. S., Schlager, H., Garnier, A., Fierli, F., Ern, M., Streibel, M., Arabas, S., Borrmann, S., Berthelier, J. J., Blom, C., Christensen, T., D'Amato, F., Di Donfrancesco, G., Deshler, T., Diedhiou, A., Durry, G., Engelsen, O., Goutail, F., Harris, N. R. P., Kerstel, E. R. T., Khaykin, S., Konopka, P., Kylling, A., Larsen, N., Lebel, T., Liu, X., MacKenzie, A. R., Nielsen, J., Oulanowski, A., Parker, D. J., Pelon, J., Polcher, J., Pyle, J. A., Ravegnani, F., Rivière, E. D., Robinson, A. D., Röckmann, T., Schiller, C., Simões, F., Stefanutti, L., Stroh, F., Some, L., Siegmund, P., Sitnikov, N., Vernier, J. P., Volk, C. M., Voigt, C., von Hobe, M., Viciani, S., and Yushkov,
V.: An introduction to the SCOUT-AMMA stratospheric aircraft, balloons and sondes campaign in West Africa, August 2006: rationale and roadmap, Atmos. Chem. Phys., 10, 2237-2256, doi:10.5194/acp-10-2237-2010, 2010.

Conti, R. J., Hoshizaki, H., Redler, K. O., and Cassady, P. E.: Atmospheric dispersion of aircraft exhaust AIAA Paper, 9, 73-100, doi:10.2514/6.1973-100, 1973.

Cooper, S. J. and Garrett, T. J.: Application of infrared remote sensing to constrain in-situ estimates of ice crystal particle size during SPartICus, Atmos. Meas. Tech., 4, 1593-1602, doi:10.5194/amt4-1593-2011, 2011.

Corti, T., Luo, B. P., de Reus, M., Brunner, D., Cairo, F., Mahoney, M. J., Martucci, G., Matthey, R., Mitev, V., dos Santos, F. H., Schiller, C., Shur, G., Sitnikov, N. M., Spelten, N., Vössing, H. J., Borrmann, S., and Peter, T.: Unprecedented evidence for deep convection hydrating the tropical stratosphere, Geophys Res. Lett., 35, L10810, doi:10.1029/2008GL033641, 2008.

Dee, D. P., Uppala, S. M., Simmons, A. J., Berrisford, P., Poli, P., Kobayashi, S., Andrae, U., Balmaseda, M. A., Balsamo, G., Bauer, P., Bechtold, P., Beljaars, A. C. M., van de Berg, L., Bidlot, J., Bormann, N., Delsol, C., Dragani, R., Fuentes, M., Geer, A. J., Haimberger, L., Healy, S. B., Hersbach, H., Hólm, E. V., Isaksena, L., Kållberg, P., Köhler, M., Matricardi, M., McNally, A. P., Monge-Sanz, B. M., Morcrette, J.-J., Park, B.-K., Peubey, C., de Rosnay, P., Tavolato, C., Thépaut, J.-N., and Vitart, F.: The ERA-Interim reanalysis: configuration and performance of the data assimilation system, Q. J. Roy. Meteor. Soc., 137, 553-597, doi:10.1002/qj.828, 2011.

de Reus, M., Borrmann, S., Bansemer, A., Heymsfield, A. J., Weigel, R., Schiller, C., Mitev, V., Frey, W., Kunkel, D., Kürten, A., Curtius, J., Sitnikov, N. M., Ulanovsky, A., and Ravegnani, F.: Evidence for ice particles in the tropical stratosphere from in-situ measurements, Atmos. Chem. Phys., 9, 6775-6792, doi:10.5194/acp-9-6775-2009, 2009.

Duda, D., Spinhirne, J. D., and Hart, W. D.: Retrieval of contrail microphysical properties during SUCCESS by the split-window method, Geophys. Res. Lett., 25, 1149-1152, doi:10.1029/97GL03159, 1998.

Duda, D., Minnis, P., and Nguyen, L.: Estimates of cloud radiative forcing in contrail clusters using GOES imagery, J. Geophys. Res., 106, 4927-4937, 2001.

Duda, D. P., Minnis, P., Nyuyen, L., and Palikonda, R.: A case study of the development of contrail clusters over the Great Lakes, J. Atmos. Sci., 61, 1132-1146, 2004.

Ettenreich, R.: Wolkenbildung über einer Feuersbrunst und an Flugzeugabgasen, Meteorol. Z., 36, 355-356, 1919.

EUROCONTROL: Aircraft Performance Summary Tables for the Base of Aircraft Date (BADA), 3.7, European Organisation for the Safety of Air Navigation, Brétigny-sur-Orge, 103, 2009.

Febvre, G., Gayet, J. F., Minikin, A., Schlager, H., Shcherbakov, V., Jourdan, O., Busen, R., Fiebig, M., Kärcher, B., and Schumann, U.: On optical and microphysical characteristics of contrails and cirrus, J. Geophys. Res., 114, D02204, doi:10.1029/2008JD010184, 2009.

Flores, J. M., Baumgardner, D., Kok, G., Raga, G., and Hermann, R.: Tropical subvisual cirrus and contrails at $-85^{\circ} \mathrm{C}, 12$ th Conference on Cloud Physics, 10-14 July 2006, Madison, WI, available at: https://ams.confex.com/ams/Madison2006/techprogram/ paper_112323.htm, 2006. 
Francis, P. N., Jones, A., Saunders, R. W., Shine, K. P., Slingo, A., and Sun, Z.: An observational and theoretical study of the radiative properties of cirrus: Some results from ICE'89, Q. J. Roy. Meteorol. Soc., 124, 809-848, 1994.

Freudenthaler, V.: Lidarmessungen der räumlichen Ausbreitung sowie mikrophysikalischer und optischer Parameter von Flugzeugkondensstreifen, Shaker Verlag, Aachen, ISBN 3-82656973-3, 2000.

Freudenthaler, V., Homburg, F., and Jäger, H.: Ground-based mobile scanning LIDAR for remote sensing of contrails, Ann. Geophys., 12, 956-961, 1994.

Freudenthaler, V., Homburg, F., and Jäger, H.: Contrail observations by ground-based scanning lidar: Cross-sectional growth, Geophys. Res. Lett., 22, 3501-3504, doi:10.1029/95GL03549, 1995.

Freudenthaler, V., Homburg, F., and Jäger, H.: Optical parameters of contrails from lidar measurements: Linear depolarization., Geophys. Res. Lett., 23, 3715-3718, 1996.

Gao, R. S., Popp, P. J., Fahey, D. W., Marcy, T. P., Herman, R. L., Weinstock, E. M., Baumgardner, D. G., Garrett, T. J., Rosenlof, K. H., Thompson, T. L., Bui, P. T., Ridley, B. A., Wofsy, S. C., Toon, O. B., Tolbert, M. A., Kärcher, B., Peter, T., Hudson, P. K., Weinheimer, A. J., and Heymsfield, A. J.: Evidence that nitric acid increases relative humidity in low-temperature cirrus clouds, Science, 303, 516-520, doi:10.1126/science.1091255, 2004.

Gao, R. C., Fahey, D. W., Popp, P. J., Marcy, T. P., Herman, R. L., Weinstock, E. M., Smith, J. B., Sayres, D. S., Pittman, J. V., Rosenlof, K. H., Thompson, T. L., Bui, P. T., Baumgardner, D. G., Anderson, B. E., Kok, G., and Weinheimer, A. J.: Measurements of relative humidity in a persistent contrail, Atmos. Environ., 40, 1590-1600, doi:10.1016/j.atmosenv.2005.11.021, 2006.

Gao, R. S., Gierczak, T., Thornberry, T. D., Rollins, A. W., Burkholder, J. B., Telg, H., Voigt, C., Peter, T., and Fahey, D. W.: Persistent water-nitric acid condensate with saturation water vapor pressure greater than that of hexagonal ice, J. Phys. Chem. A, 120, 1431-1440, doi:10.1021/acs.jpca.5b06357, 2016.

Garber, D. P., Minnis, P., and Costulis, P. K.: A commercial flight track database for upper tropospheric aircraft emission studies over the USA and southern Canada, Meteorol. Z., 14, 445-452, 2005

Gayet, J.-F., Brown, P. R. A., and Albers, F.: A comparison of incloud measurements obtained with six PMS 2D-C probes, J. Atmos. Ocean. Tech., 10, 180-194, 1993.

Gayet, J.-F., Febvre, G., and Larsen, H.: The reliability of the PMS FSSP in the presence of small ice crystals, J. Atmos. Ocean. Tech., 13, 1300-1310, 1996a.

Gayet, J.-F., Febvre, G., Brogniez, G., Chepfer, H., Renger, W., and Wendling, P.: Microphysical and optical properties of cirrus and contrails, J. Atmos. Sci., 53, 126-138, 1996b.

Gayet, J.-F., Auriol, F., Oshchepkov, S., Schröder, F., Duroure, C., Febvre, G., Fournol, J.-F., Crépel, O., Personne, P., and Daugereon, D.: In situ measurements of the scattering phase function of stratocumulus, contrails and cirrus, Geophys. Res. Lett., 25, 971-974, doi:10.1029/98GL00541, 1998.

Gayet, J.-F., Shcherbakov, V., Voigt, C., Schumann, U., Schäuble, D., Jessberger, P., Petzold, A., Minikin, A., Schlager, H., Dubovik, O., and Lapyonok, T.: The evolution of microphysical and optical properties of an A380 contrail in the vortex phase, Atmos. Chem. Phys., 12, 6629-6643, doi:10.5194/acp-12-66292012, 2012.
Gierens, K. and Schumann, U.: Colors of contrails from fuels with different sulfur contents, J. Geophys. Res., 101, 16731-16736, doi:10.1029/96JD01169, 1996.

Gierens, K., Kärcher, B., Mannstein, H., and Mayer, B.: Aerodynamic contrails: Phenomenology and flow physics, J. Atmos. Sci., 66, 217-226, doi:10.1175/2008JAS2767.1, 2009.

Gierens, K., Kästner, M., and Klatt, D.: Iridescent aerodynamic contrails: The Norderney case of 27 June 2008, Meteorol. Z., 20, 305-311, doi:10.1127/0941-2948/2011/0497, 2011.

Goodman, J., Pueschel, R., Jensen, E., Verma, S., Ferry, G., Howard, S., Kinne, S., and Baumgardner, D.: Shape and size of contrails ice particles, Geophys. Res. Lett., 25, 1327-1330, doi:10.1029/97GL03091, 1998.

Greene, G. C.: An approximate model of wake vortex decay in the atmosphere, J. Aircraft, 23, 566-573, doi:10.2514/3.45345, 1986.

Haywood, J. M., Allan, R. P., Bornemann, J., Forster, P. M., Francis, P. N., Milton, S., Rädel, G., Rap, A., Shine, K. P., and Thorpe, R.: A case study of the radiative forcing of persistent contrails evolving into contrail-induced cirrus, J. Geophys. Res., 114, D24201, doi:10.1029/2009JD012650, 2009.

Hennings, D., Quante, M., and Sefzig, R.: ICE, International Cirrus Experiment, 1989 Field Phase Report, Univ. Köln, available from Bibliothek Deutscher Wetterdienst, Offenbach, 129 pp., 1990.

Heymsfield, A.: Cirrus Uncinus generating cells and the evolution of cirriform clouds, Part I: Aircraft observations of the growth of the ice phase, J. Atmos. Sci., 32, 799-808, 1975.

Heymsfield, A., Lawson, R. P., and Sachse, G. W.: Growth of ice crystals in a precipitating contrail, Geophys. Res. Lett., 25, 13351338, doi:10.1029/98GL00189, 1998.

Heymsfield, A., Lewis, S., Bansemer, A., Iaquinta, J., Miloshevich, L. M., Kajikawa, M., Twohey, C., and Poellot, M. R.: A general approach for deriving the properties of cirrus and stratiform ice cloud particles J. Atmos. Sci., 55, 3-29, 2002.

Heymsfield, A., Baumgardner, D., DeMott, P., Forster, P., Gierens, K., and Kärcher, B.: Contrail microphysics, B. Am. Meteorol. Soc., 90, 465-472, doi:10.1175/2009BAMS2839.1, 2010.

Hoshizaki, H., Anderson, L. B., Conti, R. J., Farlow, N., Meyer, J. W., Overcamp, T., Redler, K. O., and Watson, V.: Aircraft wake microscale phenomena, in: The Stratosphere perturbed by Propulsion Effluents, edited by: Grobecker, A. J., CIAP Monography 3, US Dep. of Transportation DOT-TST-75-53, Washington, DC, USA, 1975.

Inoue, T.: On the temperature and effective emissivity determination of semi-transparent cirrus clouds by bispectral measurements in the 10 micron window region, J. Meteorol. Soc. Jpn., 63, 88-99, 1985.

Iwabuchi, H., Yang, P., Liou, K. N., and Minnis, P.: Physical and optical properties of persistent contrails: Climatology and interpretation, J. Geophys. Res., 117, D06215, doi:10.1029/2011JD017020, 2012.

Jansen, J. and Heymsfield, A. J.: Microphysics of aerodynamic contrail formation processes, J. Atmos. Sci., 72, 3293-3308, doi:10.1175/JAS-D-14-0362.1, 2015.

Jensen, E., Ackermann, A. S., Stevens, D. E., Toon, O. B., and Minnis, P.: Spreading and growth of contrails in a sheared environment, J. Geophys. Res., 103, 13557-13567, doi:10.1029/98JD02594, 1998a. 
Jensen, E., Toon, O. B., Pueschel, R. F., Goodman, J., Sachse, G. W., Anderson, B. E., Chan, K. R., Baumgardner, D., and Miake-Lye, R. C.: Ice crystal nucleation and growth in contrails forming at low ambient temperatures, Geophys. Res. Lett., 25, 1371-1374, doi:10.1029/97GL03592, 1998b.

Jensen, E., Toon, O. B., Kinne, S., Sachse, G. W., Anderson, B. E., Chan, K. R., Twohy, C. H., Gandrud, B., Heymsfield, A., and Miake-Lye, R. C.: Environmental conditions required for contrail formation and persistence, J. Geophys. Res., 103, 3929-3936, doi:10.1029/97JD02808, 1998c.

Jensen, E., Toon, O. B., Vay, S. A., Ovarlez, J., May, R., Bui, P., Twohy, C. H., Gandrud, B., Pueschel, R. F., and Schumann, U.: Prevalence of ice-supersaturated regions in the upper troposphere: Implications for optically thin ice cloud formation, J. Geophys. Res., 106, 17253-17266, doi:10.1029/2000JD900526, 2001.

Jensen, E., Pfister, L., Bui, T., Weinheimer, A., Weinstock, E., Smith, J., Pittman, J., Baumgardner, D., Lawson, P., and McGill, M. J.: Formation of a tropopause cirrus layer observed over Florida during CRYSTAL-FACE, J. Geophys. Res., 110, D03208, doi:10.1029/2004JD004671, 2005.

Jeßberger, P., Voigt, C., Schumann, U., Sölch, I., Schlager, H., Kaufmann, S., Petzold, A., Schäuble, D., and Gayet, J.-F.: Aircraft type influence on contrail properties, Atmos. Chem. Phys., 13, 11965-11984, doi:10.5194/acp-13-11965-2013, 2013.

Jones, H. M., Haywood, J., Marenco, F., O’Sullivan, D., Meyer, J., Thorpe, R., Gallagher, M. W., Krämer, M., Bower, K. N., Rädel, G., Rap, A., Woolley, A., Forster, P., and Coe, H.: A methodology for in-situ and remote sensing of microphysical and radiative properties of contrails as they evolve into cirrus, Atmos. Chem. Phys., 12, 8157-8175, doi:10.5194/acp-12-8157-2012, 2012.

Jurkat, T., Voigt, C., Arnold, F., Schlager, H., Kleffmann, J., Aufmhoff, H., Schäuble, D., Schaefer, M., and Schumann, U.: Measurements of $\mathrm{HONO}, \mathrm{NO}, \mathrm{NO}_{y}$ and $\mathrm{SO}_{2}$ in aircraft exhaust plumes at cruise, Geophys. Res. Lett., 38, L10807, doi:10.1029/2011GL046884, 2011.

Kärcher, B. and Lohmann, U.: A parameterization of cirrus cloud formation: Homogenous freezing of supercooled aerosols, J. Geophys. Res., 107, 4010, doi:10.1029/2001JD000470, 2002.

Kärcher, B. and Yu, F.: Role of aircraft soot emissions in contrail formation, Geophys. Res. Lett., 36, L01804, doi:10.1029/2008GL036649, 2009.

Kärcher, B., Peter, T., Biermann, U. M., and Schumann, U.: The initial composition of jet condensation trails, J. Atmos. Sci., 53, 3066-3083, doi:10.1175/15200469(1996)053<3066:TICOJC>2.0.CO;2, 1996.

Kärcher, B., Busen, R., Petzold, A., Schröder, F. P., Schumann, U., and Jensen, E. J.: Physicochemistry of aircraft-generated liquid aerosols, soot, and ice particles, 2. Comparison with observations and sensitivity studies, J. Geophys. Res., 103, 1712917147, doi:10.1029/98JD01045, 1998.

Kärcher, B., Burkhardt, U., Unterstrasser, S., and Minnis, P.: Factors controlling contrail cirrus optical depth, Atmos. Chem. Phys., 9, 6229-6254, doi:10.5194/acp-9-6229-2009, 2009a.

Kärcher, B., Mayer, B., Gierens, K., Burkhardt, U., Mannstein, H., and Chatterjee, R.: Aerodynamic contrails: Microphysics and optical properties, J. Atmos. Sci., 66, 227-243, doi:10.1175/2008JAS2768.1, 2009b.
Kärcher, B., Burkhardt, U., Bier, A., Bock, L., and Ford, I. J.: The microphysical pathway to contrail formation, J. Geophys. Res., 120, 7893-7927, doi:10.1002/2015JD023491, 2015.

Kästner, M.: Analysis of the optical depth evolution in a spiral contrail using AVHRR data, EUMETSAT Meteorological Satellite Conference, Dublin, Ireland, 2-6 September 2002, Poster 36, ISBN 92-9110-049-8, 2003.

Kästner, M., Kriebel, K. T., Meerkötter, R., Renger, W., Ruppersberg, G. H., and Wendling, P.: Comparison of cirrus height and optical depth dervied from satellite and aircraft measurements, Mon. Weather Rev., 121, 2708-2717, doi:10.1175/15200493(1993)121<2708:COCHAO>2.0.CO;2, 1993.

Kaufmann, S., Voigt, C., Jeßberger, P., Jurkat, T., Schlager, H., Schwarzenboeck, A., Klingebiel, M., and Thornberry, T.: In-situ measurements of ice saturation in young contrails, Geophys. Res. Lett., 41, 702-709, doi:10.1002/2013GL058276, 2014.

Kiemle, C., Wirth, M., Fix, A., Ehret, G., Schumann, U., Gardiner, T., Schiller, C., Sitnikov, N., and Stiller, G.: First airborne water vapor lidar measurements in the tropical upper troposphere and mid-latitudes lower stratosphere: accuracy evaluation and intercomparisons with other instruments, Atmos. Chem. Phys., 8, 5245-5261, doi:10.5194/acp-8-5245-2008, 2008.

Kienast-Sjögren, E., Spichtinger, P., and Gierens, K.: Formulation and test of an ice aggregation scheme for two-moment bulk microphysics schemes, Atmos. Chem. Phys., 13, 9021-9037, doi:10.5194/acp-13-9021-2013, 2013.

Knollenberg, R. G.: The optical array: An alternative to scattering or extinction for airborne particle size determination, J. Appl. Meteor., 9, 86-103, doi:10.1175/15200450(1970)009<0086:TOAAAT>2.0.CO;2, 1970.

Knollenberg, R. G.: Measurements of the growth of the ice budget in a persisting contrail, J. Atmos. Sci., 29, 1367-1374, 1972.

Koop, T., Luo, B., Tsias, A., and Peter, T.: Water activity as the determinant for homogeneous ice nucleation in aqueous solutions, Nature, 406, 611-614, doi:10.1038/35020537, 2000.

Korolev, A., Emery, E., Strapp, J., Cober, S., Isaac, G., Wasey, M., and Marcotte, D.: Small ice particles in tropospheric clouds: Fact or artifact? Airborne icing instrumentation evaluation experiment, B. Am. Meteorol. Soc., 92, 967-973, doi:10.1175/2010BAMS3141.1, 2011.

Krämer, M., Schiller, C., Afchine, A., Bauer, R., Gensch, I., Mangold, A., Schlicht, S., Spelten, N., Sitnikov, N., Borrmann, S., de Reus, M., and Spichtinger, P.: Ice supersaturations and cirrus cloud crystal numbers, Atmos. Chem. Phys., 9, 3505-3522, doi:10.5194/acp-9-3505-2009, 2009.

Kübbeler, M., Hildebrandt, M., Meyer, J., Schiller, C., Hamburger, Th., Jurkat, T., Minikin, A., Petzold, A., Rautenhaus, M., Schlager, H., Schumann, U., Voigt, C., Spichtinger, P., Gayet, J.-F., Gourbeyre, C., and Krämer, M.: Thin and subvisible cirrus and contrails in a subsaturated environment, Atmos. Chem. Phys., 11, 5853-5865, doi:10.5194/acp-11-5853-2011, 2011.

Kuhn, M., Petzold, A., Baumgardner, D., and Schröder, F.: Particle composition of a young condensation trail and of upper tropospheric aerosol, Geophys. Res. Lett., 25, 2679-2682, 1998.

Lawson, R. P., Heymsfield, A. J., Aulenbach, S. M., and Jensen, T. L.: Shapes, sizes and light scattering properties of ice crystals in cirrus and a persistent contrail during SUCCESS, Geophys. Res. Lett., 25, 1331-1334, doi:10.1029/98GL00241, 1998. 
Lawson, R. P., Pilson, B., Baker, B., and Mo, Q.: Microphysical properties of subvisible cirrus, 12th Conference on Cloud Physics, 10-14 July 2006, Madison, WI, available at: https://ams.confex.com/ams/Madison2006/techprogram/ paper_111955.htm, 2006.

Lawson, R. P., Pilson, B., Baker, B., Mo, Q., Jensen, E., Pfister, L., and Bui, P.: Aircraft measurements of microphysical properties of subvisible cirrus in the tropical tropopause layer, Atmos. Chem. Phys., 8, 1609-1620, doi:10.5194/acp-8-1609-2008, 2008.

Lee, D. S., Fahey, D. W., Forster, P. M., Newton, P. J., Wit, R. C. N., Lim, L. L., Owen, B., and Sausen, R.: Aviation and global climate change in the 21st century, Atmos. Environ., 43, 35203537, doi:10.1016/j.atmosenv.2009.04.024, 2009.

Lewellen, D. C.: Analytic solutions for evolving size distributions of spherical crystals or droplets undergoing diffusional growth in different regimes, J. Atmos. Sci., 69, 417-434, doi:10.1175/JASD-11-029.1, 2012.

Lewellen, D. C.: Persistent contrails and contrail cirrus, Part II: Full lifetime behavior, J. Atmos. Sci., 71, 4420-4438, doi:10.1175/JAS-D-13-0317.1, 2014.

Lewellen, D. C. and Lewellen, W. S.: The effects of aircraft wake dynamics on contrail development, J. Atmos. Sci., 58, 390-406, 2001.

Lewellen, D. C., Meza, O., and Huebsch, W. W.: Persistent contrails and contrail cirrus. Part I: Large-eddy simulations from inception to demise, J. Atmos. Sci., 70, 4399-4419, doi:10.1175/JAS-D13-0316.1, 2014.

Liou, K. N., Ou, S. C., and Koenig, G.: An investigation of the climatic effect of contrail cirrus, in: Air Traffic and the Environment - Background, Tendencies and Potential Global Atmospheric Effects, edited by: Schumann, U., Lecture Notes in Engineering, Springer Berlin, 154-169, 1990.

Liou, K. N., Yang, P., Takano, Y., Sassen, K., Charlock, T., and Arnott, W.: On the radiative properties of contrail cirrus, Geophys. Res. Lett., 25, 1161-1164, 1998.

Liu, X., Penner, J. E., Ghan, S. J., and Wang, M.: Inclusion of ice microphysics in the NCAR Community Atmosphere Model version 3 (CAM3), J. Climate, 20, 4526-4547, doi:10.1175/JCLI4264.1, 2007.

Lohmann, U.: Possible aerosol effects on ice clouds via contact nucleation, J. Atmos. Sci., 59, 647-656, 2002.

Mannstein, H., Meyer, R., and Wendling, P.: Operational detection of contrails from NOAA-AVHRR data, Int. J. Remote Sens., 20, 1641-1660, doi:10.1080/014311699212650, 1999.

Markowicz, K. M. and Witek, M.: Sensitivity study of global contrail radiative forcing due to particle shape, J. Geophys. Res., 116, D23203, doi:10.1029/2011JD016345, 2011.

Mazin, I. P.: Aircraft condensation trails, Atmos. Ocean. Phys. Izv., 32, 1-13, 1996.

Mazin, I. P. and Heymsfield, A. J.: On the theory of contrails, Russian Meteor. Hydrol., 9, 1-8, 1998.

McFarquhar, G. M., Baumgardner, D., Bansemer, A., Abel, S. J., Crosier, J., French, J., Rosenberg, P., Korolev, A., Schwarzenboeck, A., Leroy, D., Um, J., Wu, W., Heymsfield, A. J., Detwiler, A., Field, P., Neumann, A., Stith, J., Axisa, D., and Dong, J.: Data analysis, interpretation and presentation of in-situ measurements - Ice Formation and Evolution in Clouds and Precipi- tation: Measurement and Modeling Challenges: Chapter 11, Meteor. Monogr., in review, 2016.

Minnis, P., Young, D. F., Garber, D. P., Nguyen, L., Smith Jr., W. L., and Palikonda, R.: Transformation of contrails into cirrus during SUCCESS, Geophys. Res. Lett., 25, 1157-1160, doi:10.1029/97GL03314, 1998.

Minnis, P., Nguyen, L., Duda, D. P., and Palikonda, R.: Spreading of isolated contrails during the 2001 air traffic shutdown, 10th Conference on Aviation, Range, and Aerospace, Portland, OR, 13-16 May 2002, available at: http://www-pm.larc.nasa.gov/sass/pub/ conference/Minnis.abs.ARAMS.02.pdf, 2002.

Minnis, P., Sun-Mack, S., Young, D. F., Heck, P. W., Garber, D. P., Chen, Y., Spangenberg, D. A., Arduini, R. F., Trepte, Q. Z., William L. Smith, J., Ayers, J. K., Gibson, S. C., Miller, W. F., Chakrapani, V., Takano, Y., Liou, K.-N., Xie, Y., and Yang, P.: CERES Edition-2 cloud property retrievals using TRMM VIRS and Terra and Aqua MODIS data, Part I: Algorithms, IEEE T. Geosci. Remote, 49, 4374-4400, doi:10.1109/TGRS.2011.2144601, 2011.

Minnis, P., Bedka, S. T., Duda, D. P., Bedka, K. M., Chee, T., Ayers, J. K., Palikonda, R., Spangenberg, D. A., Khlopenkov, K. V., and Boeke, R.: Linear contrail and contrail cirrus properties determined from satellite data, Geophys. Res. Lett., 40, 3220-3226, doi:10.1002/grl.50569, 2013.

Mörl, P., Reinhardt, M. E., and Renger, W.: The use of the airborne lidar ALEX-F for aerosol tracing in the lower troposphere, Beitr. Phys. Atmos. (Contr. Atm. Phys.), 45, 403-410, 1981.

Mullins, N. A.: Case study of a jet contrail at the tropopause: Properties, evolution and radiative effects, Master Thesis, Department of Meteorology, University of Utah, 71 pp., available at: http://www.inscc.utah.edu/ tgarrett/GarrettGroup.html, 2006.

Naiman, A. D., Lele, S. K., and Jacobson, M. Z.: Large eddy simulations of contrail development: Sensitivity to initial and ambient conditions over first twenty minutes, J. Geophys. Res., 116, D21208, doi:10.1029/2011JD015806, 2011.

Ovarlez, J., Gayet, J. F., Gierens, K., Ström, J., Ovarlez, H., Auriol, F., Busen, R., and Schumann, U.: Water vapor measurements inside cirrus clouds in northern and southern hemispheres during INCA, Geophys. Res. Lett., 29, 60-61-60-64, doi:10.1029/2001g1014440, 2002.

Palikonda, R., Minnis, P., Duda, D. P., and Mannstein, H.: Contrail coverage derived from 2001 AVHRR data over the continental United States of America and surrounding areas, Meteorol. Z., 14, 525-536, doi:10.1127/0941-2948/2005/0051, 2005.

Paoli, R. and Shariff, K.: Contrail modeling and simulation, Annu. Rev. Fluid Mech., 48, 393-427, doi:10.1146/annurevfluid-010814-013619, 2016.

Penner, J. E., Lister, D. H., Griggs, D. J., Dokken, D. J., and McFarland, M.: Aviation and the global atmosphere - A special report of IPCC working groups I and III, Intergovernmental Panel on Climate Change, Cambridge University Press, 365 pp., 1999.

Penner, J. E., Chen, Y., Wang, M., and Liu, X.: Possible influence of anthropogenic aerosols on cirrus clouds and anthropogenic forcing, Atmos. Chem. Phys., 9, 879-896, doi:10.5194/acp-9-8792009, 2009.

Petzold, A., Busen, R., Schröder, F. P., Baumann, R., Kuhn, M., Ström, J., Hagen, D. E., Whitefield, P. D., Baumgardner, D., Arnold, F., Borrmann, S., and Schumann, U.: Nearfield measurements on contrail properties from fuels with dif- 
ferent sulfur content, J. Geophys. Res., 102, 29867-29880, doi:10.1029/97JD02209, 1997.

Poberaj, G., Fix, A., Assion, A., Wirth, M., Kiemle, C., and Ehret, G.: Airborne all-solid-state DIAL for water vapour measurements in the tropopause region: System description and assessment of accuracy, Appl. Phys. B, 75, 165-172, doi:10.1007/s00340-002-0965-x, 2002.

Poellot, M. R., Arnott, W. P., and Hallett, J.: In situ observations of contrail microphysics and implications for their radiative impact, J. Geophys. Res., 104, 12077-12084, doi:10.1029/1999JD900109, 1999.

Quante, M.: Turbulenz in Cirruswolken mittlerer Breiten, Fachbereich Geowissenschaften der Universität Hamburg, 207 pp., available at: https://www.deutsche-digitale-bibliothek.de/binary/ XW5M3XAPIN7KJKBOND3IENOLCQGLOOIA/full/1.pdf, 2006.

Raschke, E., Schmetz, J., Heintzenberg, J., Kandel, R., and Saunders, R.: The International Cirrus Experiment (ICE): a joint European effort, ESA J., 14, 193-199, 1990.

Ruppersberg, G. H. and Renger, W.: Invertierung der Lidar-Signale von Cirrus und Kondensstreifen unter Nutzung des Schattenwurfes, Deutsches Zentrum für Luft- und Raumfahrt, Cologne, DLRFB 91-07, 17 pp., 1991.

Sassen, K.: Contrail-cirrus and their potential for regional climate change, B. Am. Meteorol. Soc., 78, 1885-1903, 1997.

Schiller, C., Krämer, M., Afchine, A., Spelten, N., and Sitnikov, N.: Ice water content of Arctic, midlatitude, and tropical cirrus, J. Geophys. Res., 113, D24208, doi:10.1029/2008JD010342, 2008.

Schmidt, E.: Die Entstehung von Eisnebel aus den Auspuffgasen von Flugmotoren, in: Schriften der Deutschen Akademie der Luftfahrtforschung, Verlag R. Oldenbourg, München, Heft 44, 1-15, available at: http://elib.dlr.de/107948/, 1941.

Schröder, F. P., Kärcher, B., Duroure, C., Ström, J., Petzold, A., Gayet, J.-F., Strauss, B., Wendling, P., and Borrmann, S.: The transition of contrails into cirrus clouds, J. Atmos. Sci., 57, 464480, 2000.

Schumann, U.: On the effect of emissions from aircraft engines on the state of the atmosphere, Ann. Geophysicae, 12, 365-384, 1994.

Schumann, U.: On conditions for contrail formation from aircraft exhausts, Meteorol. Z., 5, 4-23, 1996.

Schumann, U.: Research on the effects of aircraft and spacecraft upon the atmosphere, Atmos. Environ., 32, 3065-3066, 1998.

Schumann, U.: Influence of propulsion efficiency on contrail formation, Aerosp. Sci. Techn., 4, 391-401, doi:10.1016/S12709638(00)01062-2, 2000.

Schumann, U.: Contrail Cirrus, in: Cirrus, edited by: Lynch, D. K., Sassen, K., O'Starr, D., and Stephens, G., Oxford Univ. Press, Oxford, 231-255, 2002.

Schumann, U.: Formation, properties and climate effects of contrails, Compt. Rend. Phys., 6, 549-565, 2005.

Schumann, U.: A contrail cirrus prediction model, Geosci. Model Dev., 5, 543-580, doi:10.5194/gmd-5-543-2012, 2012.

Schumann, U. and Graf, K.: Aviation-induced cirrus and radiation changes at diurnal timescales, J. Geophys. Res., 118, 2404-2421, doi:10.1002/jgrd.50184, 2013.

Schumann, U. and Heymsfield, A.: On the lifecycle of individual contrails and contrail cirrus - Ice Formation and Evolution in Clouds and Precipitation: Measurement and Mod- eling Challenges: Chapter 3, Meteor. Monogr., in press, doi:10.1175/AMSMONOGRAPHS-D-16-0005.1, 2016.

Schumann, U. and Wendling, P.: Determination of contrails from satellite data and observational results, in: Air Traffic and the Environment - Background, Tendencies and Potential Global Atmospheric Effects, edited by: Schumann, U., Lecture Notes in Engineering, Springer Berlin, 138-153, 1990.

Schumann, U., Ström, J., Busen, R., Baumann, R., Gierens, K., Krautstrunk, M., Schröder, F. P., and Stingl, J.: In situ observations of particles in jet aircraft exhausts and contrails for different sulfur-containing fuels, J. Geophys. Res., 101, 6853-6870, doi:10.1029/95JD03405, 1996.

Schumann, U., Schlager, H., Arnold, F., Baumann, R., Haschberger, P., and Klemm, O.: Dilution of aircraft exhaust plumes at cruise altitudes, Atmos. Environ., 32, 3097-3103, doi:10.1016/S13522310(97)00455-X, 1998.

Schumann, U., Busen, R., and Plohr, M.: Experimental test of the influence of propulsion efficiency on contrail formation, J. Aircraft, 37, 1083-1087, doi:10.2514/2.2715, 2000.

Schumann, U., Arnold, F., Busen, R., Curtius, J., Kärcher, B., Petzold, A., Schlager, H., Schröder, F., and Wohlfrom, K. H.: Influence of fuel sulfur on the composition of aircraft exhaust plumes: The experiments SULFUR 1-7, J. Geophys. Res., 107, 4247, doi:10.1029/2001JD000813, 2002.

Schumann, U., Mayer, B., Gierens, K., Unterstrasser, S., Jessberger, P., Petzold, A., Voigt, C., and Gayet, J.-F.: Effective radius of ice particles in cirrus and contrails, J. Atmos. Sci., 68, 300-321, doi:10.1175/2010JAS3562.1, 2011.

Schumann, U., Graf, K., Mannstein, H., and Mayer, B.: Contrails: Visible aviation induced climate impact, in: Atmospheric Physics - Background - Methods - Trends, edited by: Schumann, U., Springer, Berlin, Heidelberg, 239-257, doi:10.1007/978-3-64230183-4_15, 2012.

Schumann, U., Jeßberger, P., and Voigt, C.: Contrail ice particles in aircraft wakes and their climatic importance, Geophys. Res. Lett., 40, 2867-2872 doi:10.1002/grl.50539, $2013 \mathrm{a}$.

Schumann, U., Hempel, R., Flentje, H., Garhammer, M., Graf, K., Kox, S., Lösslein, H., and Mayer, B.: Contrail study with ground-based cameras, Atmos. Meas. Tech., 6, 3597-3612, doi:10.5194/amt-6-3597-2013, 2013b.

Schumann, U., Penner, J. E., Chen, Y., Zhou, C., and Graf, K.: Dehydration effects from contrails in a coupled contrail-climate model, Atmos. Chem. Phys., 15, 11179-11199, doi:10.5194/acp15-11179-2015, 2015.

Schumann, U., Graf, K., Bugliaro, L., Dörnbrack, A., Voigt, C., Wirth, M., Ziereis, H., Giez, A., and Minikin, A.: Contrail predictions for ML-CIRRUS - Method and Experiences, TAC4, DLR FB 2015-38, Bad Kohlgrub, June 2015, 132-138, 2016 a.

Schumann, U., Kiemle, C., Schlager, H., Weigel, R., Borrmann, S., D’Amato, F., Krämer, M., Matthey, R., Protat, A., Voigt, C., and Volk, M.: Long-lived contrails and convective cirrus above the tropical tropopause, Atmos. Chem. Phys. Discuss., doi:10.5194/acp-2016-940, in review, 2016b.

Spinhirne, J. D. and Hart, W. D.: Cirrus structure and radiative parameters from airborne lidar and spectral radiometer observations: The 28 October 1986 FIRE study, Mon. Weather Rev., 118, 2329-2343, doi:10.1175/15200493(1990)118<2329:CSARPF>2.0.CO;2, 1990. 
Spinhirne, J. D., Hart, W. D., and Duda, D. P.: Evolution of the morphology and microphysics of contrail cirrus from airborne remote sensing, Geophys. Res. Lett., 25, 1153-1156, doi:10.1029/97GL03477, 1998.

Stefanutti, L., Mackenzie, A. R., Santacesaria, V., Adriani, A., Balestri, S., Borrmann, S., Khattatov, V., Mazzinghi, P., Mitev, V., Rudakov, V., Schiller, C., Toci, G., Volk, C. M., Yushkov, V., Flentje, H., Kiemle, C., Redaelli, G., Carslaw, K. S., Noone, K., and Peter, T.: The APE-THESEO tropical campaign: An overview, J. Atmos. Chem., 8, 1-33, doi:10.1023/B:JOCH.0000034509.11746.b8, 2004.

Strauss, B., Meerkötter, R., Wissinger, B., Wendling, P., and Hess, M.: On the regional climatic impact of contrails: Microphysical and radiative properties of contrails and natural cirrus clouds, Ann. Geophysicae, 15, 1457-1467, 1997.

Ström, J. and Ohlsson, S.: In situ measurements of enhanced crystal number densities in cirrus clouds caused by aircraft exhaust, J. Geophys. Res., 103, 11355-11362, doi:10.1029/98JD00807, 1998.

Ström, J., Heintzenberg, J., Noone, K. J., Noone, K. B., Ogren, J. A., Albers, F., and Quante, M.: Small crystals in cirriform clouds: A case study of residue size distribution, cloud water content and related cloud properties, Atmos. Res., 32, 125-141, doi:10.1016/0169-8095(94)90056-6, 1994.

Sussmann, R.: Vertical dispersion of an aircraft wake: Aerosol-lidar analysis of entrainment and detrainment in the vortex regime, J. Geophys. Res., 104, 2117-2129, 1999.

Sussmann, R. and Gierens, K.: Lidar and numerical studies on the different evolution of vortex pair and secondary wake in young contrails, J. Geophys. Res., 104, 2131-2142, 1999.

Sussmann, R. and Gierens, K.: Differences in early contrail evolution of two-engine versus four-engine aircraft: Lidar measurements and numerical simulations, J. Geophys. Res., 106, 48994911, doi:10.1029/2000JD900533, 2001.

Szantai, A., Désalmand, F., and Desbois, M.: Monitoring the life cycle of cirrus clouds using Meteosat-4 data during ICE-1989, Meteorol. Appl., 8, 153-168, 2001.

Tan, D., Faloona, I., Brune, W. H., Weinheimer, A., Campos, T., Ridley, B., Vay, S., Collins, J., and Sachse, G.: in situ measurements of $\mathrm{HO}_{x}$ in aircraft exhaust plumes and contrails during SUCCESS, Geophys. Res. Lett., 25, 1721-1724, doi:10.1029/98GL00117, 1998.

Toon, O. B. and Miake-Lye, R. C.: Subsonic aircraft: Contrail and cloud effects special study (SUCCESS), Geophys. Res. Lett., 25, 1109-1112, doi:10.1029/98GL00839, 1998.

Twohy, C. H. and Gandrud, B. W.: Electron microscope analysis of residual particles from aircraft contrails, Geophys. Res. Lett., 25, 1359-1362, doi:10.1029/97GL03162, 1998.

Unterstrasser, S.: Large eddy simulation study of contrail microphysics and geometry during the vortex phase and consequences on contrail-to-cirrus transition, J. Geophys. Res.-Atmos., 119, 7537-7555, doi:10.1002/2013JD021418, 2014.

Unterstrasser, S.: Properties of young contrails - a parametrisation based on large-eddy simulations, Atmos. Chem. Phys., 16, 20592082, doi:10.5194/acp-16-2059-2016, 2016.

Unterstrasser, S. and Gierens, K.: Numerical simulations of contrail-to-cirrus transition - Part 1: An extensive parametric study, Atmos. Chem. Phys., 10, 2017-2036, doi:10.5194/acp-102017-2010, 2010a.
Unterstrasser, S. and Gierens, K.: Numerical simulations of contrail-to-cirrus transition - Part 2: Impact of initial ice crystal number, radiation, stratification, secondary nucleation and layer depth, Atmos. Chem. Phys., 10, 2037-2051, doi:10.5194/acp-102037-2010, 2010b.

Unterstrasser, S., Gierens, K., and Spichtinger, P.: The evolution of contrail microphysics in the vortex phase, Meteorol. Z. , 17, 145156, doi:10.1127/0941-2948/2008/0273, 2008.

Vaughan, G., Schiller, C., MacKenzie, A. R., Bower, K., Peter, T., Schlager, H., Harris, N. R. P., and May, P. T.: SCOUTO3/ACTIVE: High-altitude aircraft measurements around deep tropical convection, B. Am. Meteorol. Soc., 89, 647-662, doi:10.1175/BAMS-89-5-647, 2008.

Vázquez-Navarro, M., Mannstein, H., and Mayer, B.: An automatic contrail tracking algorithm, Atmos. Meas. Tech., 3, 1089-1101, doi:10.5194/amt-3-1089-2010, 2010.

Vázquez-Navarro, M., Mannstein, H., and Kox, S.: Contrail life cycle and properties from 1 year of MSG/SEVIRI rapid-scan images, Atmos. Chem. Phys., 15, 8739-8749, doi:10.5194/acp-158739-2015, 2015.

Voigt, C., Schumann, U., Jurkat, T., Schäuble, D., Schlager, H., Petzold, A., Gayet, J.-F., Krämer, M., Schneider, J., Borrmann, S., Schmale, J., Jessberger, P., Hamburger, T., Lichtenstern, M., Scheibe, M., Gourbeyre, C., Meyer, J., Kübbeler, M., Frey, W., Kalesse, H., Butler, T., Lawrence, M. G., Holzäpfel, F., Arnold, F., Wendisch, M., Döpelheuer, A., Gottschaldt, K., Baumann, R., Zöger, M., Sölch, I., Rautenhaus, M., and Dörnbrack, A.: In-situ observations of young contrails - overview and selected results from the CONCERT campaign, Atmos. Chem. Phys., 10, 90399056, doi:10.5194/acp-10-9039-2010, 2010.

Voigt, C., Schumann, U., Jessberger, P., Jurkat, T., Petzold, A., Gayet, J.-F., Krämer, M., Thornberry, T., and Fahey, D. W.: Extinction and optical depth of contrails, Geophys. Res. Lett., 38, L11806 doi:10.1029/2011GL047189, 2011.

Voigt, C., Jessberger, P., Jurkat, T., Kaufmann, S., Baumann, R., Schlager, H., Bobrowski, N., Giuffrida, G., and Salerno, G.: Evolution of $\mathrm{CO}_{2}, \mathrm{SO}_{2}, \mathrm{HCl}$, and $\mathrm{HNO}_{3}$ in the volcanic plumes from Etna, Geophys. Res. Lett., 41, 2196-2203, doi:10.1002/2013GL058974, 2014.

Voigt, C., Schumann, U., Minikin, A., Abdelmonem, A., Afchine, A., Borrmann, S., Boettcher, M., Buchholz, B., Bugliaro, L., Costa, A., Curtius, J., Dollner, M., Dörnbrack, A., Dreiling, V., Ebert, V., Ehrlich, A., Fix, A., Forster, L., Frank, F., Fütterer, D., Giez, A., Graf, K., Grooß, J.-U., Groß, S., Heimerl, K., Heinold, B., Hüneke, T., Järvinen, E., Jurkat, T., Kaufmann, S., Kenntner, M., Klingebiel, M., Klimach, T., Kohl, R., Krämer, M., Krisna, T. C., Luebke, A., Mayer, B., Mertes, S., Molleker, S., Petzold, A., Pfeilsticker, K., Port, M., Rapp, M., Reutter, P., Rolf, C., Rose, D., Sauer, D., Schäfler, A., Schlage, R., Schnaiter, M., Schneider, J., Spelten, N., Spichtinger, P., Stock, P., Walser, A., Weigel, R., Weinzierl, B., Wendisch, M., Werner, F., Wernli, H., Wirth, M., Zahn, A., Ziereis, H., and Zöger, M.: ML-CIRRUS - The airborne experiment on natural cirrus and contrail cirrus with the high-altitude long-range research aircraft HALO, B. Am. Meteorol. Soc., doi:10.1175/BAMS-D-15-00213.1, online first, 2016.

Weickmann, H.: Formen und Bildung atmosphärischer Eiskristalle, Beitr. Phys. Atmos. (Contr. Atm. Phys.), 28, 12-52, 1945. 
Weickmann, H. K.: A theory of the formation of ice crystals, Arch. Meteorol. Geophys. Bioklimatol. A, 4, 309-323, doi:10.1007/BF02246809, 1951.

Weigel, R., Hermann, M., Curtius, J., Voigt, C., Walter, S., Böttger, T., Lepukhov, B., Belyaev, G., and Borrmann, S.: Experimental characterization of the COndensation PArticle counting System for high altitude aircraft-borne application, Atmos. Meas. Tech., 2, 243-258, doi:10.5194/amt-2-243-2009, 2009.

Wendisch, M. and Brenguier, J.-L.: Airborne Measurements for Environmental Research: Methods and Instruments, Wiley-VCH Verlag GmbH \& Co. KGaA, Weinheim, Germany, 2013.

Wendling, P., Büll, R., Kästner, M., Mannstein, H., Meyer, R., Schröder, F., and Strauss, B.: Bestimmung klimarelevanter Eigenschaften von Kondensstreifen aus Satellitenmessungen, Abschlussbericht zum Forschungsprojekt AP 1311 des Forschungsverbundes "Schadstoffe in der Luftfahrt", DLR, 76 pp., 1997.
Wirth, M., Fix, A., Mahnke, P., Schwarzer, H., Schrandt, F., and Ehret, G.: The airborne multi-wavelength water vapor differential absorption lidar WALES: System design and performance, Appl. Phys. B, 96, 201-213, doi:10.1007/s00340-009-3365-7, 2009.

Yu, F. and Turco, R. P.: Contrail formation and impacts on aerosol properties in aircraft plumes: Effects of fuel sulfur content, Geophys. Res. Lett., 25, 313-316, doi:10.1029/97GL03695, 1998.

Yun, Y., Penner, J. E., and Popovicheva, O.: The effects of hygroscopicity on ice nucleation of fossil fuel combustion aerosols in mixed-phase clouds, Atmos. Chem. Phys., 13, 4339-4348, doi:10.5194/acp-13-4339-2013, 2013.

Zhou, C. and Penner, J. E.: Aircraft soot indirect effect on largescale cirrus clouds: Is the indirect forcing by aircraft soot positive or negative?, J. Geophys. Res., 119, 11303-11320, doi:10.1002/2014JD021914, 2014. 